\title{
Macrosegregation in direct-chill casting of aluminium alloys
}

R. Nadella ${ }^{\text {a }}$, D.G. Eskin ${ }^{\mathrm{a},{ }^{*}}$, Q. Du ${ }^{\mathrm{a}}$, L. Katgerman ${ }^{\mathrm{b}}$

a Netherlands Institute for Metals Research, Mekelweg 2, 2628 CD, Delft, The Netherlands

${ }^{\mathrm{b}}$ Delft University of Technology, Mekelweg 2, 2628 CD, Delft, The Netherlands

* Corresponding author, Tel.: +31-15-278 44 63; Fax: +31-15-278 6730

E-mail address: d.g.eskin@tudelft.nl

Number of manuscript folios: 92

Number of Figures: 27

Number of Tables: 7

Running Title: Macrosegregation 


\begin{abstract}
Semi-continuous direct-chill (DC) casting holds a prominent position in commercial aluminium alloy processing, especially in production of large sized ingots. Macrosegregation, which is the non-uniform chemical composition over the length scale of a casting, is one of the major defects that occur during this process. The fact that macrosegregation is essentially unaffected by subsequent heat treatment (hence constitutes an irreversible defect) leaves us with little choice but to control it during the casting stage. Despite over a century of research in the phenomenon of macrosegregation in castings and good understanding of underlying mechanisms, the contributions of these mechanisms in the overall macrosegregation picture; and interplay between these mechanisms and the structure formation during solidification are still unclear. This review attempts to fill this gap based on the published data and own results. The following features make this review unique: results of computer simulations are used in order to separate the effects of different macrosegregation mechanisms. The issue of grain refining is specifically discussed in relation to macrosegregation. This report is structured as follows. Macrosegregation as a phenomenon is defined in the Introduction. In Part 2, direct-chill casting, the role of process parameters and the evolution of structural features in the as-cast billets are described. In Part 3, macrosegregation mechanisms are elucidated in a historical perspective and the correlation with DC casting process parameters and structural features are made. The issue of how to control macrosegregation in direct-chill casting is also dealt with in Part 3. In Part 4, the effect of grain refining on macrosegregation is introduced, the current understanding is described and the contentious issues are outlined. The review is finished with conclusion remarks and outline for the future research.
\end{abstract}


Keywords: Macrosegregation, Grain refining, Direct-chill casting, Aluminium alloys, Microstructure 


\section{TABLE OF CONTENTS}

List of Symbols. .4

1. Introduction: Macrosegregation............................................6

2. Direct-Chill Casting: Process Parameters, Solidification and Structure

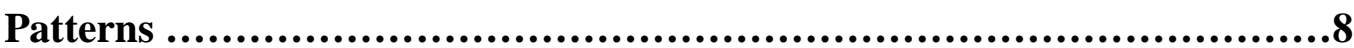

2.1 Direct-chill casting process - a brief introduction...........................8

2.2 Solidification patterns in DC cast billets..............................11

2.2.1 Characteristics of sump..................................11

2.2.2 Effect of DC casting process parameters....................17

2.3 Flow patterns in DC cast billets..................................20

2.4 Structure patterns in DC cast billets.................................27

2.4.1 Grain size.................................................

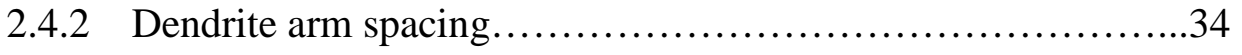

2.4.3 'Coarse-cell’ grains.......................................38

2.4.4 Porosity ................................................41

2.4.5 Non-equilibrium eutectics.................................43

3. Macrosegregation in Direct-Chill Casting of Aluminium Alloys ...........45

3.1 Segregation patterns in DC cast $\mathrm{Al}$ alloys and role of partition coefficient..46

3.2 Mechanisms of macrosegregation.....................................49

3.2.1 Historical overview.....................................50

3.2.2 Shrinkage-induced flow.................................56

3.2.3 Thermo-solutal and forced convection.......................59

3.2.4 Movement of equiaxed ('floating') grains.....................62

3.2.5 Deformation of solid network.............................66

3.3 Macrosegregation - Influence of process parameters and structure .........68

4. Role of grain refining................................................74

4.1 Basics of grain refinement in $\mathrm{Al}$ alloys...............................75

4.2 Structure formation and permeability in grain refined $\mathrm{Al}$ alloys............77

4.3 Effect of grain refining on macrosegregation - issues...................82

5. Concluding remarks...................................................87

Acknowledgements.....................................................89

References..................................................................90 


\section{List of Symbols and acronyms}

\begin{tabular}{|c|c|}
\hline A & Coefficient \\
\hline$A$ & Cross-sectional area \\
\hline $\mathrm{Bi}$ & Biot number \\
\hline $\mathrm{C}$ & Concentration \\
\hline $\mathrm{C}_{0}$ & Nominal alloy composition, Reference concentration \\
\hline $\mathrm{D}$ & Billet diameter \\
\hline $\mathrm{F}$ & Buoyancy term \\
\hline G & Thermal gradient \\
\hline$K$ & Specific Permeability \\
\hline $\mathrm{K}$ & Partition coefficient \\
\hline $\mathrm{K}_{0}$ & Permeability coefficient \\
\hline $\mathrm{L}$ & Length \\
\hline $\mathrm{L}_{\mathrm{h}}$ & Horizontal solute transfer distance \\
\hline $\mathrm{L}_{\mathrm{m}}$ & Thickness of the mushy zone \\
\hline Q & Growth Restriction Factor (GRF) \\
\hline$Q$ & Volume flow rate \\
\hline $\mathrm{R}$ & Billet radius \\
\hline $\mathrm{S}_{\mathrm{v}}$ & Specific surface area of the solid \\
\hline $\mathrm{T}$ & Temperature \\
\hline $\mathrm{T}_{0}$ & Reference temperature \\
\hline $\mathrm{T}_{\mathrm{m}}$ & Melting temperature of the alloy \\
\hline $\mathrm{T}_{\text {surf }}$ & Surface temperature of the billet \\
\hline $\mathrm{V}$ & Velocity \\
\hline $\mathrm{V}_{\text {cast }}$ & Casting speed \\
\hline $\mathrm{V}_{\text {shr }}$ & Shrinkage flow velocity \\
\hline $\mathrm{V}_{\text {sol }}$ & $\begin{array}{l}\text { Normal velocity of the solidification front (solidification or growth } \\
\text { rate) }\end{array}$ \\
\hline $\mathrm{d}$ & Distance from surface, Secondary dendrite arm spacing \\
\hline$d_{s}$ & Grain size \\
\hline g & Acceleration due to gravity \\
\hline$g_{\mathrm{s}}$ & Solid fraction \\
\hline$g_{1}$ & Liquid fraction \\
\hline
\end{tabular}




\begin{tabular}{|c|c|}
\hline h & Heat transfer coefficient, Sump depth \\
\hline$k_{\mathrm{o}}$ & Coefficient \\
\hline$k_{\mathrm{D}}$ & Permeability coefficient \\
\hline $\mathrm{k}_{\mathrm{KC}}$ & Kozeny-Carman constant \\
\hline $\mathrm{m}_{\mathrm{L}}$ & Liquidus slope \\
\hline $\mathrm{n}$ & Coarsening exponent \\
\hline $\mathrm{t}_{\mathrm{f}}$ & Solidification time \\
\hline$\Delta \mathrm{C}$ & Relative deviation of concentration from the average \\
\hline$\Delta P$ & Pressure drop \\
\hline$\alpha$ & Angle between the tangent to the isotherm and the horizon \\
\hline$\beta$ & Expansion coefficient, Volumetric shrinkage, Shrinkage ratio \\
\hline$\varphi$ & Angle between normal to the solidification front and the billet axis \\
\hline$\eta$ & Kinematic viscosity \\
\hline$\lambda$ & Thermal conductivity \\
\hline$\mu$ & Dynamic viscosity \\
\hline$v$ & Average flow velocity \\
\hline$\mu_{\mathrm{m}}$ & Apparent viscosity of the semi-solid mixture \\
\hline$\rho$ & Density \\
\hline DAS & Dendrite arm spacing \\
\hline DC & Direct-chill \\
\hline EMC & Electromagnetic casting \\
\hline EPMA & Electron probe microanalysis \\
\hline GR & Grain refined \\
\hline NGR & Non-grain refined \\
\hline SEM & Scanning electron microscopy \\
\hline
\end{tabular}

Subscripts:

$$
\begin{aligned}
& \text { S - solid } \\
& \text { l - liquid } \\
& \text { C -solutal } \\
& \text { ave - average } \\
& \text { max - maximum } \\
& \text { min - minimum }
\end{aligned}
$$

superscripts:

i - solute element

$\mathrm{Al}$ - Aluminium 


\section{Introduction: macrosegregation}

Casting techniques for wrought aluminium alloys are characterized by their productivity and the quality of the as-cast product. With reference to quality, segregation, an inhomogeneous distribution of alloying elements on different length scales, is characteristic of all cast products. It is well known that the solidification of alloys is accompanied by a certain degree of microsegregation of alloying elements due to their partitioning between liquid and solid phases during solidification, and due to the nonequilibrium nature of solidification. If, subsequently, gross relative movement between the liquid and the solid occurs, the segregation can appear on a macro-scale, which is called macrosegregation. Thus macrosegregation can be defined as the spatial nonuniformity in the chemical composition on the scale of a solidified casting. The concentrations of alloying elements may vary substantially throughout the cross section of the casting. In the extreme case, the composition in certain regions across the thickness of the ingot (billet) may be outside the registered limits established for the alloy. Although microsegregation (where diffusion distances are at the order of magnitude of the dendrite arm spacing or the cell size, usually between 10 and $100 \mu \mathrm{m}$ ) can be minimised/eliminated by heat treatments (e.g. homogenisation), the length scales associated with macrosegregation ( $\mathrm{cm}$ to $\mathrm{m}$ ) make it essentially unaffected by annealing. Hence it constitutes an irreversible defect. This defect may then persist throughout the downstream processing of the ingot (billet). This may influence heat treatment efficiency, lead to property variations, and impair the quality of the finished end product. More importantly, the occurrence of this defect can seriously limit the size, alloy composition and the allowable speed (as a consequence, the productivity) at which direct chill (DC) cast billets (ingots) are produced. 
The degree of macrosegregation in an alloy is influenced to a large extent by ingot dimensions, type and amount of alloying elements and the casting process used. Continuous or semi-continuous casting routes are commonly used to produce ingots of wrought alloy compositions, which are intended for subsequent processing $[1,2,3,4,5$, 6]. Moreover, the semi-continuous direct-chill casting is the most efficient technology for the production of large-sized ingots needed for sheet and forged products. The presence of macrosegregation sets limitations on the size and the composition of the billet to be cast in a productive and economical way. Thus the importance of macrosegregation in the production of cast products cannot be overemphasized. Macrosegregation and hot cracking are considered as major defects in DC cast Al alloys and the occurrence of these two defects is connected through solidification phenomena. In general, it is known that macrosegregation is more influenced by convective and shrinkage-induced flows in the semi-solid region of the ingot (billet) $[3,7,8,9,10,11]$. Hot cracking can initiate under certain conditions in the lower part of the semi-solid region, close to the solidus isotherm, when the solid fraction is more than 0.9. The subject of hot cracking in $\mathrm{Al}$ alloys has been extensively reviewed recently [12].

This literature review is confined to macrosegregation in $\mathrm{Al}$ alloys and is structured as follows. In Part 2, the DC casting process is introduced to the reader; the role of process parameters, the flow and solidification patterns are explained and related to structure evolution in as-cast billets (ingots). Subsequently in Part 3, the problem of macrosegregation is defined; the mechanisms underlying macrosegregation are illustrated with the aid of computer simulations. The correlation with DC cast process parameters and structural features is attempted (Part 3). The issue of how to control macrosegregation is also dealt in Part 3. In Part 4, the effect of grain refining on 
macrosegregation is introduced, the current understanding is described and the contentious issues are outlined. The review ends with conclusions remarks.

\section{Direct-chill casting - Process Parameters, Solidification and Structure Patterns}

\subsection{Direct-chill casting process - a brief introduction}

Direct-chill (DC) casting of aluminium was invented in 1936-1938 almost simultaneously in Germany (W. Roth, VAW) and the USA (W.T. Ennor, ALCOA). This technology was based on the existing methods of casting for copper and aluminium alloys suggested by B. Zunkel (1935) and S. Junghans (1933). Rapid development and industrial use of this method of casting was facilitated by requirements of the aircraft industry for large billets (both round and flat). This demand was first driven by increasing passenger airline transport and, later by military needs during World War II. By the end of the war, almost all wrought aluminium was produced by direct-chill casting in the United States, the Soviet Union, and Germany.

Excellent reviews are available on the technological developments together with the insights into the process $[1,2,4,13]$. Typical DC cast products include large rectangular sections known as ingots (approx. $500 \times 1500-2000 \mathrm{~mm}$ which are further rolled into plate, sheet and foil) and cylindrical sections known as billets (up to 1100 $\mathrm{mm}$ in diameter which are further forged or extruded to form rods, bars, tubes and wires). In this review we will use these names interchangeably, if not stated otherwise.

During DC casting, liquid metal is poured into a water-cooled mould, which is initially closed by a starting block beneath. Once the liquid metal freezes on the starting block and a solid shell is formed close to the mould walls, the starter block is lowered into a pit with a constant casting speed $\mathrm{V}_{\text {cast }}$ while keeping the metal level in the mould at a certain height. The solid shell forms due to the heat flow through the water-cooled 
mould (primary cooling). While the outer part of the ingot is now solid, the inner core is still semi-solid/liquid. Further cooling of the ingot bulk to a temperature below the alloy solidus is achieved by quenching (cooling, chilling) the solid shell directly with water jets (Fig. 1) as the ingot descends beneath the lower edge of the mould (secondary cooling, which actually provides up to $95 \%$ heat extraction [13]). In a vertical process, the casting stops when the bottom of the pit is reached. A horizontal variant of the process can be truly continuous with flying saws separating completely solid part throughout the casting duration.

Surface quality and microstructure have received a lot of attention in DC casting technology. Mould lubrication and air flushing are used to separate the solid shell from the mould, to control primary cooling rate, and to minimise sticking. Interaction between the (semi-) solid shell and the mould may cause a rough surface with different type of defects, such as cold shuts, bleed-outs, and drag marks. As will be discussed later, the surface region of the DC cast material is characterized by a mixed fine/coarse microstructure with a cyclic macrostructural pattern $[6,13,14]$. In addition there is a specific macrosegregation pattern with large variations in chemical composition at the surface/subsurface. This affects the quality of the surface and subsurface layers and can lead to problems during downstream processing, e.g. edge cracking and streaking during rolling and extrusion. The billet needs to be "scalped” by removing the surface layer. Thus it is much more economical to produce good enough cast surfaces for direct working without or with minimized prior scalping.

To counter the above undesirable effects, several mould technologies such as low-head casting, hot-top casting, lubrication through the mould, air pressurised moulds, electromagnetic casting (EMC) etc. have been devised with the aim to control the mould (primary) cooling [13]. The hot top, most widely used nowadays in DC 
casting moulds, is a refractory reservoir with a ceramic insert in the mould. This type of moulds was pioneered by G.E. Moritz (Reynolds, 1958) and further developed by A.G. Furness and J.D. Harvey (British Aluminium, 1973). The hot top eliminates the need of thorough control of melt level in the mould and makes the process more manageable [4]. Further control of the primary cooling by constant air/oil supply through a fineporous graphite ring was suggested by R. Mitamura and T. Itoh (Showa Denko, 1977) and mastered by Wagstaff Inc. in the 1980s. The main improvement was the surface quality. Electromagnetic casting (EMC) goes one step further and is based on the concept of mould-less casting, in which the liquid metal is constrained by an electromagnetic field while it is chilled by water jets [15]. This technology was invented by Getselev (Kuibyshev Aluminium Works, 1969). The most obvious advantage of this method is the production of very smooth surfaces in billets that can be directly processed. In addition, eddy currents in the melt alter the flow patterns, which have immediate effect on structure and macrosegregation. More discussion on EMS will follow in the later sections.

The main DC cast process variables are casting speed (the speed at which the solid is withdrawn from the mould), water flow rate (the cooling rate), and the melt temperature (level of melt superheat). The optimum casting speed depends on the alloy composition and the casting size, and is usually between 3 and $20 \mathrm{~cm} / \mathrm{min}$. The water flow rate ranges from 2000 to $4000 \mathrm{~mm}^{3} / \mathrm{s}$ per $1 \mathrm{~mm}$ of the mould circumference [13], which equals to 75 to $150 \mathrm{l} / \mathrm{min}$ for a 200-mm circular mould. Typical melt temperatures are in the range of 690 to $725^{\circ} \mathrm{C}$ for commercial $\mathrm{Al}$ alloys. 


\subsection{Solidification patterns in DC cast billets}

\subsubsection{Characteristics of sump}

The process variables determine thermal conditions of casting and, therefore the temperature distribution in different sections of the billet. Together with the alloy composition this decides the dimensions and geometry of the transition, between liquid and solid, region in the billet. The billet during casting comprises several, well defined zones as shown in Fig. 2. The sump consists of the liquid pool (1) and the transition region (2). The transition region is bound by liquidus and solidus isotherms and can be further subdivided into the slurry and the mushy (3) zones with the border between them represented by a coherency isotherm (e.g. at a solid fraction of 0.3 in Fig. 2a). The condition of coherency can be defined as the moment (or temperature) when solid grains (usually dendrites) start to impinge upon one another, forming a macroscopically coherent structure [16], as shown schematically in Fig. 2b. In this paper, reference to the mushy zone is always made to the region below the coherency isotherm, while the region between the liquidus and the coherency isotherms is called a slurry. For wrought commercial Al alloys used in DC casting, the solid fraction at which this transition occurs is between 0.2 and 0.33 [16]. The coherency isotherm in most cases outlines the (continuous) solidification front. The solidification front and the isotherms indicate the progress of solidification in thermal and geometrical terms. Different mechanisms of macrosegregation are acting in different zones of the transition region as shown in Fig. $2 \mathrm{~b}$ and will be discussed in detail later in this review.

The depth of the sump (defined as the distance along the ingot/billet centreline from the bottom of the hot top (see Fig. 1) to the solidus isotherm) is one of the characteristic features of the solidification profile that exists upon DC casting (Fig. 2a). The sump depth mainly depends on casting speed, alloy type and size of the casting and 
is typically around 0.7 times the billet radius $[5,13]$. For the billet, the sump depth $(\mathrm{h})$ increases with the square of the radius (R), linearly with casting speed and is inversely proportional to the alloy thermal conductivity according to the following formula $[1,17]$

$$
\mathrm{h}=\left[\mathrm{AR}^{2} \mathrm{~V}_{\text {cast }}\right] /\left[4 \lambda_{\mathrm{s}}\left(\mathrm{T}_{\mathrm{m}}-\mathrm{T}_{\text {surf }}\right)\right],
$$

where A is a coefficient depending on the alloy (latent heat of fusion, density of solid, specific heat of solid), $V_{\text {cast }}$ is the casting speed, $\lambda_{s}$ is the thermal conductivity of solid, $T_{m}$ is the melting temperature of the alloy, and $T_{\text {surf }}$ is the surface temperature of the billet (or water temperature). The coefficient A determines the solidus temperature of the alloy.

A similar relationship can be derived for flat ingots, with ingot thickness substituting for billet radius in Eq. (1). Although this formulation is derived based on the assumption of the constant surface temperature and conical shape of the sump, it proves to be valid in practice $[1,5,18]$. The sump depth normalized to the billet radius is shown to increase linearly with the increasing thermal Peclet number ${ }^{1}$, which means that the sump depth is inversely proportional to the alloy thermal conductivity $[5,13]$. The direct consequence of Eq. (1) is the rule that the ratio between the sump depth and the billet radius is constant if

$$
\mathrm{V}_{\text {cast }} \mathrm{R}=\text { const }[1,5] \text {. }
$$

In practice the casting speed is reduced as the diameter (or thickness) increases.

The dimensions of the transition region are not, however, changing uniformly along the billet cross-section. There is a general tendency of widening the transition region towards the centre of the casting.

\footnotetext{
${ }^{1}$ Peclet number $=\mathrm{LV} / \alpha$, where $\mathrm{L}$ is the characteristic length (billet radius), $\mathrm{V}$ is the velocity (casting speed), and $\alpha$ is the thermal diffusivity $\left(\lambda / \rho c_{p}\right)$ where $\lambda, \rho, c_{p}$ are thermal conductivity, density, and heat capacity, respectively. This number shows the ratio between heat advection and heat conduction on the same length scale.
} 
The solidification of the billet follows an interesting pattern due to the specifics of the DC casting process. The billet surface solidifies in the mould under the influence of primary cooling (Fig. 3). At some point above the base of the mould, the shell shrinks away from the mould due to thermal contraction of the ingot, forming an air gap (which depends on the mould design). This air gap drastically reduces the heat extraction through the mould, which may even lead to partial re-melting of the shell. Thus the subsurface is formed under decreased heat extraction. Once the secondary cooling takes effect, the next inner layer is solidified under high cooling rates, where water jets hit the surface. From then onwards, the cooling rate decreases as the centre is approached. If the mould is deep and metal level is high, then the air gap will extend over a greater length with the risk of surface defects through local collapse of the weak solid network or bleed outs [4].

In addition to this cooling rate (defined as the inverse of the time required to pass the solidification range, which is determined mainly by heat transfer conditions), the billet structure is also influenced by another factor called 'solidification rate' (or growth rate i.e., the normal velocity of the solidification front, $\mathrm{V}_{\text {sol }}$ ) which depends on the geometry of the solidification front (sump shape in the case of DC casting). This is proportional to the casting speed and is given by

$$
\mathrm{V}_{\text {sol }}=\mathrm{V}_{\text {cast }} \cos \varphi \text {, }
$$

where $\varphi$ is the angle between the normal to the solidification front and the billet axis [5]. Though the casting speed and cooling conditions are presumed constant during steady-state casting, the local solidification rate and the thermal gradient $(G)$ change with position along the solidification front (Fig. 4a) $[1,5,19]$. The solidification rate is maximum in the centre and on the periphery of the billet, where the angle $\varphi$ is nil. 
The sump profile can be observed experimentally by doping the melt during casting with liquid of different composition [2], by addition of a grain refiner [20, 21], or by emptying the sump during casting [5, 22] (Fig. 4b).

The cooling rate is an important characteristic that determines to a great extent the structure and stress evolution in the as-cast material. It is a measure of heat extraction and varies throughout the transition region, both in vertical and horizontal directions. There is a general decrease of the cooling rate towards the centre of the billet with a frequently experimentally observed sudden increase in the very centre [5]. In the vertical direction, the cooling rate is lower in the slurry zone and much higher in the mushy zone [23].

Several reasons can be behind these observations. First of all, the overall shape of the cooling curve can be explained by the extension of the slurry region. The temperature variation within the slurry region is rather small whereas its width is increasing towards the billet centre (Fig. 2a, 4a). The rate of solid-phase formation in aluminium alloys is, however, very high, which means that over $30 \%$ of the solid phase can be formed within a few degrees below the liquidus. The formation of the solid phase produces latent heat of solidification and pumps additional thermal energy into the slurry zone, effectively slowing down the cooling. As a result a nearly isothermal plateau appears in the first portion of the cooling curve and becomes longer on approaching the billet centre. Secondly, the central part of the billet is formed in the last stage of solidification. This means that the amount of latent heat that is released in a particular horizontal cross-section of the billet decreases towards the bottom of the sump, as most of the lower cross-section has been already solidified and does not release latent heat anymore. Therefore, the cooling in the central-bottom part of the mushy zone (second portion of the cooling curve) is more efficient than in the slurry 
zone. Four factors may further enhance the acceleration of cooling in the central part of the billet as compared to an intermediate radial (thickness) position. (i) The lower part of the sump (central portion of a billet) is formed, in most cases, in the range of secondary and downstream cooling (Fig. 1) where the heat transfer is the highest. (ii) In addition, the heat is extracted from this part of the billet mostly through the solid phase that has a higher heat conductivity than the liquid. (iii) Some influence can be imposed by melt flow in the liquid/slurry part of the billet (see Section 2.3). Hotter melt penetrates the slurry region about the mid-radius, possibly impeding the cooling efficiency. However, in the central-bottom part of the slurry zone, the colder melt is driven upwards, additionally cooling the melt in this section of the billet. (iv) And, finally, the high solidification-front velocity in the centre of the billet (Eq. (3)) may narrow the mushy zone as a result of a higher upward velocity of the solidus isotherm as compared to the liquidus velocity.

One should be very careful in attributing the measured cooling curve to the actual cooling rate that determines the structure formation in the solidification range. It is true that if we take the temperature measurement versus casting length and assume a constant casting speed, we can recalculate the data in terms of temperature versus time. But this "cooling rate" can be related to the formed structure only if the solid phase follows the tip of a thermocouple, in other words - travels from the liquidus to the solidus at the casting speed. The actual situation in the sump of the billet (ingot) is more complicated with thermo-solutal convection and gravity involved and with the resultant complex flow patterns that exist in the liquid and slurry zones of the billet (see Section 2.3). The inhomogeneous distribution of cooling rates in the transition region is reflected in the inhomogeneous structure found in different sections of the billet. 
In general, the cooling rate encountered in a commercial size DC cast ingot varies from 0.4 to $10 \mathrm{~K} / \mathrm{sec}$ [24].

\subsubsection{Effect of DC casting process parameters}

Out of all DC casting process parameters, casting speed exerts a dominant influence on the depth and shape of the sump, a fact that has been noticed by the pioneers of this technology $[1,17]$. Increase in casting speed causes sharp deepening of the sump by changing both the sump depth and the distance between liquidus and the solidus isotherms $(1+2$ and 2 in Fig. 2a) with other isotherms in the transition region moving further apart (Fig. 5a, b). However, across the billet cross-section, the vertical distance between liquidus and solidus changes with casting speed unevenly in the radial direction (Fig. 5c). So the effect of increasing casting speed is much more pronounced in the central part of the billet.

Earlier discussion on the sump depth pertains to the steady-state regime (a situation where the sump depth and the position of the isotherms are invariant with time). As a rule of a thumb, the steady state is considered to be reached after a length equal to one billet diameter is cast after the point where the casting speed is varied. Recent calculations on the evolution of sump depth with time in a transient state (during changing casting speed) showed that the steady state constant depth is reached even before the billet-diameter length [25]. A transient casting regime with continuous change of casting speed results in thermal inertia with correspondingly delayed development of sump, which has been experimentally and numerically shown in a number of studies, e.g. [25, 26, 27]. As a result, the depth of the sump can "overshoot", i.e. the depth keeps increasing at a constant or even decreasing casting speed.

In comparison with casting speed, water flow rate and melt temperature exert less influence on the sump dimensions. 
It is experimentally shown that the change in water flow rates has almost no effect on the characteristics of the sump, especially at high casting speeds [18]. At lower casting speeds, the sump depth and the width of the transition region in the billet centre tend to increase with water flow [18]. However, a slight decrease in sump depth is reported at high water flow rates and at low melt superheats, evidently due to the overall increase in heat extraction [28]. Generally, water flow rate has marginal effect ${ }^{2}$ on the temperature distribution provided that this flow rate is sufficient to assure the nucleate boiling regime when the heat transfer coefficient is the highest [13, 29], which is normally the case during DC casting.

Increase in melt temperature can deepen the sump due to the increase in total heat that needs to be removed via the heat transfer through the surface, and raised temperature gradients in the liquid pool [30, 31, 32]. Computer simulations of directchill casting confirm that the increase in melt temperature deepens the sump (region $1+$ 2, see Fig. 2a) and narrows the transition region (region 2) by shifting both the liquidus and the solidus isotherms downwards [25, 33]. But liquidus position is affected to a greater extent. At the periphery of the billet the solidus tends to move downwards with increasing melt temperature and this can often result in bleed-outs during DC casting [33]. Generally, a lower melt temperature results in a shallower and more isothermal sump.

\subsection{Flow patterns in DC cast billets}

One of the main causes of macrosegregation is the relative movement between solid and liquid phase. As we did in the previous section, it is convenient to divide the solidifying zone into two parts by the so-called coherence fraction contour: a slurry zone in which

\footnotetext{
${ }^{2}$ If the Biot number, $\mathrm{Bi}$ (given by hd/ $\lambda_{\mathrm{s}}$ where $\mathrm{h}$ is the heat transfer coefficient, $\mathrm{d}$ is the distance from the surface and $\lambda_{s}$ is the thermal conductivity of the solid) is greater than 1 , heat flow is dominated by conduction $\left(\lambda_{\mathrm{s}}\right)$. With typical values for $\mathrm{h}\left(10^{4} \mathrm{~W} \mathrm{~m}^{-2} \mathrm{~K}^{-1}\right)$, and $\lambda_{\mathrm{s}}\left(150 \mathrm{~W} \mathrm{~m}^{-1} \mathrm{~K}^{-1}\right)$, the critical distance is $15 \mathrm{~mm}$ from the surface. Deeper inside the billet, the heat flow is controlled by convection.
} 
the solid phase is floating or suspended in the liquid and a mushy zone where the solid forms a coherent network and moves uniformly downwards at a specified speed (casting speed) (Fig. 2). The flow patterns in these two parts are different. In the slurry zone, the volume fraction of solid grains is in the range between 0 and the coherency fraction (which is e.g. between 0.2 and 0.3). The drag force imposed on the liquid phase by the solid is relatively small and the flow characteristics are mainly determined by forced convection and thermal-solutal (natural) convection. The forced convection can be a result of filling conditions and there are different inlet and melt distribution designs to ensure a stable and turbulent-free filling. On the other hand, it can be also an intrinsic feature of the casting technology, e.g. upon electro-magnetic casting. Some implications of forced convection are considered in Section 3.4. Thermal-solutal convection is initiated due to the temperature and concentration gradients and its buoyancy term in the momentum equation is related to the temperature and average concentration by [34]:

$$
F=-\rho_{l}\left[\beta_{T, l}\left(T-T_{0}\right)+\sum_{i=1}^{n} \beta_{C, l}^{i}\left(C_{l}^{i}-C_{0}^{i}\right)\right] g
$$

where $\rho_{\mathrm{l}}$ is the liquid density, $\beta_{\mathrm{T}, \mathrm{l}}$ and $\beta_{\mathrm{C}, \mathrm{l}}$ are the thermal and solutal expansion coefficients for the liquid phase, $\mathrm{T}$ is the temperature, $\mathrm{C}_{l}$ is the liquid concentration, $\mathrm{T}_{0}$ is the reference temperature, $C_{0}$ is the reference concentration, $g$ is the gravity acceleration, and index $i$ is related to solute elements.

Another important feature of the flow in the slurry zone is the settling of suspended solid grains during their movement along with the liquid, due to a higher density of the solid phase as compared to the liquid. The simplest expression to quantify these phenomena is suggested by $\mathrm{Ni}$ and Incropera [35] as

$$
\vec{V}_{s}-\vec{V}_{l}=\frac{1-g_{s}}{18 \mu_{m}}\left(\rho_{s}-\rho_{l}\right) d_{s}^{2} \mathrm{~g},
$$


where $V_{s}$ and $V_{l}$ are the velocities of the solid and liquid phases, respectively; $g_{\mathrm{s}}$ is the fraction of solid; $\rho_{s}$ is the solid density; $d_{s}$ is the grain size; $g$ is the gravity acceleration, and $\mu_{\mathrm{m}}$ is the apparent viscosity of the semi-solid mixture.

In the mushy zone, on the other hand, the fraction of solid phase increases from the coherency fraction to 1 ; and the solid phase progressively forms a rigid network, effectively damping the liquid flow. Therefore, the flow velocity in the mushy zone is small and the flow is mainly driven by shrinkage and deformation of solid network.

The ability of the liquid to flow inside the mushy zone (or any porous structure) is called permeability. The flow rate of a penetrating liquid at the exit of a porous sample and the pressure drop per unit length, $\Delta P^{\prime} / L$ are described by Darcy's law [36]:

$$
Q=\frac{k_{D} A \Delta P^{\prime}}{L},
$$

where $Q$ is the volume flow rate, $A$ is the cross-sectional area, and $k_{D}$ is the permeability coefficient. This permeability coefficient depends on the fluid properties. To make the permeability dependent only on the geometry of the solid phase, a specific permeability, $K$, is introduced as:

$$
K=\mu k_{\mathrm{D}}
$$

where $\mu$ is the dynamic viscosity of the fluid. This permeability depends on the packing of dendrites, hence on the volume fraction and morphology of the solid phase.

The same law can be written in terms of the average (superficial) flow velocity $v$ as follows [37]:

$$
v=-\frac{K}{\mu g_{1}}\left(\frac{\Delta P}{L}+\rho_{1} g\right),
$$

where $g_{1}$ is the volume fraction of liquid, $\rho_{\mathrm{l}}$ is the density of liquid, and $g$ is the gravity acceleration. 
Among analytical models that describe permeability of a coherent solid network using structure parameters, the Kozeny-Carman relationship is widely acknowledged. This relationship couples the evolution of volume fraction during solidification and a tortuosity of the structure to the permeability as follows [38, 39, 40, 41]:

$$
K=\frac{\left(1-g_{\mathrm{s}}\right)^{3}}{k_{K C} S_{\mathrm{v}}^{2} g_{\mathrm{s}}^{2}}
$$

where $g_{\mathrm{s}}$ is the solid fraction, $\mathrm{S}_{\mathrm{v}}$ is the specific surface area of the solid phase, and $k_{K C}$ is the Kozeny-Carman constant taken equal to 5 for equiaxed structures [38].

It should be noted that the Kozeny-Carman relationship could be written in different ways depending on which structure parameter is most important for the permeability.

The real dendritic structures are, of course, quite complicated and the melt flow through their network can go both along grain boundaries (extradendritic flow) and through intradendritic channels (intradendritic flow) as was suggested by Dobatkin [3]. A rather complex model that describes extradendritic and intradendritic channels in the mushy zone has been developed by Wang and Beckermann [42]. They use a concept of grain envelope that separates the inner space of the grain from the exterior. The permeability is then a function of the ratio of extradendritic and intradendritic permeabilities.

In numerical simulations, e.g. modelling of macrosegregation [11], it is convenient to use permeability depending only on the solid fraction. Thus the so-called Blake-Kozeny equation is adopted:

$$
K=k_{0} \frac{\left(1-g_{\mathrm{s}}\right)^{3}}{g_{\mathrm{s}}^{2}},
$$


here $k_{0}$ is a coefficient that takes into account structure length scale and morphology.

For simplicity this coefficient is usually considered constant, which is apparently a rather rough assumption.

Flow patterns in the transition region of a solidifying billet have been investigated by means of analytical studies, numerical simulations and experimental measurements.

The analytical approach has been adopted by Davidson and Flood [43] to investigate strong buoyancy-driven flows occurring in the slurry zone ${ }^{3}$. They developed a model to predict the temperature and velocity distributions throughout the liquid metal pool. It was demonstrated that the flow field could be separated into a relatively quiescent, stratified core bound by intense thermally driven jets formed within a boundary layer close to the mould wall where the temperature varies from the core temperature to the wall temperature (Fig. 6a). The wall jets allow the hot melt from the upper part of the sump to cool at the relatively cold solidification front. These jets collide at the base of the sump in a region of intense viscous dissipation and the flow turns upwards.

Eskin and Du [44] also used an analytical approach to investigate the shrinkageinduced flow in the mushy zone. The shrinkage flow is directed normally to the coherency fraction contour and its magnitude can be estimated as

$$
\mathrm{V}_{\text {shr }}=\mathrm{V}_{\text {cast }} g_{1} \beta \cos (\alpha)
$$

where $\mathrm{V}_{\text {shr }}$ is the shrinkage flow velocity, $\mathrm{V}_{\text {cast }}$ is the casting speed, $\beta$ is the volumetric shrinkage (can be taken as 0.06 for aluminium alloys), $\alpha$ is the angle between the

\footnotetext{
${ }^{3}$ The magnitude of the natural convection can be represented by Grashof number which is given by $\left[\mathrm{g} \beta\left(\mathrm{T}-\mathrm{T}_{0}\right) \mathrm{L}^{3}\right] / \eta^{2}$ where $\mathrm{g}$ is acceleration due to gravity, $\beta$ is the volumetric thermal expansion coefficient, $\mathrm{T}$ is the source temperature, $\mathrm{T}_{0}$ is the ambient temperature, $\mathrm{L}$ is the characteristic length (e.g. sump depth), and $\eta$ is the kinematic viscosity.
} 
tangent to the liquid fraction contour and the horizon, and $g_{1}$ is the liquid volume fraction.

Flow patterns given by the analytical approach are rather approximate and lack fine details as compared to those that can be obtained by numerical simulations. Nevertheless, analytical solutions are useful as a guide and check for numerical simulations [32]. This is because (a) an analytical model indicates the areas of the flow field with large gradients, and this helps to define the areas where fine numerical meshing is appropriate; and (b) the analytically predicted structure of the flow field can be compared with numerical simulation results to check whether the macroscopic flow features are reproduced, at least qualitatively.

Numerical simulations can give a more vivid picture of the flow pattern in the sump as shown in Fig. 6b where the flow pattern is obtained as a result of simulation of a 200-mm round billet [25]. The casting speed is $200 \mathrm{~mm} / \mathrm{min}$ and the casting temperature is $675^{\circ} \mathrm{C}$.

The velocity field comprises four distinct flow zones, namely a bulk liquid zone (solid fraction, $\left.g_{\mathrm{s}}=0\right)$, a slurry region $\left(g_{\mathrm{s}}=0-0.3\right)$, a mushy zone $\left(g_{\mathrm{s}}=0.3-1\right)$, and a solid zone $\left(g_{\mathrm{s}}=1\right)$. The flow pattern in the slurry zone is quite complex. The prominent features are (a) the re-circulation zone with the flow upwards into the liquid bath and then downwards back to the slurry region, and (b) the stagnant zone with a very slow fluid motion closer to the ingot centre (Fig. 6b). In the mushy zone, the solid and liquid phases co-exist. While the coherent solid phase moves downward at the casting speed, the solid network is saturated with liquid that is moving in different directions: at lower fractions solid towards the centre of the billet and at higher fractions solid towards the periphery. Close to the billet surface the liquid flows from the coherent isotherm to the 
solidus contour. Below the solidus contour the solid moves uniformly at the casting speed.

The flow in the mushy zone, in spite of its small magnitude (velocities are around $10^{-4} \mathrm{~m} / \mathrm{s}$ or $6 \mathrm{~mm} / \mathrm{min}$ as compared to the casting speed of $200 \mathrm{~mm} / \mathrm{min}$ ), involves the highly enriched liquid. The contribution of this flow the macrosegregation is important, as we will discuss later in Section 3.2.

Nicolli et al. have modelled the flow induced by volumetric deformation [45]. Like solidification-shrinkage induced flow, it occurs in the mushy zone and its magnitude is rather small. It has been shown that the contribution of this flow to the macrosegregation can be as important as that the shrinkage-induced flow [45].

Close to the surface of a billet, relatively high solidification and cooling rates in a narrow shell cause large thermal gradients. As a result, the rates of solidification shrinkage and thermal contraction are also high as compared to the inner part of the billet. This causes large shrinkage- and deformation-induced flows directed towards the surface of the billet. These flows are further assisted by the aligned convection flow (see Fig. 6b), the metallostatic pressure of the melt, and weakening of the mushy zone by partial remelting in the air-gap region. As a consequence of all these phenomena, there is a strong positive segregation formed at the surface of the billet (sometimes extended to liquation or penetration of the liquid melt through the shell) accompanied by a zone of negative subsurface segregation. The latter is a result of incomplete compensation of the surface segregation by the incoming melt.

Experimental studies of flow patterns and velocities are limited by the available selection of techniques that are not very suitable for application to liquid metals that have appreciable melt temperature. In most cases, water models with particle-velocity tracking measurements are used. There have been also limited attempts to use reaction 
and magnetic velocity probes for studying melt velocities. A good review on the experimental methods can be found elsewhere [46] and Table 1 summarizes some of the techniques and their applicability to DC casting.

Among DC casting process parameters, the casting speed directly influences the convection in a proportional way. A higher casting speed deepens the sump and favours higher temperature gradients, which, in turn enhances thermal buoyancy. Increasing the melt temperature amplifies the vortex flow in the slurry zone and increases the flow velocity at the slurry/mushy zone border (see Fig. 6b) [33].

In addition to the casting parameters, alloy composition and grain refining may influence the flow pattern in an indirect way by altering the properties of the liquid and/or solid phases. For example, alloying elements can differently affect the liquid and solid density. The alloy density $\rho$ is related to the solute concentration of each individual element by a simple mixture law, which can be expressed mathematically as [47]

$$
\frac{1}{\rho}=\frac{1}{\rho^{A l}}+\sum_{i}\left(\frac{1}{\rho^{i}}-\frac{1}{\rho^{A l}}\right) C^{i},
$$

where $C^{i}$ is the concentration of the i-element.

Therefore, alloying elements heavier than (Al) such as $\mathrm{Cu}$ and $\mathrm{Mn}$ will increase the alloy density while light-alloying elements such as Mg will decrease it.

In reality, all the discussed contributions and effects of various parameters on the flow are acting simultaneously but in different proportions. Therefore, the resultant flow pattern is a complex superimposition of all the factors.

\subsection{Structure patterns in DC cast billets}

The microstructure of the DC cast ingot in terms of grain size, dendrite arm spacing (DAS), non-equilibrium eutectics, porosity, and appearance and volume fraction of 
"floating grains" is important not only for understanding specific defects such as hot cracking and macrosegregation, but also in assessing the overall quality in terms of subsequent processing. As shown in the flow chart in Fig. 7, the structure and the associated defect formation depend on a number of inter-linked parameters.

The evolution of the structural features and the dependence on the process parameters is of interest. Despite a good amount of literature on the observations of various structural features $[9,18,28,33,48,49,50,51,52]$, systematic studies on the variation of these microstructural features across the billet cross-section with respect to process parameters are limited, except for a few works [18, 28, 33, 48, 53].

In the following sub-sections, each of the above structural features is dealt with respect to the DC casting process parameters and chemical composition ${ }^{4}$.

\subsubsection{Grain size}

A uniform and fine grain size is desirable for optimum formability and uniform mechanical properties in wrought products. Grain structure (average size, size distribution, and morphology) is an important parameter in influencing the defects, e.g. hot cracking. In DC castings the grain structure depends on the alloy composition and, in practice is primarily controlled by the introduction of heterogeneous nuclei (i.e. grain refining) and growth conditions, being also influenced by the cooling rate [25, 54, 55]. It is well known that grain refining has a dramatic effect on the grain size and morphology as illustrated in Fig. 8. Further discussion on grain refining is presented in Chapter 4. Solute elements in the liquid phase generally slow down the growth velocity of the newly formed grains, and more grains are thereby allowed to nucleate. This observation is in a base of so-called "growth restriction" theory of grain refinement, the discussion on which can be found elsewhere [56, 57].

\footnotetext{
${ }^{4}$ Unless stated, it is understood that general reference to DC cast billet/ingot is for the condition that is not grain refined (i.e., Non-grain refined, NGR).
} 
The grain size tends to increase from the surface to the centre of the billet or slab [18, 33, 58]. This is illustrated in Fig. 9a where the grain size coarsens toward the centre of the billet with a minimum around 15 to $20 \mathrm{~mm}$ from the surface (due to direct water impingement) [18]. A measurable grain refinement is reported for the central part of a slab $(1050 \times 550 \mathrm{~mm})$ of a 5182 alloy, which was explained by the bimodal grain-size distribution with the occurrence of 'smaller' grains caused by grain fragmentation and transport within the entire transition region [59].

Out of the DC cast process variables, water flow rate exhibits the least effect with respect to grain size variation. A higher casting speed causes some grain refinement, correlated to the corresponding increase in the cooling rate. The refinement of grain size with the increase in casting speed is more noticeable in the central part of the billet than at the periphery [18, 33] (Fig. 9a). A higher melt temperature produces coarser grains, mostly due to de-activation of potent solidification sites [33]. Grain coarsening at higher melt temperatures is found mostly in the central part of the billet [33].

The grain distribution in the casting depends to a great extent on the alloy composition. Figure 10 demonstrates some of the typical features of grain variation across the billet cross-section of a 200 -mm billet from a solute-rich 7075 alloy.

In dilute alloys, the subsurface region exhibits fine equiaxed grains; further inside columnar grains grow to give place to a coarser equiaxed grains in the centre. This is observed for example in an $\mathrm{Al}-1 \% \mathrm{Cu}$ alloy as compared to more concentrated (>2\%) binary Al-Cu alloys [48]. The columnar to equiaxed transition (CET) is known to be controlled by constitutional undercooling; and higher solute concentrations (e.g. in commercial $\mathrm{Al}$ alloys) facilitate this with total suppression of columnar grains $[37,60]$. 
Observations on various binary Al-Cu alloys in a 200-mm round DC cast billets $[18,33,48]$ show that in general equiaxed structures are observed. Narrow zones of columnar grains are noticed in an $\mathrm{Al}-2.8 \% \mathrm{Cu}$ billet at high melt temperatures $\left(760^{\circ} \mathrm{C}\right)$ and high casting speeds (200 mm/min), or when the alloy is further diluted to less than $\sim 1 \% \mathrm{Cu}$.

In certain Al alloys such as AA 2219 and AA 7050, a fan shaped columnar structure, known as twinned columnar growth (TCG, also known as feathery crystals) is often observed [61]. This problem is associated with both nucleation and growth of new grains early in the solidification event. On the basis of DC casting experience, Bäckerud et al. [62] outline the main factors, which influence the appearance of feathery grains. These include increased temperature gradients in the melt ahead of the growth front, high cooling rates, poor grain refinement and existence of certain alloying elements in the melt. Absence of strong melt flow is yet another factor favouring the feathery grain formation [63]. Their formation should be prevented as the existence of this feature affects the performance of the semi-product (e.g. loss in ductility). The occurrence of feathery crystals is detrimental in terms of formability due to their anisotropic nature. Until the seventies, it was a severe problem in DC casting, but improvements in casting techniques and use of grain refiners allowed the production of twinned-crystals-free billets and ingots.

In electromagnetic casting, unlike conventional DC casting, the grain size is more homogeneously distributed throughout the cross section of the ingot, which is a result of forced convection, lower thermal gradients, and more intensive transport of the solid phase within the slurry zone.

In grain-refined (GR) billets, the radial distribution of grain size is similar to that in NGR billets, i.e. with an increase in grain size towards the centre [49, 58, 64]. The 
variation in grain morphology and size is, however less pronounced as compared to non-grain refined counterpart, and the grain refinement makes the structure of alloys less cooling-rate sensitive (Fig. 11). It is observed that except for a slight increase close to the centre, the grain size remains almost unchanged. These trends have been observed on commercial alloys 2024, 7075 [21, 58] and 5182 [59]. Work on GR commercial Al alloys by directional solidification showed the impact of cooling rate on the grain size appears to be stronger at a lower cooling rate [24].

For a given grain-refined alloy, the variation in grain size seems to be dependent on a combination of ingot (billet) size, casting speed and amount of grain refiner. Among these parameters, the ingot size may be a crucial factor but it is difficult to find any data in literature where the billet size has been systematically varied with reported effect on grain refining. The effect of process parameters, in particular the influence of casting speed on the refinement and the variation of grain size is also not investigated in detail. But it is observed that increased casting speed has only a minor effect in decreasing the grain size [58].

The degree of grain refinement and grain distribution across the DC cast ingot (billet) is also a function of inoculant amount used [64]. The grain size decreases with increasing concentration of grain refiner, the effect being more pronounced as the ingot (billet) centre is approached. However, once a given alloy is 'sufficiently' inoculated (as discussed in section 4.2), further additions are not important with respect to the decrease in grain size and the alloy becomes less sensitive to cooling rate. Increasing the refiner amount may, however, influence the grain morphology $[65,66]$ as discussed below.

In general, grain morphology in commercial, grain refined castings is equiaxed and dendritic [8, 21, 49, 58, 59, 64, 67, 68, 69]. However, non-dendritic grains have been reported in DC cast $\mathrm{Al}$ alloys upon grain refining [8, 49, 70, 71]. A special 
cavitation-aided melt processing is known to be a powerful means to produce nondendritic structure in various commercial alloys [72, 73]. Evidently, the formation of non-dendritic structure is a function of alloy composition, nature of grain refiner, and casting conditions. It is shown, for example that a grain refined DC-cast Al-Mn alloy exhibits typical features of cellular grain growth while an Al-Mg-Si alloy shows dendritic grain structure that due to different amounts of constitutional undercooling [49]:

$$
\left[\mathrm{m}_{\mathrm{L}}(1-\mathrm{K}) \mathrm{C}_{0}\right] / \mathrm{K}
$$

where $\mathrm{m}_{\mathrm{L}}$ is the slope of the liquidus, $\mathrm{K}$ is the partition coefficient, and $\mathrm{C}_{0}$ is the nominal alloy composition.

The shape of the grains is more dendritic in the NGR part and more globular in the GR part in a sheet ingot of AA 5182 [70]. In certain Al-Li-Mg alloys the nondendritic grain structure can be dominant upon addition of zirconium. Grain refinement with scandium or scandium and zirconium is known to facilitate non-dendritic solidification in $\mathrm{Al}-\mathrm{Mg}$ and $\mathrm{Al}-\mathrm{Zn}-\mathrm{Mg}$ alloys [71]. Cavitation melt treatment produces non-dendritic structure within a wide spectrum of alloy compositions and ingot sizes, which is attributed to the multiplication of solidification sites and narrowing of the transition region [72]. Yu and Granger [8] reported that within the central portion of a grain refined 2024 alloy, isothermal dendrites ('floating grains') appear to be nondendritic compared to the rest of the structure, which is dendritic. Further discussion on 'floating grains' follows in Sections 2.4.3 and 3.2.4.

The formation of non-dendritic structure is shown to be beneficial for the structure homogeneity of DC cast products, improving their mechanical properties in the vicinity of the solidus, diminishing macrosegregation and decreasing cracking susceptibility [72]. On the other hand, there are reports that the formation of very fine 
globular grains can increase the hot tearing susceptibility due to the limited permeability of the mushy zone $[65,66]$.

The important feature of the non-dendritic grains that are formed during solidification $^{5}$ is the unique dependence of the non-dendritic grain size on the cooling rate. The size of the non-dendritic grain at a certain cooling rate is the same as the dendrite arm spacing of the dendritic grain formed at the same cooling rate [72].

\subsubsection{Dendrite arm spacing (DAS)}

Secondary dendrite arm spacing is an important structure parameter that reflects local solidification conditions. In practice, the average dendrite arm spacing (DAS), also often referred to as cell size, is measured on polished sections of as-cast samples. In contrast to the dendritic grain structure, DAS is more sensitive to the cooling rate as the dendritic cell structure reflects the local conditions for heat extraction during solidification and is controlled by the solidification time. The relationship between secondary DAS and solidification time is given by the equation [37]:

$$
\mathrm{d}=\mathrm{At}_{\mathrm{f}}^{\mathrm{n}}
$$

where $\mathrm{d}$ is the secondary DAS $(\mu \mathrm{m}), \mathrm{t}$ is the local solidification time $(\mathrm{s}), \mathrm{n}$ is the coarsening exponent (approx. 0.33 to 0.5 for aluminium alloys), and $\mathrm{A}$ is a constant depending on the alloy. The same type of relationship exists between the DAS and the solidification rate during DC casting. Dobatkin was probably the first who has reported this relationship back in 1948 [1].

Uneven distribution of solute (microsegregation) occurs within dendrite branches as a result of nonequilibrium solidification, which can be approximately described by the Scheil equation [37]

\footnotetext{
${ }^{5}$ Non-dendritic grains can be also formed during isothermal anneals in the semi-solid temperature range, which is a common practice in preparing structure for thixoforming processing. The mechanisms of the nondendritic morphology formation are completely different. In the case of solidification, nondendritic structure is "pre-dendritic", i.e. the dendritic structure is not yet developed. In the case of isothermal annealing, the nondendritic structure is "post-dendritic" and is formed by coarsening of existing dendrites.
} 


$$
\mathrm{C}_{\mathrm{s}}=\mathrm{C}_{0} \mathrm{~K}\left(1-\mathrm{g}_{\mathrm{s}}\right)^{\mathrm{K}-1} \text {, }
$$

where $C_{s}$ is the composition of the solid at the fraction solid $g_{s}, C_{0}$ is the nominal alloy composition, and $\mathrm{K}$ is the equilibrium partition coefficient. Homogenizing this solute distribution is usually the first step in the downstream processing of a DC cast ingot. The time at a given homogenizing temperature is linked to DAS, although in practice, the times are generally set by the phase transformation, break up and spheroidisation of intermetallic particles [30].

The mechanical properties of semi-solid and solid alloys are determined by dendrite arm spacing; with ductility, fracture toughness and yield strength being improved in a fine dendritic structure.

DAS is an important parameter that determines to a great extent the distribution of micro porosity and non-equilibrium eutectics. It also characterizes the permeability of the mush region, which affects both macrosegregation and hot cracking tendency. As expected, across the billet radius, DAS increases towards the centre due to a general decrease in cooling rate and widening of the transition region. This was observed experimentally in different studies [18, 33, 48, 49, 52, 53, 59, 64, 68, 74]. At the same time, there are some variations in the DAS distribution along the billet diameter or ingot horizontal axis. The finest DAS is observed at some distance away from the surface, in the section that solidifies in the region of water impingement onto the surface (Fig. 1, Fig. 9b). The dendrite arms are coarser in the central portion and in the region where the air gap is formed (Fig. 3, Fig. 9b). If there is no contact with the mould (e.g. electromagnetic casting), the edge effects are absent [52]. Then the DAS continuously increases from the surface to the centre as the heat extraction is solely due to cooling by water. 
In DC casting, DAS depends on the size of the billet or ingot. This is related to the distance through which the heat from the centre of the ingot has to be transported to the cooled surface. Among DC cast process parameters, casting speed has a greater effect on the refinement of DAS [18, 28] (Fig. 9b) whereas increasing the water flow rate only slightly refines DAS [18]. However, increase in casting speed beyond a certain level does not significantly refine DAS [30]. Melt temperature mostly influences the DAS in the centre of the billet, causing its coarsening [33]. Under similar DC casting conditions, alloy composition is found to have a significant influence on the magnitude and variation of DAS across the billet cross section [74], more solute-rich alloys having finer DAS [75].

Reports on variation in DAS in grain-refined billets too show a general coarsening of DAS from the surface towards the centre of the billet indicating the strong effect of cooling rate [59, 64, 68, 74]. However, for different alloys, grain refining seems to even out the differences in DAS that otherwise existed in NGR condition (Fig. 12). The DAS is almost unchanged with varying amounts of $\mathrm{Al}-\mathrm{Ti}-\mathrm{B}$ inoculants (from $0.009 \mathrm{Ti}$ to $0.028 \mathrm{Ti}$ ) in a DC cast slab of pure $\mathrm{Al}$ [64].

There are reports on the local DAS refinement in the central portion of DC cast billets and ingots, irrespective of grain-refining practice [30, 53, 59, 64, 68, 74]. These observations are in line with uneven change of cooling rate and solidification-front velocity in the billet cross-section as we have discussed earlier in Section 2.2.1. Appearance of so-called floating grains with coarser cell structure and, correspondingly, duplex structure in the centre of a casting can make the pattern even more complex (see Section 2.4.3). But careful analysis of DAS without taking into account coarse-cell grains confirms that there is some DAS refinement in the central portion of the billet. Figure 12 demonstrates the refinement of DAS in the central portion of 200-mm billets 
from 7075 and 2024 alloys. Note that the 7075-billet had duplex structure only when grain refined, whereas the 2024-billet exhibited duplex structure irrespective of grainrefiner addition $[21,58]$.

Studies on direct comparison of the DAS variation across the ingot thickness for both NGR and GR ingots prepared under identical conditions are rare [59, 68, 74]. While almost similar values of DAS are quoted at the billet centre [68], Glenn et al. [59] measured lesser DAS in the NGR ingot compared to GR ingot, especially as the centre was approached. They attributed this observation to the contribution from large showering crystals. Closer to the periphery, grain refining had little effect on DAS. Our studies indicate that grain-refined billets always exhibit greater DAS, while alloy constitution may have a significant influence on the magnitude of this variation [74] (Fig. 12). It is important to note here that the measured DAS is usually the average cell size that is typically smaller for higher-order branches. Therefore, the average DAS of a large, fairly branched dendrite will be smaller than the average DAS of a fine, barely branched grain.

The formation of non-dendritic structure upon additions of large amounts of grain refiner or special casting practice changes the grain morphology and, as we have already mentioned, the cooling rate becomes the main parameter controlling the grain size [72].

\subsection{3 'Coarse-cell’ grains}

The observation of duplex structures is typical of the central portion of DC cast ingots and billets. As shown in Fig. 13, a few grains exhibit coarser internal structure (larger DAS and thicker dendrite arms). The origins of such grains is a matter of discussion but there is a generally adopted opinion that they are formed elsewhere in the slurry region of the casting and then transported to the place where they are found, hence the name 
"floating" grains. The occurrence and distribution of coarse ("floating") grains is of considerable importance, as it constitutes one of the mechanisms of macrosegregation as will be discussed in section 3.2.4.

The appearance of floating grains or, as they have been called in earlier years, "daisies", "white”, or "isothermal” crystals is reported in the earliest accounts on DC casting, e.g. by Dobatkin in 1948 [1]. Their role in the formation of macrosegregation has been also recognized long ago. In more recent past, the importance of floating grains for macrosegregation formation during DC casting has been emphasized [8] and experimental evidence of duplex microstructures is reported by several researchers [9, 18, 21, 28, 33, 58, 68, 70]. Practices that promote a deeper sump (e.g. faster casting speed) and a wider transition region (e.g. low casting temperatures) provide the condition for collection of large solute-depleted "isothermal" dendrites. The amount of coarse-cell dendrites increased with raising casting speed in a 400-mm 2024 alloy billet [28] and also in 200-mm billet from binary Al-Cu alloys [48]. In the work of Dorward and Beerntsen [28], the largest and most obvious isothermal dendrites are observed in billets at high cast speed $(6.35 \mathrm{~cm} / \mathrm{min})$ compared to a lower casting speed (3.8 $\mathrm{cm} / \mathrm{min}$ ). It is noted that low metal superheat (lower melt temperatures) results in a more isothermal sump with lower thermal gradients, which may be more conducive to the growth of floating isothermal primaries. However, detailed studies on the role of melt temperature showed that the distribution of floating grains depends more on the casting speed [33]. At a low casting speed, floating grains are observed throughout the cross section of the billet at a lower melt temperature and concentrate in the central part of the billet with increasing temperature. At a high casting speed, both the amount of floating grains and their spread across the billet increase with the increasing melt temperature. 
It is suggested [33] that deepening of the sump and more severe currents in the vicinity of the mushy zone with increasing melt temperature and casting speed create more possibilities for 'floating' grains to form, grow and settle. On the other hand, it is argued [31] that on increasing melt temperature, the deepening of the sump and higher temperature gradients in the liquid bath might reduce the amount of floating grains.

Experiments with various DC cast binary $\mathrm{Al}-\mathrm{Cu}$ (1 to $4.5 \%$ ) alloys show that the fraction of coarse-cell grains increases with copper concentration [48].

In spite of the good experimental evidence of 'coarse-cell' grains, studies have shown that it is not a regular phenomenon, though the reasons are not clear yet. Finn et al. [68] did not notice any duplex structures in an NGR Al-4.5 Cu ingot. Similar results are obtained for an NGR Al-Zn-Mg-Cu billet [21]. Although in both the cases, the GR ingots and billets did show duplex structures. To add to this, Glenn et al. [59] introduced a showering crystal concept where small crystals (not coarse-cell) found in the central portion of the billet represented broken/remelted dendrites that had been carried into the central part of the sump.

Emley states that grain refining seems to promote the formation of coarse-celled dendrites [4]. But, as we have mentioned earlier, microstructural observations on grain refined ingots are rather limited. It is worth noting that the modern hypothesis on the importance of coarse dendrites for macrosegregation is based on observations made on grain refined Al-Cu-Mg alloy sheet ingots [8]. Microstructural observations on duplex structures were made by Finn et al. [68], with coarse dendrites appearing to be clustered together in the central portion of grain refined binary $\mathrm{Al}-\mathrm{Cu}$ alloy ingot. On the other hand, floating grains are not observed in GR sheet ingot although duplex microstructures are seen in the NGR ingot of a 5182 alloy [70]. 
Table 2 summarises some of the reported observation of duplex structures upon DC casting, showing quite a scatter in these reports.

An extensive experimental research program at TU Delft/NIMR indeed shows that floating grains are a common feature observed in various commercial $\mathrm{Al}$ alloys that are DC cast with grain refining performed in the furnace (Fig. 13b) [21, 58, 69]. The DAS of coarse grains is around 2 to 3 times that of the finer structures $[68,74]$. The morphology of these coarse grains sometimes makes it difficult to conclude whether they are non-dendritic [8] or dendritic [68], although in most cases they appear to be dendritic with large DAS and little branching [21, 58].

Considering the complex flow patterns existing in the sump of a DC cast billet (Section 2.3) and structure evolution in GR ingots (Sections 2.4 and 4.2), it is not surprising that floating grains are observed. But, to date, there is not a single study where detailed microstructural observations have been carried out with respect to their volume fraction, distribution around the central portion of the ingot, and chemical composition. Their significance in deciding the centreline segregation during DC casting is still a matter of speculation.

\subsubsection{Porosity}

In general, porosity in aluminium alloys is caused by (a) difference in solubility of hydrogen in the liquid and solid states, and (b) difference in densities between liquid and solid aluminium. The former results in hydrogen precipitation in a gaseous form during solidification, and the latter - in solidification shrinkage that, in many cases, cannot be compensated by liquid feeding. The amount and distribution of pores are dependent on the concentration of hydrogen, alloy composition, cooling rate, mushy zone dimensions, and microstructure. In most cases the porosity observed in as-cast 
material is of mixed, shrinkage-gaseous origin. Microporosity present in the DC cast ingot is usually healed (welded) during downstream deformation processing.

There are controversial data on the correlation between the hydrogen concentration and the porosity. Hydrogen distributes unevenly across the billet (ingot) cross-section. It can be called a macrosegregation of hydrogen, though in reality there is no long-distance transport of hydrogen during solidification [5]. The concentration of hydrogen found in a particular section of the billet (ingot) is a function of cooling conditions there and is a result of balance between the possibility for gas evolution during solidification (degassing at lower cooling rates) and gas trapping in the solid solution (supersaturation at high cooling rates). The latter can cause porosity formation during annealing of castings. The influence of cooling rate is evident when hydrogen levels are high (e.g. with increasing $\mathrm{Mg}$ levels in an Al-Mg alloy) [76]. Closer to the chill surface, the number of pores increases but the average size remains almost constant. Near the centre (lower cooling rate), the average pore size increases, but the number of pores remains constant.

A few data exists in literature on the variation of porosity in DC cast billets [18, 53, 76]. Measured values of porosity show a tendency for an increase towards the centre of the billet. In addition to this, the equivalent pore radius increases from surface towards the centre, similar to the distribution of DAS. In other words, the bigger the DAS, the larger is the pore radius [53]. It is observed that most of the pores exist between secondary dendrite arms, with a small fraction distributed along the grain boundary. Structure refinement results in the general decrease in pore size. For example casting at a higher speed leads to a corresponding refinement in pore size over the entire cross-section of the billet [18]. At the same time the amount of centreline pores increases with the casting speed [77]. On the other hand, changing the melt temperature 
within practically reasonable range had virtually no effect either on the distribution or the amount of pores [33].

Similar to DAS measurements, the amount and size of pores sometimes reported to decrease the centre of the billet (ingot) [53].

\subsubsection{Non-equilibrium eutectics}

The solidification of alloys under usual casting conditions deviates from the equilibrium solidification path. For most of aluminium alloys which are of hypoeutectic type that means the enrichment of the residual liquid in solutes and eventual formation of eutectics, often referred to as non-equilibrium eutectics.

The eutectic, by definition, represents the last liquid that solidifies and, therefore, its presence in the as-cast structure is an indication of the solidification conditions that have lead to the appearance of this last liquid and of the availability of the liquid phase at late stages of solidification. The presence of liquid at high volume fractions of solid in combination with the ability of this liquid to penetrate through the solid network is very important for the occurrence of such casting defects as pores and hot tears. Limited data exists in the literature on the variation in the fraction of eutectic from surface to the centre of the ingot, even for alloys that are severely vulnerable to hot cracking.

An important and quite persistent feature of non-equilibrium eutectic distribution in the billet is the minimum in the central portion of the billet cross-section $[33,48]$. This means that the amount of last available liquid is always lower in the centre of the billet than at its periphery as shown in Fig. 14. 
The variation in the cooling rate -5 to $20 \mathrm{~K} / \mathrm{s}$ from the centre to the periphery of a 200-mm billet - cannot explain the observed dependence as the eutectic fraction does not show any significant change in this cooling-rate range [75]. Several other phenomena can influence the volume fraction of eutectics. We can suggest the following line of logic for the case of direct-chill casting. Solidification during directchill casting occurs under conditions of convection that is rather active in the transition region of the billet (see Section 2.3). According to Diepers et al. [78] convection can significantly increase the coarsening exponent, affecting the coarsening kinetics [79]. The width of the transition region is maximum in the centre of the billet and the area of stagnant flow where grains can ripen is always present there. As a result the coarsening and back diffusion may occur in the centre of the billet much more efficiently than at the periphery, decreasing the amount of eutectics. On the other hand, structure coarsening may facilitate liquid penetration into the mushy zone by increasing the permeability of the solid network. In this case, depending on the direction of this flow, the amount of eutectic formed by the solute-rich liquid increases or decreases in certain sections of the billet. And finally, the negative macrosegregation in the centre of the billet can further contribute to the decreased amount of eutectics.

At usual and high casting temperatures, the casting speed and water flow rate slightly affect the amount of eutectic in the central portion of the billet as shown in Fig. 14. The eutectic fraction increases with the casting speed, the water flow rate having an opposite effect. Interestingly enough, at very low casting temperatures, the amount of non-equilibrium eutectic decreases with increasing the casting speed [33]. The interrelation between cooling rate, solidification rate, sump dimensions and the fineness of structure can be responsible for such behaviour. 
The casting temperature has a strong effect on the volume fraction and distribution of non-equilibrium eutectic, especially at high casting speeds as illustrated in Fig. 14b. More eutectic is concentrated in the centre of the billet upon casting from high melt temperatures. In this case, the coarseness of the structure in combination with more active melt flows (see Section 2.3) may facilitate a deeper penetration of the solute-rich melt into the mushy zone in the centre of the billet, effectively increasing the amount of eutectic.

\section{Macrosegregation in direct-chill casting of aluminium alloys}

Macrosegregation is an irreparable defect and is bound to occur in large castings. The question then remains: how far we can exert a control over this in order to minimise macrosegregation, if not preventing it altogether. This approach is different from handling hot cracking where it needs to be completely prevented; else the ingot will be rejected for further processing. For a given alloy, macrosegregation is linked to variety of structural parameters such as the morphology of the forming solid phase (which determines the existence of 'floating' grains and permeability of mushy zone), magnitude of solidification shrinkage, level of solute rejection to the melt, and movement of the solid phase in the liquid and slurry regions (which defines the distribution and volume fraction of 'floating' grains). Thermo-solutal convection and forced flow in the liquid may aid or counteract the effects of ingot shape and melt entry on macrosegregation.

Modelling the macrosegregation is normally aimed at (semi) quantitative predicting the occurrence and severity of macrosegregation by considering the basic mechanisms involved. Although the basic mechanisms have been well recognised, the challenge at present is in determining the magnitude in which these mechanisms are affecting the macrosegregation. Further, any model requires experimental validation and 
often in practice this is done by separate research groups, which does not guarantee the complete similarity of process conditions. In the following sections, attention is focussed on the basic mechanisms involved, influence of DC cast process parameters on macrosegregation, correlations with the structure of DC cast products, and, finally discussion of the factors that control macrosegregation.

\subsection{Segregation patterns in DC cast Al alloys and role of partition coefficient}

The fundamental reason for macrosegregation lies in microsegregation, or partitioning of solute elements between liquid and solid phases during solidification. It is, therefore not a surprise that the composition profiles of alloying elements in the DC cast billet cross-section, which characterize the macrosegregation patterns, depend on the partition coefficient, $\mathrm{K}$, whether it is less or greater than 1 . The coefficients are defined as the slope of the liquidus over the slope of the solidus lines in a binary phase diagram of the particular elements in aluminium. Most of the alloying elements and impurities (e.g. $\mathrm{Cu}$, Mg, Zn, Li, Mn, Si, Fe) are present in aluminium alloys at hypoeutectic concentrations with $\mathrm{K}<1$. The compositional variation of these elements in a commercial scale DC cast Al alloy exhibits a pattern as shown Fig. 15. There is a negative (solute-depleted) segregation in the centre adjoined by positive (solute-rich) segregation approximately at mid-radius (or mid-thickness) with a solute depletion at subsurface followed by strong positive segregation at the surface. In the absence of macrosegregation, the deviation should follow the horizontal straight line at zero. Certain elements ( $\mathrm{Ti}$ and $\mathrm{Cr}$ ) which have a peritectic reaction with aluminium (with $K>1$ ) exhibit a segregating tendency, which is exactly opposite to the trend provided in Fig. 15 (i.e., with a centreline positive segregation). 
Further it is observed that the extent of deviation of various alloying elements (with $\mathrm{K}<1$ ) in a commercial $\mathrm{Al}$ alloy closely follows the magnitude of the distribution coefficient [80]. If $\mathrm{K}$ is close to 1 , it implies close spacing of liquidus and solidus and hence little tendency for segregation. On the other hand, values with K much smaller than 1 result in strong partitioning of alloying element. Table 3 provides the data of $\mathrm{K}$ for various elements $[9,67,80]$. The compositional deviation in various commercial $\mathrm{Al}$ alloys is inversely proportional to the partition coefficients of alloying elements $[9,58$, 80]. For example, in a 2024 alloy it is shown that Fe exhibits the highest segregation and $\mathrm{Mn}$ is very sluggish with almost no segregation $[58,80]$.

Figure 16 graphically illustrates the increasing tendency for segregation with decreasing partition coefficient of the alloying element. It is worth mentioning here that the extent of segregation of a particular alloying element depends more on the base alloy itself rather than on its absolute content in this alloy [80].

Macrosegregation can be represented in the following ways:

1. Relative deviation of concentration from the average (either fraction or percentage $)=\left(\mathrm{C}_{\mathrm{i}}-\mathrm{C}_{\text {ave }}\right) / \mathrm{C}_{0}$

2. Amount of segregation or segregation degree (in percent) $=C_{i}-C_{0}$

3. Segregation ratio or index $=\mathrm{C}_{\max } / \mathrm{C}_{\min }$ or $\left(\mathrm{C}_{\max }-\mathrm{C}_{\min }\right) / \mathrm{C}_{0}$ (either fraction or percentage)

Where $C_{i}$ is the mean composition at a specific location, $C_{0}$ is the average (or nominal) alloy composition; $\mathrm{C}_{\max }$ and $\mathrm{C}_{\min }$ are the maximum and minimum concentrations, respectively, as shown in Fig. 15. Representation of macrosegregation by the relative deviation allows the comparison of various elements in a specific alloy or same alloying element in different $\mathrm{Al}$ alloys. Note that the last representation does not identify the type of profile i.e. maximum or minimum at the billet centre [28]. Sometimes the total 
relative deviation of alloying element across the billet/ingot is taken as the sum of the absolute values of the low deviation $\left(\mathrm{C}_{\min }\right)$ and the average of the high deviation $\left(\mathrm{C}_{\max }\right)$ points ([80], see Fig. 15).

\subsection{Mechanisms of macrosegregation}

We have already mentioned on several occasions that the relative movement between solid and liquid phases and the solute rejection by the solid phase are two essential conditions to form macrosegregation. The possible mechanisms behind this relative movement and the enrichment will be discussed in the following sections. Let us analyse how can the macrosegregation form upon these two conditions. For this, we shall consider a representative volume (which can be an element in a finite element/volume simulation), in which liquid flows straight downward. It is assumed that it flows from a hotter region to a cooler region (i.e. in the direction towards the solidus) as illustrated by the number of equiaxed grains in Fig. 17. Solidification shrinkage is present, so more liquid mass flows in than flows out, as indicated by the number of velocity arrows in Fig. 17.

We can now analyse how the relative flow direction determines the sign of macrosegregation. At the upper surface of the representative volume, since solid fraction is lower than at the bottom surface, the liquid is less enriched. Therefore the solute-enriched liquid that flows out through the bottom surface is replaced by the less enriched liquid entering through the upper surface. As a result, the representative volume is diluted. Given that the enrichment of liquid phase is directly linked to the temperature, we may conclude that when the flow direction is opposite to the temperature gradient, negative segregation tends to form.

Solidification shrinkage alters the macrosegregation of this representative volume element in another direction. Shrinkage leaves empty space, which has to be 
filled up by the flow. Therefore the mass that flows out is less than the one that flows in. Bear in mind that the liquid phase has been enriched by the solidification implying that its concentration is larger than the nominal concentration of this volume element. Hence the representative volume element is enriched.

Although the idea behind macrosegregation mechanisms seems to be clear, it took quite a time to get to the current stage of understanding.

\subsubsection{Historical overview}

The fact that large-scale castings and ingots are not homogeneous with respect to their chemical composition has been known for centuries. It is widely cited that Italian metallurgist and foundryman V. Biringuccio described segregation in bronze gun barrels in his book "De la Pirotechnia” as early as in 1540 [81]. In 1574 AustroHungarian chemist L. Ercker published his observations of liquation in precious alloys [82]. According to a brilliant review by Pell-Wallpole [83], most observations and studies of macrosegregation during the XIX-th century were done on precious metals, including works by W.C. Roberts-Austin (1875) and E. Matthey (1890) in Great Britain. It was not until the beginning of the XX-th century, however, that macrosegregation attracted real scientific interest, first as related to steel and bronze ingots and, later - to aluminium billets and ingots. We can mention the pioneering works of T. Turner, M.T. Murray, E.A. Smith, O. Bauer, H. Arndt, R.C. Reader, R. Kühnel, and F.W. Rowe in copper alloys and those of G. Masing, W. Claus, S.M. Voronov, and W. Roth in aluminium alloys (citation information is available in Ref. [83]).

The simplest way to explain the macrosegregation is to imagine that the advancing solidification front pushes the liquid enriched in the solute (in case $\mathrm{K}<1$ ) towards the hotter part of the casting, e.g. the centre. In reality the driving force behind 
such a transport of the liquid phase is either convection or shrinkage-driven flow. This kind of macrosegregation is called "normal” segregation. It is a direct consequence of microsegregation and can be easily predicted and estimated using the phase diagram data. However, the frequently observed macrosegregation pattern in DC cast ingots and billets is just opposite - the periphery of the casting is enriched in the solute while the centre remains solute-lean (see Fig. 15). This type of macrosegregation is called "inverse" and is quite typical of non-ferrous alloys, including aluminium alloys. The ultimate form of "inverse" segregation is liquation or exudation at the casting surface, when the solute-rich liquid penetrates through the outer shell of a casting and solidifies at the surface as liquates or eutectic exudates. Obviously, in this case the solute-rich liquid is transported in the direction opposite to the solidification-front movement.

During the first half of the XX-th century quite a number of theories have been suggested for the explanation of inverse segregation [83]. These theories attempted to explain the numerous observations. It was experimentally found that the inverse segregation occurred in alloys with a considerable freezing range, e.g. works by Claus and Goederitz in 1928 and Voronov in 1927 and 1929. The presence of hydrogen was shown to promote exudations, while melt overheating increased the degree of segregation. Generally it was concluded by Masing and Dahl as early as in 1926 that hydrogen in aluminium alloys would adversely affect macrosegregation if it were trapped in the mushy zone. Therefore this influence was only typical of moderate cooling rates, when hydrogen was neither quenched in solid aluminium nor escaped from the solidifying metal. The cooling rate was noted to be a determining factor in segregation already in early accounts, e.g. J.T. Smith in 1875. Bauer and Arndt (1921) emphasized a steep temperature gradient in the ingot as an essential condition for macrosegregation. While Voronov (1929) showed that any change in casting conditions 
which increased the cooling rate, i.e. reduced casting temperature, colder mould, lower pouring rate, increased mould conductivity, would increase the degree of inverse segregation in duralumin ingots cast in permanent moulds [84].

The properties and grain structure of an alloy were also under scrutiny in relation to macrosegregation [83]. First of all it was shown that the segregation developed during solidification and not in the liquid state. The transition from the normal to inverse segregation was experimentally observed on increasing the thickness of the solidified shell of an ingot, e.g. by Fraenkel and Gödecke in 1929. The inverse segregation was often less in finer equiaxed structures than in columnar or coarse dendritic structures. This was related to the different mechanisms of feeding the solidification contraction, i.e. liquid feeding in columnar structures and mass feeding in equiaxed structure [83]. As early as in 1925, Masing et al. correlated inverse segregation to volume contraction during solidification of metallic alloys [83]. This theory was further developed by Phelps (1926) and Verö (1936) and formed a basis for the modern views on macrosegregation.

Some of the proposed theories were short-lived; some were developed into the current theory of macrosegregation. Let us first review some of the ideas that failed to be proven by experimental and industrial practice.

First theories suggested in the 1920-1930s wrongly assumed that segregation occurred in the liquid state. Two prominent figures here were S.W Smith who suggested in 1917-1926 the theory of mobile equilibrium and Benedicks (1925) with the theory of thermo-solutal segregation. In the former case the segregation of low-melting components towards the hot spot of the casting was explained by the tendency of the system to lower its melting point in the region of solidification. In the latter theory, temperature and solute gradients in the liquid resulted in the difference of solute 
concentration in different part of the casting. The theory of Benedicks pinpointed one of the mechanisms of segregation but failed to explain inverse segregation because he did not consider the solidification-related phenomena. Within the same timeframe, the theory of contraction pressure was suggested and supported by a number of scientists, e.g. Kühnel (1922), Price and Philips (1927) and Voronov (1929). The idea was that a solid shell formed at the top of a casting exerted pressure onto the liquid and forced it sideways to the surface. Thermal contraction of the ingot shell might cause hot cracking and the solute-rich liquid filled the formed gaps. This theory explained well the formation of surface exudations but failed to explain the occurrence of inverse segregation in castings with the open liquid surface. One of the most popular theories of inverse segregation was proposed by Genders in 1927. From his viewpoint, gas dissolved in the melt concentrated in residual, solute-rich liquid pools and then evolved, forcing this liquid along grain boundaries towards the cooling surface. This theory was able to explain numerous experimental observations, emphasized the role of continuous solid network but could not explain segregation in gas-free or rapidly solidified castings. An interesting story happened with the theory of crystal migration proposed by Voronov in 1927 [84] and supported by Watson in 1933. Within this theory, solute-lean primary crystals detached from the solidified shell and were pushed towards the centre of the casting by the solidification front under conditions of small thermal gradient. This theory was rejected in the 1940s because it contradicted numerous experimental observations on inverse segregation happening in castings without stray crystals. In the 1980s this theory was revived in application to DC casting by Yu and Granger [8] and Chu and Jacoby [9], and will be discussed in more detail in Section 3.2.4.

The foundation for our current understanding of macrosegregation mechanisms, especially with regard to inverse segregation during DC casting has been laid down by a 
number of prominent scientists. Gulliver in 1920 and Bauer and Arndt in 1921 put forward the idea that the inverse segregation was driven by interdendritic feeding, when liquid moved in the direction opposite to the solidification front, driven by capillary forces. It was assumed that normal segregation occurred in equiaxed structures, and inverse - in columnar structure, because the latter provided interdendritic channels.

The inverse segregation is, however, observed in all type of structures. And there must be a more universal driving force for interdendritic flow than just capillary force. The solution was found in the volumetric contraction during solidification (Phelps, 1926) and corresponding shrinkage-driven flow (Verö, 1936 [85]). Solidification shrinkage created a pressure drop over the semi-solid region (mushy zone) that forced the solute-rich liquid in the transition region to flow in the direction towards the cooling surface. The role of partition coefficient was established. It was explicitly stated that the segregation was a phenomenon occurring in the transition region of the casting. This theory could be equally applied to columnar and equiaxed grain structures.

The specifics of direct-chill casting were included in the theory of macrosegregation by Brenner and Roth in 1940 [86] who suggested that the macrosegregation upon DC casting occurred in layers: surface layers received soluterich liquid but did not part with it whereas the central part expelled the solute-rich liquid but did not get fresh liquid because of the limited feeding. The concept of interdendritic feeding was supplemented with the idea of intradendritic feeding by Dobatkin in 1948 [1]. He also emphasized the importance of continuous (coherent) solid network for the occurrence of macrosegregation, stating that in the slurry zone only gravity-driven segregation of floating grains was possible. The role of air gap for the formation of surface exudations was highlighted by Pell-Walpole in 1949 [83]. And, finally, Brenner 
and Roth [86] and Dobatkin [1] suggested that the extent of macrosegregation during DC casting depended on the width of the transition region, the inclination of the solidification front to the billet axis, and the casting speed that controlled these parameters.

The current understanding of the macrosegregation mechanisms can be formulated rather simply: relative movement of liquid and solid phases during solidification in the presence of solute partitioning (microsegregation). On a phenomenological level, we can single out several types of such a relative movement that happens in the sump of a billet during direct-chill casting:

- thermo-solutal convection in the liquid sump caused by temperature and concentration gradients, and the penetration of this convective flow into the slurry and mushy zones of a billet;

- transport of solid grains within the slurry zone by gravity and buoyancy forces, convective or forced flows;

- melt flow in the mushy zone that feeds solidification shrinkage during solidification;

- melt flow in the mushy zone caused by metallostatic pressure;

- melt flow in the mushy zone caused by deformation (e.g. thermal contraction) of the solid network;

- forced melt flow caused by pouring, gas evolution, stirring, vibration, cavitation, rotation etc., which penetrates into the slurry and mushy zones of a billet or changes the direction of convective flows.

Let us now look at these mechanisms in more detail.

\subsubsection{Shrinkage-induced flow}

It is well known by now that one of the reasons for inverse (negative) centreline segregation is the volumetric solidification shrinkage (which is 6 to 8 vol. \% in $\mathrm{Al}$ alloys) and the corresponding melt flow that tries to compensate for this shrinkage. The contribution of this shrinkage-induced flow is significant in the stationary solid 
dendritic network region, i.e., the mushy zone. The reason for this is the difference between the average (nominal) composition and the feeding-liquid composition, which is obviously greater in the mushy zone than in the slurry region. The shrinkage-induced flow is directed normal to the solid (or coherency) fraction contour, towards the deeper part of the mushy zone. It contributes to the negative centreline segregation and positive surface segregation [10, 87, 88].

Recently a simple analytical model [44] was suggested to estimate the magnitude of the shrinkage-induced macrosegregation during DC casting. The shrinkage-induced flow, which is perpendicular to the coherency-fraction contour, can be decomposed into two components (Fig. 18). The horizontal component along the billet radius is directed towards the billet surface and the vertical component goes along the casting direction. Although the vertical downward flow will dilute the local volume element by bringing less enriched liquid into it as we discussed in the beginning of section 3.2, the negative centreline segregation will not form if only this vertical downward flow is present. It can be explained if one imagines that, as solidification proceeds, the process eventually comes to a point where lesser and lesser liquid is taken out and only solute accumulation caused by shrinkage occurs. This case is identical to the steady state unidirectional solidification analysed by Flemings et al. [7, 89]. It is the horizontal component of the shrinkage-induced flow that takes the solute away from the centre to the surface $[1,7]$, though this solute transport physically occurs very slowly and over relatively short distances. Step by step, however, an overall solute transfer takes place from the centre of the billet to its surface. The depletion in the centre cannot be compensated, as there is no horizontal inflow of the solute from more enriched regions. At the surface, there is a pile-up of the solute as there is no outflow. Because the magnitude of the shrinkage-induced flow is dependant on the shrinkage ratio, one 
may conclude that the corresponding macrosegregation should depend on the dimensions of the mushy zone and the degree of shrinkage. Obviously, such a flow is also strongly affected by the permeability of the mushy zone and, hence its microstructure.

Based on these considerations, the proposed model links the macrosegregation to the local slope of the coherency isotherm $(\alpha)$, the thickness of the mushy zone $\left(\mathrm{L}_{\mathrm{m}}\right)$, shrinkage ratio $(\beta)$, and the solidification path of an alloy (taken into account in the coefficient A) through a so-called horizontal solute transfer distance [44] (see also Fig. 18):

$$
\mathrm{L}_{\mathrm{h}}=\mathrm{AC}_{0} \mathrm{~L}_{\mathrm{m}} \beta(\sin 2 \alpha) / 2
$$

The derivative of Eq. (16) with respect to radial distance from the billet centre (R) will lead to the net efflux and is a measure of the macrosegregation caused by solidification shrinkage, with $\left(d \mathrm{~L}_{\mathrm{h}} / d \mathrm{R}\right) / \mathrm{C}_{0}$ reflecting the relative segregation.

This analytical approach can be used to estimate roughly the extent of the shrinkage-induced macrosegregation by running heat transfer calculations only.

Generally, all macrosegregation models that can predict inverse segregation during DC casting include the shrinkage-driven flow [90].

\subsubsection{Thermo-solutal and forced convection}

Thermo-solutal convection is the liquid movement (flow) due to temperature and concentration differences that exist either in the liquid pool (1 in Fig. 2a) or in the slurry portion ((2-3) in Fig. 2a). Inherent to the DC casting are the temperature differences between the centre and the surface of the billet, which lead to density differences in the liquid. So when the cooler (heavier) liquid sinks at the periphery, this initiates a flow towards the centre and the resultant momentum forces liquid to rise at the centre. Below the liquidus, this flow is complemented (or may be opposed) by the solutal differences 
caused by the progressive solidification towards the solidus isotherm. This thermosolutal buoyancy-induced flow transports solute-rich liquid towards the ingot centre, thus tending to cause positive centreline segregation. The impact of thermo-solutal (and forced) convection is more significant in the low-solid fraction region where the drag effect imposed onto the liquid by the solid is not strong.

The convection flow induces a complex relative movement between solid and liquid, which will be summarized below and is partially illustrated in Fig. 6b. Close to the surface just below the liquidus, this relative movement is of penetration type powered by forced convection and its flow direction is pointing to the deeper part of the mushy zone. It brings the less enriched liquid into the deeper part of the two-phase region. Since the flow direction is opposite to the temperature gradient, it contributes to the negative segregation for the regions it passes through. Before the friction imposed by the increasing amount of the solid phase fully damps this penetration flow, it gradually changes its direction due to the reflection from the rigid surface of the semisolid region and to the general direction of thermal-solutal buoyancy. Now the relative movement is directed from the deeper (colder) part of the mushy zone to the lessenriched (hotter) slurry centre. This part of the flow enriches the region, which it passes through. At the centre, the relative flow goes upwards and contributes to the enrichment of the region.

It is clear that when only the thermal and solutal convection is taken into account, ignoring shrinkage-driven flow and exudation, the positive centreline segregation forms as a result of denser and solute-enriched liquid flowing towards the ingot centre [10, 90, 91, 92]. An important feature of solutal convection is the solutal buoyancy. In multicomponent alloys the contribution of every solute to the buoyancy force may complement or counteract each other. In the case of a 2024 (Al-Cu-Mg) 
alloy, the addition of $\mathrm{Mg}$ to the binary $\mathrm{Al}-\mathrm{Cu}$ alloy influences the final macrosegregation pattern by its opposite contribution to the solutal buoyancy in comparison with $\mathrm{Cu}$ [91]. As a result, Fig. 19 shows that the extent of macrosegregation is reduced as compared to the binary $\mathrm{Al}-\mathrm{Cu}$ alloy.

The analysis above is also valid for forced convection. For example, Chu and Jacoby showed that an ingot cast by the bi-level transfer method had more centreline segregation as compared to an ingot cast by the level pour method due to the difference in induced convective currents [9]. The ingot cast by the level pour method showed 15\% less negative centreline segregation.

The importance of forced flow for macrosegregation becomes clear when the melt is mechanically or electromagnetically stirred. Figure 20 shows some experimental results obtained upon DC casting of aluminium alloys. One can see that the controlled forced convection can completely change the macrosegregation pattern from inverse to normal. Recently similar results were reported by Zhang et al. [93] for EMC of a 7075 alloy.

Grain refined structure, due to the delayed structure coherency, seems to allow a deeper penetration of the convection flow into the slurry zone with the corresponding washing-out of the solute-rich liquid and the transport of this liquid to the centre [68]. On the other hand, grain refinement will make the transport of the free grains easier, which will have the opposite effect on the macrosegregation as will be discussed in the next section.

\subsubsection{Movement of equiaxed grains ('floating' grains)}

Movement and sedimentation/growth of solid fragments has been identified as one of the important mechanisms of centreline segregation in DC cast billets and ingots. As we have already mentioned in section 3.2.1, the link between the transport of solute-lean 
grains and the inverse segregation is not a novelty. And this idea was already rejected in 1940s as it contradicted the cases of inverse segregation where no floating grains had been found. However, the applicability of this mechanism of macrosegregation to DC casting was supported by numerous experimental observations of a duplex structure, characterized by a mixture of fine-branched dendrites and coarse-cell dendrites (see section 2.4.3), near the ingot centreline (Fig. 13) [8, 9, 18, 21, 28, 33, 58, 68]. Hence, the mechanism of inverse segregation by floating grains has been reinstated in the 1980s. It is inferred that the origin of these coarse-cell structure are the detached dendrites, which were initially formed at the time of ingot shell formation [8,9]. It is explained that these broken dendrites are carried by the convection currents (see section 2.3), grow isothermally at a certain temperature in the upper part of the transition region (hence 'isothermal dendrites') before being finally entrapped by the solidifying ingot at the bottom of the sump [8]. The strong downward flow along the solidification front is proposed to transport crystals to the centre and additionally that flow gives rise to a nearly isothermal central liquid pool. A larger DAS (which is often 3 to 3.5 times the average DAS measured in the centre [58]) is due to the unconstrained growth of these grains in the melt volume ahead of the solidification front for prolonged times. In addition to the fragmentation of dendrites at the solidification front, it is also probable that these crystals originate on the open surface of the melt (or hot top) or by heterogeneous nucleation in undercooled liquid ahead of it [3]. It is also suggested that different grains have different travel time within the slurry region due to the convection flows [18]. As a result, some of the grains spend considerably longer time in the transition region than others, before being captured by the solidification front. Frequently these grains finish solidification at a higher undercooling in the mushy zone, which results in a finer DAS at the grain periphery [18] (see Fig. 13a). 
As we have already mentioned, the negative segregation in a DC cast billet/ingot centre is to a certain extent attributed to the presence and accumulation of these coarse solute-lean dendrites in the bottom of the sump, although their presence is not a necessary condition for the negative centreline segregation to occur [68]. The concept of coarse ('floating') grains can also partially explain why the negative centreline macrosegregation becomes stronger with increasing casting speed and/or ingot size (see section 2.4.3), though the same tendency would be when the shrinkage-induced flow is acting (see section 3.2.2). The mainstream concept assumes that if the coarse-cell dendrites are solute-poor, fine dendrites (the last to solidify) are rich in solute $[8,28]$. Another line of argument is proposed by Chu and Jacoby [9], who suggested that the fine-cell dendrites originated from the start of the solidification in the region of rapid cooling (i.e. dendrites detached and transported from the periphery to the centre and frozen into the solidification front without further growth) and coarse cells grew in situ. It is stated that these fine dendrites, which are solute poor, are responsible for the negative centreline segregation. Though floating grains are accepted in the literature as an important source of negative centreline segregation, doubts have been expressed as to what extent they affect the macrosegregation [94]. As for the experimental evidence, the presence of floating grains is obvious in non-grain refined alloys, whereas the separation of microstructures in grain-refined DC cast alloys is rather difficult.

Quantitative analysis in terms of compositional differences in the grains with different dendrite arm spacings is rare in the literature. Electron probe microanalysis (EPMA) measurements across a coarse dendrite reveals a uniform plateau of copper depletion away from the cell boundary [8].

We performed local composition EPMA measurements on several coarse and fine cells in the structures shown in Fig. 13 [74]. Line scans of $\mathrm{Cu}$ and $\mathrm{Mg}$ 
concentrations in these DC cast samples of both non-grain refined and grain refined 2024 alloys showed clearly that the coarser cells are more solute depleted as compared to the 'regular' finer cells (Fig. 21). From these measurements, the minimum $\mathrm{Cu}$ and Mg concentrations were tabulated for coarse and fine cells as given in Table 4. Note that the nominal composition of this alloy was $3.6 \mathrm{wt} \% \mathrm{Cu}$ and $1.4 \mathrm{wt} \% \mathrm{Mg}$.

It can seen that (a) for both NGR and GR samples the minimum concentrations reach lower values in the coarse cells than in the finer cells, and (b) grain refinement does not seem to make much difference for the minimum concentration.

Researchers have also utilized the modelling approaches to investigate how the movement of solid grains influences macrosegregation [95, 96] Due to gravity (in the case when the solid phase density is higher than that of the liquid phase) the floating grains tends to settle down while being swept by the surrounding liquid. The liquid also exerts a resistance for this sedimentation. Assuming a case where the liquid is so sticky that the floating grains cannot escape from its capture, the solute-lean solid grains travel along with the solute-enriched liquid. In other words, they have the same trajectories. As a result, there will be no macrosegregation. The description of drag between floating grains and its surrounding forms the essential part of modelling work. A simple expression which was derived from the Stokes law was used to approximate the solidliquid velocity differences [97]. It was concluded that the floating dendrites were responsible for the centreline negative macrosegregation [96]. Another approach could be the two-phase model with one phase for the grains and the other for the liquid, in which the interaction between these two phases is modelled by a drag force present in the momentum equations of each phase. This model was applied to model the macrosegregation of steel ingots [98]. 


\subsubsection{Deformation of solid network}

Another possible driving force for macrosegregation is deformation of the dendritic network in the coherent mushy zone and the related flows (see section 2.3). Deformation can be externally induced (in the case of continuous casting of steels) or thermally induced. The latter applies to DC casting of Al alloys. Results indicate [45] that even small volumetric strains ( 2\%), which can be associated with thermally induced deformations, can lead to segregations comparable to that resulting from solidification shrinkage. This mechanism is important for the subsurface and surface segregation [99] when exudation results when the coherent mush is not in direct contact with the mould (Fig. 3). Marked reduction in the heat flow causes a reheating of the surface above the region of secondary cooling by a water spray, which causes partial remelting with solute-rich interdendritic liquid forced by the metallostatic pressure through. With reference to Fig. 15, the surface enrichment is attributed to a combination of the contraction-driven flow toward the mould wall and the exudation induced by local remelting of the ingot surface when the solid shell pulls away from the mould.

After the discussion of various mechanisms of macrosegregation in $\mathrm{DC}$ cast $\mathrm{Al}$ alloys, it is clear that the important question that remains open for now is the extent of contribution of each of the mechanisms to the overall segregation picture. The computer simulations that take into account this or that mechanism of segregation could help in fundamental understanding. However, the level of modern models and their numerical solution is not yet adequate for the comprehensive answer. And experimental observations are mostly related to the result of the combined action of different mechanisms. Nevertheless, it can be summarized that in DC casting (i) thermal convection promotes the positive (normal) centreline segregation; (ii) the contribution of solute convection depends on the density of the solute element but in many cases it 
works in the same direction as the thermal convection; (iii) the role of forced convection (stirring) depends on its direction; (iv) shrinkage-induced flow causes negative (inverse) centreline segregation and positive surface segregation; (v) floating grains contribute to the negative centreline segregation; whereas (vi) the effect of deformation-induced flow depends on the sign of deformation, in most cases deformation promotes positive segregation.

\subsection{Macrosegregation - Influence of process parameters and structure}

At a practical level the macrosegregation greatly depends on a number of parameters, which are alloy specific (alloy composition, grain refining, partition coefficient of the alloying element), process specific (casting speed, melt temperature or metal superheat, water flow rate or cooling rate), and technology specific (ingot size, metal head, metal feeding system into the mould). These parameters will be discussed in this section. The effect of grain refining is covered separately in Chapter 4.

Macrosegregation depends on the alloy in question. Generally, as we have discussed in section 3.1 decreasing the partition coefficient of an element $(K<1)$ tends to maximise the segregation of this element. However, studies pertaining to various alloys under identical DC casting conditions are rare. In the study on three commercial $\mathrm{Al}$ alloys (6009, 3104 and 5182) [80], it is noted that the extent of relative segregation of a particular alloying element depends more on the alloy type rather than on the absolute concentration of this element in the alloy, which means that elemental segregation is influenced by the presence of other alloying elements due to their contribution to solutal buoyancy as has been discussed in section 3.2.3. From modelling perspective, this is very important [91]. Experimental work under identical conditions on a 2024 alloy and an equivalent binary $\mathrm{Al}-\mathrm{Cu}$ alloy indicated that the presence of $\mathrm{Mg}$ influence the segregation of $\mathrm{Cu}$ [74]. However, the segregation patterns of $\mathrm{Cu}$ and $\mathrm{Mg}$ 
follow the same trend, indicating that the influence of solutal buoyancy is less than the contribution of thermal convection and shrinkage-induced flow.

Casting speed is the most important variable during DC casting, which exerts a dominant influence on the defects (both macrosegregation and hot cracking). Technologically, the casting speed determines the productivity. However, increasing casting speed and/or ingot size normally deteriorates the quality in terms of macrosegregation and hot cracking tendency and it is thus necessary to strike a suitable balance between them. It is well known from the early and following works $[1,8,18$, $21,28,33,58,69,80]$ that the severity of macrosegregation increases with the casting speed. This change is fundamentally correlated with the sharp variation in the sump depth and the extent of variation of transition region (see section 2.2.1). Good correlation was obtained between the measured radial distribution of segregation and the vertical distance between liquidus and solidus isotherms (Fig. 5c) for an $\mathrm{Al}-4.5 \mathrm{Cu}$ alloy [18]. But closer to the periphery, the role of the transition region thickness becomes less pronounced, obviously due to the decisive role of high temperature gradients and exudation. There is an obvious connection between the deepening of sump with increasing the casting speed and the increased steepness of the solidification front. The latter is linked to the shrinkage-induced flow (see section 3.2.2) and the extent of negative centreline segregation. The amount of floating grains tends to increase with the casting speed [48], which seems to be in line with the enhanced negative macrosegregation.

Of the DC cast process parameters, the water flow rate, beyond a certain sufficient level, has a minimal effect on the macrosegregation, although not much attention was paid to it in the literature. It is stated that water flow rate did not significantly affect the extent of macrosegregation [80]. Our studies with flow rates in 
the range from 150 to $250 \mathrm{l} / \mathrm{min}$ on a $200-\mathrm{mm}$ diameter billet of an $\mathrm{Al}-4.5 \% \mathrm{Cu}$ alloy have shown that macrosegregation slightly increases with water flow rates at a casting speed of $120 \mathrm{~mm} / \mathrm{min}$ [18]. Similar results were reported elsewhere [28].

Although it seems to be important, little consideration has been given to the melt temperature (melt superheat) in the DC casting literature on the defect formation. Our experiments upon DC casting of an $\mathrm{Al}-2.8 \% \mathrm{Cu}$ alloy with the variations in melt temperatures from 701 to $760^{\circ} \mathrm{C}$ (48 to $107^{\circ} \mathrm{C}$ melt superheat) show that centreline macrosegregation remains virtually unaffected but the subsurface segregation becomes more pronounced [33]. It is observed that the amount of floating grains in the centre of the billet considerably increases with the melt temperature. An analysis of melt flow in dependence on the melt temperature performed using computer simulation allowed us to argue the following mechanism [25, 33]. The increased tendency for the enriched melt to move downwards to the centre of the billet may be compensated by the increased presence of floating grains, leading to unchanged segregation patterns in the centre. At the same time, more considerable convection flow at the periphery of the billet facilitates the exudation. It has been also suggested that lower melt superheat may lead to more macrosegregation due to the conditions in the sump favourable for the growth of isothermal grains (hence a higher fraction of 'floating' grains) [28]. The distribution of the floating grains changes with the melt temperature and casting speed [33]. As we have already mentioned in section 2.4.3, low superheat and low casting speed assure a wide spread of floating grains in the billet cross-section, thereby evenly distributing their impact on the macrosegregation. Experimental, though rather limited results suggest that the effect of melt temperature may be dependent on the amount of water flow [28]. At lower water-flow rates, the decreasing melt temperature increases the macrosegregation whereas an opposite trend is observed at higher flow rates. 
Macrosegregation is very much sensitive to the ingot/billet size (either diameter or thickness). Experimental data on a $\mathrm{DC}$ cast $\mathrm{Al}-\mathrm{Cu}-\mathrm{Mg}$ alloy have shown a pronounced effect of ingot thickness compared to the casting speed on the centreline segregation [8] due to increased natural convection in addition to the increase in sump depth. This is explained by the disproportionate increase in the sump depth with the ingot thickness as compared to the sump deepening with the casting speed [100].

Livanov et al. [5] suggested a criterion of transition from normal to inverse macrosegregation during DC casting:

$$
\mathrm{V}_{\text {cast }} \mathrm{D}=\mathrm{A} \text {, }
$$

Where $\mathrm{D}$ is the billet diameter in $\mathrm{mm}$ and $\mathrm{A}$ equals 11500 for $\mathrm{Al}$ alloys cast in a conventional mould without hot top. At lower casting speeds and smaller diameters the macrosegregation is normal, otherwise - inverse. The dependence (eq. 17) was confirmed by experimental data. The range of casting speeds that can provide normal segregation is, however, significantly lower than commercial casting speeds.

Optimum melt level (metal head) is essential for the formation of a stable and strong solid shell as the liquid metal starts to freeze onto the mould surface. If the conditions are not optimum, due to the large metallostatic pressure and recirculation of the melt, this shell tends to remelt, leading to liquation and intense macrosegregation $[18,21]$.

Metal feeding system and the effect of the direction of melt flow as it enters the mould is shown to influence the severity of segregation $[9,80]$. For example in an $\mathrm{Al}-$ $\mathrm{Zn}-\mathrm{Mg}-\mathrm{Cu}$ ingot, it is shown that the ingot cast by level pour method has about $15 \%$ decrease in the negative centreline segregation as compared to the same ingot cast by bilevel transfer method due to the stronger convection in the latter [9]. These results indicate the degree of negative centreline segregation is influenced by the convective 
flow in the liquid pool. In a bi-level metal transfer method, maximum Mg segregation in an AA 3104 alloy is observed with a conventional fibreglass headscreen (which has fine mesh and covers most of the area of the ingot head), which had the effect of diverting the melt flow horizontally in all the directions around the mould [80]. But with the optimum design of the metal flow distributors as shown in Fig. 22, significant reduction in the centreline segregation is observed as the metal flow is diverted downwardly into the upper part of the ingot sump [80]. The hypothesis suggested to explain the reduced macrosegregation includes (a) limited presence and growth of isothermal dendrites due to the general displacement of isotherms, especially the liquidus, and (b) possible transport of detached dendrites, if any, towards and further above the liquidus which results in their remelting.

Electro-magnetic casting (EMC) is shown to have a dramatic influence in decreasing the macrosegregation due to the very nature of the process, the stirring that is introduced and shallow sump depths that can be achieved (for the same casting speed as compared to the normal DC casting under identical conditions). The result can be dramatic as illustrated in Fig. 20b. Recently it was shown for an Al-Zn-Mg-Cu alloy that an almost uniform chemical composition in the ingot could be obtained once the frequency of the electromagnetic field was optimised [93]. Production of billets with minimal surface/subsurface segregation (smooth surface) is one of the biggest advantages of this technique. Despite the additional equipment and the costs involved, this method provides a way to minimise macrosegregation both in the billet centre and at the periphery. In addition, the absence of air gap upon EMC eliminates the exudations. 
The correlation between structure and macrosegregation is not straightforward. While the structural features originate from the local effects, macrosegregation is the result of global effects within the solidification domain.

The only structural feature that can be directly linked to the macrosegregation is the 'floating' grains (their presence, amount and distribution around the central portion of the DC cast billet), as we have already discussed in sections 2.4.3 and 3.2.4.

The effect of casting speed in GR billet is the same as in NGR billets, i.e. more severe macrosegregation occurs $[8,21,58,69,80]$. In the first instant this is directly related to the increase in sump depth at higher casting speeds [69]. It is pointed out, however that the effect of casting speed seems to be dependent on the type and potency of the grain refiner used [80]. Considering the importance of casting speed and grain refiner in macrosegregation, this point is worthy of further research. The effects of grain refinement are discussed in more detail in the next Chapter.

From the above discussion, it is certain that macrosegregation is an irreparable defect. Further, it prevents certain alloy compositions from being cast at a faster rate (in an economical way) and/or being produced into bigger ingots. The obvious remedies for macrosegregation include reduction of casting speed, limiting the ingot size/dimensions, adjusting the alloy composition etc. But sometimes these solutions are technologically impracticable. And in reality, it may not be possible to manipulate the alloy composition.

Technologically, it is possible to control macrosegregation by managing fluid flow and solid movement through forced convection and/or an optimised melt distribution system. 


\section{Role of grain refining}

In order to obtain finer grain sizes and avoid wide variations in the grain morphology, grain refining is normally employed during DC casting of aluminium alloys [101]. The effectiveness of the grain refiner is judged by the grain size and morphology achieved [57].

With respect to DC casting, it is generally accepted that hot cracking is more severe if the grain morphology is not equiaxed and that a finer structure allows a higher casting speeds before hot tears appear [101]. In addition to this, the following advantages of grain refinement can be listed [24, 67, 102]:

1. Improved mechanical properties (strength and ductility).

2. Improved formability during subsequent processing (extrusion and rolling).

3. Reduction of surface defects during extrusion and rolling.

4. Reduced need or time for homogenisation treatment.

5. Improved anodising properties of the end product.

6. Reduced porosity.

It is however worth mentioning that many methods such as forced convection (electromagnetic stirring, ultrasonic cavitation, mechanical stirring, directed fluid flow etc.) and control of casting parameters (solidification rate and temperature gradients) are known to enable structure refining even without special alloying additions. For example, in EMC fine grain size is attained due to the dendrites detached from the solidification front by the forced flow and acting as heterogeneous nucleation sites ahead of the solidification front. But in the casting of aluminium alloys, chemical inoculation is often preferred as it is the most economical and efficient way [67]. Before we embark on the role of grain refining on macrosegregation, a brief introduction on grain refining is given. 


\subsection{Basics of grain refinement}

The most widely used inoculants are master alloys based on the Al-Ti-B system, notably $\mathrm{Al}-5 \% \mathrm{Ti}-1 \% \mathrm{~B}$ (Al5Ti1B) and Al3Ti1B, which essentially contain a mixture of $\mathrm{TiB}_{2}$ and $\mathrm{Al}_{3} \mathrm{Ti}$ particles in the $\mathrm{Al}$ matrix. The former is widely used in Europe while the latter is common in the United States [24]. These grain refiners have a Ti:B ratio larger than 2.2:1 (wt. \%), which is the stoichiometric ratio required for the formation of the $\mathrm{TiB}_{2}$ phase. The remaining $\mathrm{Ti}$ is combined with aluminium to form $\mathrm{Al}_{3} \mathrm{Ti}$. For example, in the Al3Ti1B master alloy, 2.2\% $\mathrm{Ti}$ in the grain refiner is tied with boron as $\mathrm{TiB}_{2}$ and the remaining $0.8 \%$ titanium forms $\mathrm{Al}_{3} \mathrm{Ti}$. Other common master alloys are based on the $\mathrm{Al}-\mathrm{Ti}-\mathrm{C}$ system (grain refining by $\mathrm{TiC}$ particles). Unlike $\mathrm{Al}-\mathrm{Ti}-\mathrm{B}$ grain refiners, $\mathrm{Al}-\mathrm{Ti}-\mathrm{C}$ grain refiners have a lesser tendency for particle agglomeration and higher resistance to poisoning effect (for instance in 7000-series alloys containing $\mathrm{Zr}$ and Cr) [24]. In this category, Al3Ti0.15C composition is commonly adopted for studies on DC cast $\mathrm{Al}$ alloys. Currently, commercial grain refiners are produced as a 9.5 mm diameter rod. During industrial DC casting, this rod is continuously fed into the molten metal stream at a constant rate as the melt passes through the launder. The usual range of grain-refining rod addition varies from 1 to $10 \mathrm{~kg} /$ tonne of melt, which corresponds to $0.003 \%$ to $0.03 \% \mathrm{Ti}$ if $\mathrm{Al} 3 \mathrm{Ti} 1 \mathrm{~B}$ is used [103].

Excellent reviews are available on various aspects of grain refining, which includes production of master alloys (microstructure of grain refiners as controlled by manufacturing methods) [104], grain refining tests to assess the performance of various grain refiners [101, 104], practical aspects of grain refinement [105], phase composition of grain refiners [106], and mechanisms of grain refining [56, 57, 101, 104].

The microstructure of $\mathrm{Al}-\mathrm{Ti}-\mathrm{B}$ grain refiners consists of large $\mathrm{Al}_{3} \mathrm{Ti}$ particles (around $60 \mu \mathrm{m}$ ) and much finer boride particles mostly agglomerated in clusters within 
the $\mathrm{Al}$ matrix (Fig. 23). The average $\mathrm{TiB}_{2}$ particle size is around 1-2 $\mu \mathrm{m}$ [107]. The desirable characteristics for a good grain refiner may be summarized as follows: (i) small ( $1 \mu \mathrm{m}) \mathrm{TiB}_{2}$ particle size, (ii) absence of large $\mathrm{TiB}_{2}$ agglomerates $(<50 \mu \mathrm{m})$, and (iii) low concentration of non-metallic inclusions (oxides and salt clusters) [67]. When the grain refiners are added to the melt, $\mathrm{TiB}_{2}$ insoluble particles provide potent substrates for nucleation sites for Al grains while excess $\mathrm{Ti}$, gained through the rapid dissolution of $\mathrm{Al}_{3} \mathrm{Ti}$ particles, contributes to the constitutional effect on growth of aluminium grains [56]. Though $\mathrm{Al}_{3} \mathrm{Ti}$ is a more potent nucleant than $\mathrm{TiB}_{2}$ and requires lesser undercooling to become active, it is thermodynamically unstable in liquid $\mathrm{Al}$ alloy melts (with hypo-peritectic concentrations of $\mathrm{Ti},<0.15 \mathrm{wt} \%$ ). Hence, it is considered that upon dissolution of a master alloy rod, $\mathrm{Ti}$ is evenly distributed in the liquid [108]. Several mechanisms have been postulated in the literature and have been extensively reviewed $[56,57,101,104]$. A discussion on the theories is out of the scope of this review. Let us only mention that the $\mathrm{TiB}_{2} /$ liquid interface seems to be the critical place on which the quest for nucleation mechanism should be focused [109]. Recently, it was experimentally observed that a thin layer of a metastable $\mathrm{Al}_{3} \mathrm{Ti}$ phase was formed at the surface of $\mathrm{TiB}_{2}$ particles prior to the nucleation of (Al) solid solution [110]. This layer then disappeared while the (Al) phase grew.

\subsection{Structure formation and permeability in grain refined Al alloys}

Two issues seem to stand out with respect to the macrosegregation in grain refined DC cast billets/ingots. Firstly, the issue of coarse-cell (floating) grains, which includes the definition of the floating grain and the accuracy of their separation in the structure, for any quantitative estimates. The other issue concerns the permeability of the mushy zone. Broadly, both of the above points bring forth the discussion on the grain morphology of grain-refined billets and its variation across the ingot. In this section, the development 
of microstructure in grain-refined $\mathrm{Al}$ alloys is discussed with respect to the microstructural evolution in DC cast $\mathrm{Al}$ alloys (section 2.3). Alloy design in wrought commercial $\mathrm{Al}$ alloys is based on the requirements with respect to formability, corrosion resistance, mechanical properties etc. So any changes in the alloy chemistry beyond the grade limits are generally not admissible as a means to control alloy castability, as-cast microstructure etc. The nucleation and growth aspects are crucial in understanding the solidification and evolution of structure in GR commercial Al alloys. The final grain size depends on the nucleant particle size and its potency, undercooling (controlled in many cases by cooling rate) and segregation power of solute elements. We shall discuss these factors below.

Once the population of foreign nucleants $\left(\mathrm{TiB}_{2}\right.$ for $\mathrm{Al}-\mathrm{Ti}-\mathrm{B}$ master-alloy grain refiners) is unleashed into the melt, nucleation occurs heterogeneously on the potent substrates. The smaller the undercooling required for an (Al) grain to form on the substrate particle, the more potent the particle. The undercooling necessary for free growth increases with decreasing the nucleant particle size (Fig. 24 [107]). In general, $\mathrm{Al}-\mathrm{Ti}-\mathrm{B}$ master alloys show the $\mathrm{TiB}_{2}$ particle distribution as shown in Fig. 24 with dominant particle sizes of $1 \mu \mathrm{m}$ or less [107]. In addition to this, both nucleation and growth of the grain greatly depend on alloy composition. The review by Easton and StJohn [56] drew important conclusions on the role of alloying elements in the melt. A high solute level allows a greater solutal (constitutional) undercooling to be achieved ahead of the solidification front thereby activating more and more grain refining particles leading to an increased grain density (finer microstructure). This is very important, as it is known that the overall grain refinement efficiency of commercial grain refiners is rather poor with the fraction of active particles, which participate in the nucleation of grains, being very small (0.1 to $1 \%)$ [57]. This inefficiency is attributed to 
the accelerated rate of latent heat release after the early nucleation events. When this rate exceeds the rate of external heat extraction, the temperature of melt starts to increase thus limiting its undercooling [111]. On the other hand, some solute elements in aluminium alloys can affect the grain refinement in a negative manner through “poisoning” the nucleation on refiner particles [112].

The amount of constitutional (solute) undercooling (see Eq. 13) and the corresponding decrease in the as-cast grain size with solute content can be quantified in terms of a growth-restriction factor (GRF), Q that is given by [113]

$$
\mathrm{Q}=\mathrm{m}_{\mathrm{L}}(\mathrm{K}-1) \mathrm{C}_{0},
$$

where $\mathrm{m}_{\mathrm{L}}$ is the liquidus slope, $\mathrm{K}$ is the partition coefficient of the solute and $\mathrm{C}_{0}$ is the bulk solute content (nominal alloy composition). Table 5 provides the data for GRF given by solutes commonly found in $\mathrm{Al}$ alloys. For ternary and higher-component systems (e.g. commercial Al alloys), an approximate value of Q can be obtained [114] by treating the individual solute effects additively $\left\{\sum \mathrm{m}_{\mathrm{L}}\left(\mathrm{K}^{\mathrm{i}}-1\right) \mathrm{C}_{0}{ }^{\mathrm{i}}\right\}$, provided the amount of alloying elements is limited (below any eutectic or peritectic reaction) and there are no phases formed during the early stages of solidification process between the solutes. Table 6 lists estimated values of GRF for some commercial alloys.

The proportion of nucleant particles that become active is very sensitive to the GRF of an alloy [111]. When Q is increased, the increase in fraction solid at a given undercooling is slowed and this allows less potent $\mathrm{TiB}_{2}$ particles to be active. Dendritic growth rate is inversely proportional to GRF and at higher GRF (hence at a low growth rate), the undercooling of the melt and the nucleation period are large which results in a great number of nucleant particles becoming active with a great decrease in grain size.

Out of all elements, one can see that Ti has the largest growth-restriction effect per one wt. \% added. In order to make the constitutional contribution high (thus 
increasing the 'grain refinability' of master alloys), Ti additions are made either to the master alloy or to the alloy itself. Hence, small concentrations of free Ti should be present in the melt to ensure a GRF $>15$, the level needed for optimum growth conditions upon grain refinement [20,67]. Due to cost considerations the practice over the years tends towards using a lower Ti:B-ratio alloys. Thus the master alloy is used essentially to supply the necessary $\mathrm{TiB}_{2}$ nuclei for grain refining with excess $\mathrm{Ti}$ being added as a low cost Al-Ti master alloy [67].

As one see from Table 6, the composition of the alloy affects its response to grain refiner through $\mathrm{Q}$. The higher the $\mathrm{Q}$ value, the better the response to grain refinement and the greater the decrease in grain size [115]. According to this, grain refinement becomes progressively easier in the series $1 \mathrm{xxx}, 3 \mathrm{xxx} \approx 6 \mathrm{xxx}, 5 \mathrm{xxx}$, $2 \mathrm{xxx} \approx 7 \mathrm{xxxx} \mathrm{Al}$ alloys, providing there is no poisoning effect (e.g. by $\mathrm{Zr}$ in $7 \mathrm{xxx}$ series alloys) [67, 108, 114, 115].

As expected, the as-cast grain size depends on the amount of grain refiner. Although statistically it appears that a larger number of nucleants $\left(\mathrm{N}_{\mathrm{P}}\right)$ can facilitate more nucleation events (and thereby decreasing grain size), it was found that increasing the grain refiner amount beyond a certain level does not help in further structural refinement [111]. This is due to the fact that as the amount of inoculant particles participating in nucleation (at a given undercooling) increases, so does the latent heat release leading to recalescence at a smaller undercooling, thereby lowering the efficiency of the grain refiner [57]. For a given alloy, the critical level of grain refiner addition depends on the alloy composition, i.e. its GRF [115]. Data from model experiments [24] and DC cast trials [58, 74] justify this point.

During DC casting, the addition rate is controllable (feeding of rod with a specified rate in the launder) and is performed according to the casting recipe. 
Depending on the alloy composition, the minimum level of grain refiner addition required to achieve a desirable microstructure is investigated and empirical relationships are formulated to optimise the usage of grain refiners [115]. This has not only economical benefits but also helps in reducing unwanted inclusions in the ingot. Furthermore, as it is discussed later (section 4.4), there seems to be a tendency for the macrosegregation to increase with “overalloying” with grain refiners [80].

The increase in the cooling rate, generally, facilitates the grain refinement and allows less potent $\mathrm{TiB}_{2}$ particles to be involved in solidification [66]. However, available data show that commercial grain refined alloys are little sensitive to cooling rate within the limits relevant to DC casting $[21,58,115]$.

The morphology of the equiaxed grains has a profound influence on the coherency and permeability of the mushy zone upon DC casting. Permeability is also important in understanding of feedability and porosity in shaped castings. We have already discussed the basics of permeability in section 2.3 and mentioned there that the permeability depends on the morphology, taking grain size or dendrite-arm spacing as the decisive structure parameter $[27,66]$. Permeabilities for globular structures (nondendritic) are approximately one order of magnitude greater than permeabilities for dendritic-globular structures at the same fraction of solid [38]. On the other hand, for spherical grains a decrease in grain size will lead to a reduction in permeability [66].

With reference to DC casting, it is often assumed that grains are globular for GR condition (hence grain size is the deciding factor). For NGR condition, however, the dendrite arm spacing is the conventionally used length scale which gives a higher 'grain density' (i.e., lower permeability) than the GR counterpart [10]. If GR billet has a dendritic structure with a DAS similar to that in NGR billet, then both of them have similar permeabilities. 
The variation of permeability with solid fraction is important (see Eqs. 9, 10) in assessing its role on the macrosegregation. In this respect, it is beneficial to analyse the permeability above and below the coherency isotherm. For Al alloys, coherency isotherm is around $0.2-0.3 \mathrm{gs}_{\mathrm{s}}$. With grain refining, the fraction solid at which the coherency occurs increases significantly from 0.25 to 0.53 and this difference results in the delayed dendrite coherency as illustrated in Table 7.

\subsection{Effect of grain refining on macrosegregation - issues}

Despite a good amount of literature available on DC cast $\mathrm{Al}$ alloys, the effect of grain refining with respect to macrosegregation remains unclear and relatively few articles are available on this subject $[8,21,58,59,68,69,70,80,116]$. Apart from being limited in scope, the published reports are sometimes contradicting with respect to the effect and degree to which the macrosegregation is affected. With reference to DC casting, systematic variation of various process parameters and correlations with the microstructure are particularly lacking for grain refined $\mathrm{Al}$ alloys. This is rather surprising considering the fact that grain refining is routinely employed during DC casting of $\mathrm{Al}$ alloys.

When compiling data from various reports, care should be exercised in drawing conclusions as the experimental conditions vary greatly, e.g. ingot size, shape, and metal feeding procedure including the type and amount of grain refiner and the method of addition. $\mathrm{Yu}$ and Granger [8] reported negative centreline segregation of $\mathrm{Cu}$ and $\mathrm{Mg}$ with a corresponding positive segregation of $\mathrm{Ti}$ in grain refined sheet ingots of an $\mathrm{Al}-$ $\mathrm{Cu}-\mathrm{Mg}$ alloy. The type and the amount of grain refiner were not mentioned. Further, no comparisons were made with an equivalent non-grain refined alloy. Gariepy and Caron [80] examined the effect of grain refining practices (mostly Al5Ti0.2B) on centreline macrosegregation in sheet ingots of commercial 3104 (Al-Mn-Mg), 5182 (Al-Mg- 
Mn), and 6009 (Al-Si-Mg) alloys. The reported variable parameters included feeding system, ingot thickness (63.5 $\mathrm{cm}$ and $66 \mathrm{~cm}$ ), casting speed (4 to $7 \mathrm{~cm} / \mathrm{min}$ ), and amount of grain refiner (varied up to $0.005 \mathrm{Ti}$ ). Their investigations demonstrated a direct correlation between the increasing Ti content (by increasing the grain refiner rod feed rate) and the magnitude of segregation. An increase in grain refining addition was followed by an almost linear increase in segregation of Mg (Figs. 25, 26).

The effect of grain refiner addition was also dependent on the feeding system. For example, that in the 3104 alloy it was observed that an increase in grain refiner additions from 0.0013 to $0.0031 \%$ increased the Mg segregation by $28 \%$ for a channelbag distribution system (Fig. 25) ${ }^{6}$. It should be mentioned that the data points were reported for different casting speeds, which might have induced higher segregation levels. The data for a COMBO $\mathrm{bag}^{6}$ indicated that the non-grain refined ( $\left.0 \% \mathrm{Ti}\right)$ alloy exhibited much lower segregation (4.6\%) as compared to another set of the grainrefined alloy. Similar experimental data for the 5182 alloy (Fig. 26) showed that grain refining increased $\mathrm{Mg}$ segregation.

The detrimental effect of grain refining on macrosegregation is ascribed to the nucleation of a larger number of free dendrites at the solidification front and consequent sweeping of those to the bottom of the sump [80]. It is also suggested that the tendency for macrosegregation depends on the alloy composition and seems to follow the 'grain refinability' of the various systems (as discussed in section 4.2). On the other hand, Glenn et al. [59] invoked the formation and distribution of 'showering crystals' (see section 3.2.4). They argued that in all cases small showering crystals were responsible for the negative centreline segregation. In this case, the formation of large showering crystals, whose average solute content is higher than that of the small showering

\footnotetext{
${ }^{6}$ Channel and COMBO bags are commercially available small size fibreglass melt distributors.
} 
crystals, can actually lower the magnitude of negative segregation in the central zone of a non-grain refined billet [59].

Lesoult et al. [70, 116] also reported that grain refining caused more severe centreline segregation in a DC cast $\mathrm{Al}-\mathrm{Mg}$ sheet ingot. Data from their work is plotted along with the data obtained by Glenn et al. [59] in Fig. 27. Remarkably, duplex microstructures (mixture of coarse and fine grains) were observed only in the NGR ingot, where the segregation is less severe, but not in the GR ingot. Consequently the negative centreline segregation is not specifically associated with the presence of duplex microstructures (or "floating” grains). It was pointed out that grain morphology was an important factor to be considered [70], which in their case was more dendritic in NGR ingot and more globular in the GR ingot. Combined effects of the changed permeability and movement of equiaxed grains were taken responsible for the experimentally observed segregation patterns.

Contrary to the above observations, there is a study, which shows that grain refining induces positive centreline segregation. Finn et al. [68] showed that grain refining with Al5Ti0.2B produced positive centreline segregation in 530-mm billets of an $\mathrm{Al}-4.5 \% \mathrm{Cu}$ alloy. On the other hand, the non-grain refined counterpart exhibited the usual pattern of negative centreline segregation. Both the DC cast billets were produced at a casting speed of $3.8 \mathrm{~cm} / \mathrm{min}$ with the $65 \mathrm{~K}$ superheat, a bi-level feeder and a floating diffuser being used. Interestingly, the grain refined billet exhibited positive centreline segregation despite the observation of duplex microstructures (i.e., with a possible solute-lean grains). As a probable reason for this changing centreline pattern with the addition of grain refining, the high permeability in the mushy region, which allowed advection of solute-rich liquid (buoyancy-driven flow) toward the centreline, was suggested. On the other hand, in the case of non-grain refined billets (columnar 
structure), the less permeable mush reduced such advection, and the remaining shrinkage-driven flow produces negative centreline segregation. In both cases, strong positive macrosegregation due to shrinkage-driven flow and exudation was measured at the ingot surface [68]. It is worth noting that the casting parameters (speed and size) in the above experiments were close to the threshold condition for the transition from positive to negative centreline segregation described by Eq. 17.

Our studies on various commercial $\mathrm{Al}$ alloys showed that addition of an Al3Ti1B grain refiner does not affect the macrosegregation in 200-mm billets cast at 8 to $12 \mathrm{~cm} / \mathrm{min}[21,58,69]$. Considering the nature of microstructures and the amount of coarse-cell grains, it is inferred that mushy zone permeability might be high enough so as to compensate the depletion of alloying elements caused by solute-lean grains.

The effect of casting speed could be clearly seen in increasing the severity of segregation in both non-grain refined and grain refined ingots. This effect is statistically more significant when the grain refiner additions are either small or nil [80]. The last statement indicates that macrosegregation in well grain-refined alloys is marginally sensitive to the casting speed.

Segregation tendency is also dependent on the type of grain refiner. For the same feeding conditions, the increased potency of an Al5Ti0.2B master alloy in enhancing the macrosegregation is evident as compared to an Al-6\% Ti alloy (Fig. 27). As it is known that boron-containing $\mathrm{Al}-\mathrm{Ti}$ master alloys are superior to binary Al-Ti alloy in inducing grain refinement, this means that structural refinement directly affects the macrosegregation. A similar effect was observed by Glenn et al. [59] when a $\mathrm{TiB}_{2-}$ refined 5182 ingot showed greater centreline depletion of Mg as compared to similarly cast Ti-refined and non-grain refined ingots that exhibited almost matching macrosegregation patterns. 


\section{Concluding remarks}

The macrosegregation in DC cast billets and ingots with a controlled grain structure is still an open field for future research.

The current understanding of the macrosegregation mechanisms is based on two essential conditions: relative movement between solid and liquid phase and the enrichment of the liquid phase. The major driving forces for the relative movement are:

- thermo-solutal and buoyancy-driven convection in the liquid sump and the penetration of this convective flow into the slurry and mushy zone

- transport of solid grains within the slurry zone by gravity and convective flows

- melt flow in the mushy zone induced by solidification shrinkage

- melt flow in the mushy zone caused by thermal contraction of the solid network

- forced melt flow caused by metallostatic pressure, pouring, gas evolution, stirring, vibration, cavitation, rotation etc., which penetrates into the slurry and mushy zone

Modelling the macrosegregation is normally aimed at (semi) quantitative predictions of the occurrence and severity of macrosegregation by considering the basic mechanisms involved. While some successes have been reported in predicting measured macrosegregation patterns in industrially relevant casting processes, there are still numerous areas where further development is required. Although the basic mechanisms have been well recognised, the challenge at present is in determining the magnitude in which, these mechanisms are affecting the macrosegregation.

More work, both experimental and theoretical, is needed to understand fully the effects of the movement of equiaxed grains, their morphology, and the permeability of the mushy zone in its different regions, on the segregation. Macrosegregation phenomena cannot be predicted without detailed consideration of the evolving microstructure. Thus further progress in macrosegregation modelling can only be made 
if the evolution of the microstructure and the interplay between different mechanisms of macrosegregation are included as well. While solidification research in the past has largely focused on the prediction of interphase stability and segregation patterns under diffusive conditions, macrosegregation modelling requires a quantitative understanding of the convective interactions at the different length scales.

The role of floating grains needs to be established with respect to the detailed local composition measurements. This may help not only to understand their influence on the already depleted by shrinkage-induced flow centre but also to get an insight into their origin and mode of growth before appearing at the centre. This is very important with reference to grain-refined ingots where the coarse-cell grains are not a defect but a prominent structure feature that reflects the very nature of the solidification process.

\section{Acknowledgements}

This review is written within the framework of the research program of the Netherlands Institute for Metals Research (www.nimr.nl), Project MC4. 02134. 


\section{References}

[1] Dobatkin VI. Continuous casting and casting properties of alloys. Moscow: Oborongiz; 1948.

[2] Lewis DM, Savage J. The principles of continuous casting of metals. In: Metallurgical reviews, London: The Institute of Metals; 1956, vol. 1, p. 65116.

[3] Dobatkin VI. Ingots of aluminium alloys. Sverdlovsk: Metallurgizdat; 1960.

[4] Emley EF. Int Met Rev 1976;(6):75-115.

[5] Livanov VA, Gabidullin RM, Shepilov VS. Direct-chill casting of aluminium alloys. Moscow: Metallurgiya; 1977.

[6] Granger DA. Ingot casting in the aluminium industry. In: Vasudevan AK, Doherty RD, editors. Aluminum alloys - contemporary research and applications. Treatise on materials science and technology. Vol. 31, London: Academic Press Inc; 1989, p. 109-35.

[7] Flemings MC, Nereo GE. Trans Metall Soc AIME 1967; 239:1449-61.

[8] Yu H, Granger DA. In: Starke Jr. EA, Sanders Jr. TH, editors. Int. Conf. Aluminum alloys - Their physical and mechanical properties, Charlottesville, Virginia. Warley (UK): EMAS; 1986, p. 17-29.

[9] Chu MG, Jacoby JE. In: Bickert CM, editor. Light metals 1990.Warrendale (PA): TMS; 1990, p. 925-30.

[10] Reddy AV, Beckermann C. In: Voller VR, El-Kaddah N, Marsh SP, editors. Materials processing in the computer age II, Warrendale (PA): TMS, 1995, p. 89-102.

[11] Vreeman CJ, Schloz JD, Krane MJM. J Heat Transfer 2002;124:947-53.

[12] Eskin DG, Suyitno, Katgerman L. Progr Mater Sci 2002;49:629-711.

[13] Grandfield JF, McGlade PT. Materials Forum 1996;20:29-51.

[14] Bergmann WJ. Metall Trans 1970;1:3361-64.

[15] Getselev ZN, Balakhontsev GA, Kvasov FI, Cherepok GV, Varga II, Martynov GI. Continuous casting in electromagnetic mould. Moscow: Metallurgiya; 1983.

[16] Arnberg L, Bäckerud L, Chai G. Solidification characteristics of aluminum alloys. Vol. 3: Dendrite Coherency. Des Plaines (IL): American Foundrymen’s Society; 1996. 
[17] Roth W. Aluminium 1943;25:283-91.

[18] Eskin DG, Zuidema Jr. J, Savran VI, Katgerman L. Mater Sci Eng A 2004;A384:232-44.

[19] Meredith MW, Worth J, Brown JM, Hamerton RG. In: Crepeau PN, editor. Light Metals 2003. Warrendale (PA): TMS; 2003, p.1111-18.

[20] Chu MG. Metall Trans A 1992;23A:2323-25.

[21] Nadella R, Eskin D, Katgerman L. In: Sørlie M, editor. Light metals 2007. Warrendale (PA): TMS; 2007, p. 727-32.

[22] Veinik AI. Theory of special casting methods. Moscow: Mashgiz; 1958.

[23] Drezet J-M. Direct-chill and electromagnetic casting of aluminium alloys: thermomechanical effects and solidification aspects. Dr. Sci. Techn. Thesis. Lausanne: EPFL; 1996.

[24] Chu MG. In: Schneider W, editor. Light Metals 2002. Warrendale (PA): TMS; 2002; p. 899-907.

[25] Du Q, Eskin DG, Katgerman L. Mater Sci Eng A 2005;A413-414:144-50.

[26] Commet B, Delaire P, Rabenberg J, Storm J. In: Crepeau PN, editor. Light Metals 2003, Warrendale (PA): TMS; 2003, p. 711-17.

[27] Grandfield JF, Wang L. In: Tabereaux AT, editor. Light Metals 2004. Warrendale (PA): TMS; 2004, p. 685-90.

[28] Dorward RC, Beerntsen DJ. In: Bickert CM, editor. Light Metals 1990, Warrendale (PA): TMS; 1990, p. 919-24

[29] Zuidema J, Katgerman L, Opstelten IJ, Rabenberg JM. In: Anjier JI, editor. Light Metals 2001. Warrendale (PA): TMS; 2001, p. 873-78.

[30] Devadas C, Musulin I, Celliers O. In: Proc. $5^{\text {th }}$ Intl. Extrusion Technology Seminar, Hyattsville: 1992, p. 121-28.

[31] Tarapore ED. In: Campbell PG, editor. Light Metals 1989, Warrendale (PA): TMS; 1989, p. 875-80.

[32] Reese JM. Metall Mater Trans A 1997;28B:491-99.

[33] Eskin DG, Savran VI, Katgerman L. Metall Mater Trans A 2005;36A:1965-76.

[34] Du Q, Eskin DG, Katgerman L. Metall Mater Trans A 2007;38A:180-189.

[35] Ni J, Incropera FP. Inter J Heat Mass Transfer 1995;28:1285-96

[36] Hubbert MK. The Theory of Ground-Water Motion and Related Papers, New York: Hefner Publishing, 1969.

[37] Flemings MC, Solidification processing, Mc-Graw Hill, 1974. 
[38] Poirier DR, Ganesan S. Mater Sci Eng A 1992;157:113-23.

[39] Nielsen Ø, Olsen SO. In: Tiryakioglu M, Crepeau PN, editors. Shape Casting: The John Campbell Symposium as held during TMS Annual Meeting, 2005, San Francisco, CA, USA, , Warrendale: TMS, 2005, p. 103-112.

[40] Carman PC. Trans Inst Chem Eng London 1937;15:150-6.

[41] Kozeny J. Sitzungsberg Akad Wiss Wien 1927;136,:271-306.

[42] Wang CY, Beckermann C. Metall Trans A 1993;24A:2787-802.

[43] Davidson PA, Flood SC. Metall Mater Trans B 1994;25B:293-302

[44] Eskin DG, Du Q, Katgerman L. Scr Mater 2006;55:715-18.

[45] Nicolli LC, Mo A, M’Hamdi M. Metall Mater Trans A 2005;36A;433-42.

[46] Argyropoulos SA. Scand J Metall 2002;30:273-85.

[47] Mo A. Metall Mater Trans A 1998;29A:2189-94.

[48] Suyitno, Eskin DG, Savran VI, Katgerman L. Metall Mater Trans A 2004;35A:3551-61.

[49] Langsrud Y. In: $8^{\text {th }}$ Intl. Light Metals Congress, Leoben-Vienna, Austria; 1987. p. 481-85.

[50] Lal K, Lakner J, Kovach Csetenyi E. Light Metal Age, 1990; (10):23-26.

[51] Snyder WJ, Kirby JL, Levy SA. In: Campbell PG, editor. Light metals 1989. Warrendale (PA): TMS; 1989. p. 853-57.

[52] Buxmann K, Gold E. Journal of metals 1982;34:28-34.

[53] Nagaumi H. Sci Technol Adv Mater 2001;2:49-57.

[54] Livanov VA. In: Proceedings of the First Technological Conference of Metallurgical Plants of Peoples' Commissariat of Aviation Industry, Moscow: Oborongiz; 1945. p. 5-58.

[55] Furrer P. In: Starke Jr. EA, Sanders Jr. TH, editors. Inter. Conf. On aluminum alloys, their physical and mechanical properties, Charlottesville, Virginia; 1986. p. 1303-20.

[56] Easton MA, StJohn D. Metall Mater Trans A 1999;30A:1613-23.

[57] Quested TE. Mater Sci Tech 2004;20:1357-69.

[58] Nadella R, Eskin D, Katgerman L. Mater Sci Forum 2006;519-521:1841-46.

[59] Glenn AM, Russo SP, Paterson PJK. Metall Mater Trans A 2003;34A:151323.

[60] Hutt J, StJohn D. Int J Cast Metals Res 1998;11:13-22.

[61] Granger DA, Liu J. JOM 1983;35:54-59. 
[62] Bäckerud L, Kril E, Tamminen J. Solidification characteristics of Aluminium alloys, Vol. 1: Wrought Alloys 1986, Pp. 39-47

[63] Turchin AN, Zuiderwijk M, Pool J, Eskin DG, Katgerman L. Acta Mater 2007;55:3795-3801.

[64] Håkonsen A, Mortensen D, Benum S, Vatne HE. In: Eckert CE, editor. Light Metals 1999, Warrendale (PA): TMS; 1999. p. 821-27.

[65] Warrington D, McCartney DG. Cast metals 1991;3:202-08.

[66] Easton M, Grandfield J, StJohn D, Rinderer B. Mater Sci Forum 2006;519521:1675-80.

[67] Granger DA. In: Welch B, editor. Light metals 1998. Warrendale (PA): TMS; 1998. p. 941-52.

[68] Finn TL, Chu MG, Bennon WD. In: Beckermann C, editor. Micro/Macro scale phenomena in solidification. New York, ASME; 1992. p. 17-26.

[69] Nadella RK, Eskin D, Katgerman L. In Müller HR, editor. Continuous Casting of Non-ferrous metals, 2005, Neu-Ulm, Germany, Wiley-VCH Verlag GmbH \& Co, p. 277-82.

[70] Lesoult G, Albert V, Appolaire B, Combeau H, Daloz D, Joly A et al. Sci Tech Adv Mat 2001;2:285-91.

[71] Eskin GI. Ultrasonics Sonochem 1994;1: 59-63.

[72] Eskin GI. Ultrasonic Treatment of Light Alloy Melts. Amsterdam: Gordon\&Breach OPA; 1998.

[73] Eskin GI. Z Metallkde 2002; 93: 502-7

[74] Nadella R, Eskin D, Katgerman L. - unpublished work

[75] Eskin D, Du Q, Ruvalcaba D, Katgerman L. Mater Sci Eng A 2005;A405:110.

[76] Lee PD, Atwood RC, Dashwood RJ, Nagaumi H. Mater Sci Eng A, 2002;A328:213-22.

[77] Suyitno, Eskin DG, Katgerman L. Mater Sci Eng A 2006;A420:1-7.

[78] Diepers HJ, Beckermann C, Steinbach I. Acta Mater 1999;47:3663-78.

[79] Du Q, Eskin DG, Jacot A, Katgerman L. Acta Mater 2007;55:1523-32.

[80] Gariepy B, Caron Y. In: Elwin L. Rooy, editor. Light metals 1991. Warrendale (PA): TMS; 1991. p. 961-71

[81] Beringuccio V. Pirotechnia, 1540. Translated by C.S. Smith, M.T. Gnudi, Cambridge, MA: MIT Press, 1966, p. 259-60. 
[82] L. Ercker. Beschreibung allerfürnemisten mineralischen Ertzt und Bergwercksarten, Prague, 1574. Translated by J. Pittus as Fleta Minor. The Laws of Art and Nature, in Knowing, Judging, Assaying, Fining, Refining and Enlarging the Bodies of Confined Metals. Pt. 1, London: T. Dawks, 1683.

[83] Pell-Walpole WT. Met. Treatment Drop Forging, 1949; Summer:103-15; Autumn:171-82.

[84] Voronov SM, Z. Metallkde 1929, vol. 21, p. 310 (cited from [83]).

[85] Verö J. Metal Industry 1936; 48: 431-494.

[86] Brenner P, Roth W. Z. Metallkde 1940;32:10-14.

[87] Drezet J-M, Gremaud M, Rappaz M. In: Müller HR, editor, Continuous Casting, Wiley-VCH, Weinheim, 2005, pp. 151-61.

[88] Du Q, Eskin D, Katgerman L. In Gandin Ch.A, Bellet M, editors. Modeling of Casting, Welding and Advanced Solidification Processes XI, TMS, Warrendale, PA, 2006, p. 235-242.

[89] Mehrabian R, Keane M, Flemings MC. Metall Trans 1970;1:1209-20.

[90] Beckermann C. Inter Mater Rev 2002;47:243-61.

[91] Du Q, Eskin DG, Katgerman L. Metall Mater Trans A 2007; 38:180-189.

[92] Flood SC, Katgerman L, Voller VR: In Rappaz M, Ozgu MR, Mahin KW, editors. Modeling of casting, welding and advanced solidification processes $\mathrm{V}$, TMS, Warrendale, PA, 1991, pp. 683-90.

[93] Zhang B, Cui J, Lu G. Mater Sci Eng 2003;A355:325-30.

[94] Flemings MC. ISIJ Int 2000;40:833-41.

[95] Vreeman CJ, Krane MJM, Incropera FP. Int J Heat Mass Transfer 2000;43:677-86.

[96] Vreeman CJ, Krane MJM, Incropera FP. Int J Heat Mass Transfer 2000;43:687-704.

[97] Ni J, Incropera FP. Int J Heat Mass Transfer 1995;38:1271-84.

[98] Appolaire B, Combeau H. In Stefanescu D, Warren J, Jolly M, Krane M, editors. Modeling of Casting, Welding and Advanced Solidification Processes X, TMS, Warrendale, PA, 2003, p. 221-28.

[99] Thevik HJ, Mo A, Rusten T. Metall Mater Trans B 1999;30B:135-42.

[100] Flood SC, Davidson DA. Mater Sci Tech 1994;10:741-51.

[101] McCartney DG. Inter Mater Rev 1989:34:247-60.

[102] Vatne HE, Aluminium 1999;75:84-90. 
[103] Greer L, Cooper PS, Meredith MW, Schneider W, Schumacher P, Spittle JA, Tronche A. Adv Engg Mater 2003;5:81-91.

[104] Murty BS, Kori SA, Chakraborty M. Int Mater Rev 2002;47:3-29.

[105] Granger DA. In Engh TA, Lyng S, Øye HA, editors. Refining and alloying of liquid aluminium and ferro-alloys, Aluminium-Verlag Düsseldorf, 1985; p. 231-45.

[106] Belov NA, Eskin DG, Aksenov AA. Multicomponent phase diagrams: applications for commercial aluminium alloys. Oxford: Elsevier; 2005.

[107] Schneider WA, Quested TE, Greer AL, Cooper PS. In: Crepeau PN, editor. Light metals 2003. Warrendale (PA): TMS; 2003. p. 953-59.

[108] Bäckerud L, Johnsson M. In: Hale W, editor. Light metals 1996. Warrendale (PA): TMS; 1996. p. 679-85.

[109] Mohanty PS, Gruzleski JE. Acta Mater 1995; 43:2001-12.

[110] Iqbal N, van Dijk NH, Offerman SE, Moret MP, Katgerman L, Kearley GJ. Acta Mater 2005;53:2875-80.

[111] Maxwell I, Hellawell A. Acta Metall 1975;23:229-37.

[112] Jones GP, Pearson J. Metall Trans B 1976;7B:223-34.

[113] Moriceau J. Rev Aluminium 1972;12:977-88.

[114] Kearns MA, Cooper PS. Mater Sci Tech 1997;13:650-4.

[115] Easton M, StJohn D, Sweet E. In: Tabereaux AT, editor. Light metals 2004. Warrendale (PA): TMS; 2004. p. 827-31

[116] Joly A, Grün GU, Daloz D, Combeau H, Lesoult G. Mater Sci Forum 2000;329-330: 111-20. 


\section{Figure Captions}

Fig. 1. Schematic of the DC cast process. Main process parameters are underlined.Fig. 2. Schematic representation of the transition region (a) Illustration of the liquidus (L) and solidus (S) isotherms in a typical DC cast round billet. Coherency isotherm is marked as 30\%. The liquid pool depth (1), transition region (2), mushy zone (3), and the sump depth (1+2) are indicated in the diagram, and (b) regions in which different macrosegregation mechanisms are operating

Fig. 3. Interruption of mould cooling and air gap formation during solidification of the ingot shell upon DC casting [4]. a, primary (mould) cooling; b, interruption of mould cooling owing to formation of air gap; c, secondary (direct water) cooling.

Fig. 4. (a) Scheme of isotherms, solidification rate and thermal gradient distributions during DC casting, and (b) experimentally observed sump profile outlined by addition of a grain refiner (200-mm billet of a 6061 alloy).

Fig. 5. Dependence of the sump depth in the centre of the billet on the casting speed (a) experimental data for 195-mm billets from three binary $\mathrm{Al}-\mathrm{Cu}$ alloys [1]; (b) experimentally measured sump depth $(1+2)^{\prime}$ and calculated molten pool depth (1), transition region (2), and sump depth (1+2) for a 200-mm Al-4.5\% Cu billet cast at two casting speeds (numbers are as in Fig. 2a) [18]; and (c) the variation of the thickness of the transition region along the billet radius for two casting speeds [18].

Fig. 6. Flow patterns in a round billet during DC casting obtained analytically (a) and numerically (b): (a) shows bulk flow pattern in the liquid part of the sump [43] and (b) detailed flow pattern with velocity vector plots together with the solid fraction contours at $g_{\mathrm{s}} 0,0.3$, and 1 [25].

Fig. 7. Interrelation between process parameters and the structure and defect formation upon DC casting of Al billets

Fig. 8. Typical grain size and morphology as observed in 7075 DC cast billets: (a) nongrain refined, and (b) grain refined $(0.005 \% \mathrm{Ti})$

Fig. 9. Distribution of structure parameters in the horizontal section of a billet at different casting speeds ((A) $120 \mathrm{~mm} / \mathrm{min},(\boldsymbol{\square}) 160 \mathrm{~mm} / \mathrm{min},(\bullet) 200 \mathrm{~mm} / \mathrm{min})$ : (a) grain size, and (b) dendritic arm spacing; [18].

Fig. 10. Macrostructure of a 7075 DC cast billet (200-mm diameter) exhibiting the morphological variations from periphery to the centre. 
Fig. 11. Difference in the distribution of grain size with grain refining [21, 58]. The microstructures for the 7075 alloy are illustrated in Fig. 8.

Fig. 12. Difference in the distribution of DAS with alloy type and grain refining [74]. Filled symbols are for NGR condition and open symbols indicate GR condition. The microstructures in the 2024 billet centre are presented in Fig. 13.

Fig.13. Duplex grain structures in the centre of round DC cast billets exhibiting coarsecell (floating) and fine-cell dendrites (Al-Cu-Mg alloy): (a) non-grain refined and (b) grain refined $(0.006 \% \mathrm{Ti})$ [58]

Fig. 14. Distribution of non-equilibrium eutectics along the 200-mm billet diameter: (a) effect of casting speed, $\mathrm{Al}-4.5 \% \mathrm{Cu}$, melt temperature $715^{\circ} \mathrm{C}$ and (b) effect of melt temperature, $\mathrm{Al}-2.8 \% \mathrm{Cu}$, casting speed $20 \mathrm{~cm} / \mathrm{min}$. Fig. 15. Schematic representation of macrosegregation pattern for an element with $K<1$. The subsurface segregation is not taken into consideration while calculating different segregation indices. $\Delta \mathrm{C}$ is the relative deviation of concentration from the average, $\left(\mathrm{C}_{\mathrm{i}}-\mathrm{C}_{\text {ave }}\right) / \mathrm{C}_{\text {ave }}$.

Fig. 16. Centreline segregation of alloying elements vs. distribution coefficient [80]. The \% deviation is plotted as the total relative deviation of an alloying element taken as the sum of the absolute values of the low (negative) deviation and the average of the high (positive) deviation points (Refer Fig. 15)

Fig. 17: Representative volume of the mushy zone

Fig. 18. A scheme illustrating the directions of shrinkage flow (black arrows, $V_{\text {shr }}$ ) in the mushy zone, its horizontal component $\mathrm{V}_{\mathrm{h}}$, the thickness of the mushy zone between the coherency isotherm and the solidus $\left(\mathrm{L}_{\mathrm{m}}\right)$, and the directions of thermo-solutal convective flows (grey arrows) in the sump above the coherency isotherm. Only half of a billet is shown, the centre being on the left and the surface on the right [44].

Fig. 19. Relative segregation of $\mathrm{Cu}$ and $\mathrm{Mg}$ along the radius from the centre (on the left) to the surface (to the right) of a billet cast at $12 \mathrm{~cm} / \mathrm{min}$ : Case 1 - Presence of $\mathrm{Mg}$ is not included in the model (identical to the binary $\mathrm{Al}-\mathrm{Cu}$ alloy); Case $2-\mathrm{Mg}$ is included in the segregation model [91]. Note the change in the segregation of copper.

Fig. 20. Effect of forced convection on macrosegregation in 2024-alloy billets of 280mm diameter (a), 270-mm diameter (b, c, curve 1), and 370-mm diameter (b, c, 
curve 2): (a) mechanical stirring in the sump (1 and 2 strong, 3, medium, and 4, weak); (b) electro-magnetic casting; and (c) without stirring [3, 5].

Fig. 21. Microprobe measurements of $\mathrm{Mg}$ and $\mathrm{Cu}$ concentrations in the coarse-cell (top) and fine-cells regions (bottom) of a NGR sample from a DC cast 2024 billet (corresponding microstructure is given in Fig. 13a).

Fig. 22. Design of metal flow distributors used in bi-level transfer system [80]

Fig. 23. Optical micrograph of an Al5Ti1B master alloy showing large $\mathrm{Al}_{3} \mathrm{Ti}$ particles and numerous $\mathrm{TiB}_{2}$ clusters of particles within the (Al) matrix (Courtesy: Jan Boomsma, TU Delft).

Fig. 24. The size distribution of $\mathrm{TiB}_{2}$ particles in an Al3Ti1B master alloy along with the undercooling necessary to initiate a free growth of (Al) [107].

Fig. 25. Variation of $\mathrm{Mg}$ centreline segregation in $\mathrm{DC}$ cast 3104 billet with $\mathrm{Ti}$ concentration and melt-feeding system. Data obtained from Ref [80] and replotted. The \% deviation is plotted as total relative deviation of alloying element taken as the sum of the absolute values of the low (negative) deviation and the average of the high (positive) deviation points (Refer Fig. 15).

Fig. 26. Variation of Mg centreline segregation in DC cast 5162 billet with the Ti concentration and melt-feeding system. The arrows indicate the direction of segregation variation with increasing casting speed. Data obtained from [80] and replotted.

Fig. 27. Effect of grain refining on the Mg segregation patterns in a 5182 (Al-4.5\% Mg) alloy. Grain refined: solid line; non-grain refined: dotted line (Circles refer to the width of the ingot [59] whereas triangles, to the thickness of the ingot [116]). 
Table 1

Summary of the techniques for measuring fluid velocities

\begin{tabular}{|c|c|c|c|}
\hline Technique & $\begin{array}{l}\text { Temperature } \\
\text { range }\end{array}$ & $\begin{array}{l}\text { Measurement } \\
\text { range, } \mathrm{m} / \mathrm{s}\end{array}$ & Comments \\
\hline $\begin{array}{l}\text { Hot } \\
\text { wire/film }\end{array}$ & $<100^{\circ} \mathrm{C}$ & $0.05-0.1$ & Not suitable for $\mathrm{Al}$ melts \\
\hline Pitot tube & $<100^{\circ} \mathrm{C}$ & High speeds & $\begin{array}{l}\text { Not suitable for high temperatures and } \\
\text { recirculation flows. Not suitable for } \mathrm{Al} \text { melts }\end{array}$ \\
\hline Propeller & $\begin{array}{l}\text { Wide range, } \\
\text { providing } \\
\text { suitable } \\
\text { materials }\end{array}$ & Wide range & $\begin{array}{l}\text { Difficult choice of materials. Measures } \\
\text { instantaneous velocities. Experimental } \\
\text { difficulties to build for liquid Al. Can be used } \\
\text { for water models. }\end{array}$ \\
\hline Drag probes & $\begin{array}{l}\text { Tested up to } \\
350^{\circ} \mathrm{C}, \\
\text { possibly can } \\
\text { be used at } \\
\text { higher } \\
\text { temperatures }\end{array}$ & $\begin{array}{l}0.03-0.25 \\
0.1-1.5 \\
\text { Can be used } \\
\text { only over } \\
\text { limited depth. }\end{array}$ & $\begin{array}{l}\text { Requires precise design and machining. } \\
\text { Measures averaged velocities. May be suitable } \\
\text { for liquid Al. }\end{array}$ \\
\hline $\begin{array}{l}\text { Karman } \\
\text { vortex probe }\end{array}$ & Up to $1600^{\circ} \mathrm{C}$ & $\begin{array}{l}0.2-0.7 \\
\text { Can be used } \\
\text { only for } \\
\text { subsurface } \\
\text { velocities. }\end{array}$ & $\begin{array}{l}\text { Measures one-directional velocity. Suitable } \\
\text { for liquid } \mathrm{Al} \text {. }\end{array}$ \\
\hline $\begin{array}{l}\text { Particle } \\
\text { imaging } \\
\text { velocimetry }\end{array}$ & Not limited & $\begin{array}{l}\text { Wide range of } \\
\text { averaged } \\
\text { velocities }\end{array}$ & $\begin{array}{l}\text { Generally not suitable for liquid } \mathrm{Al} \text {, but can be } \\
\text { used for tracing surface velocities. For in- } \\
\text { depth velocities requires radioactive tracers } \\
\text { and radioscopic registration. }\end{array}$ \\
\hline $\begin{array}{l}\text { Laser } \\
\text { Doppler } \\
\text { velocimetry }\end{array}$ & Not limited & Wide range & $\begin{array}{l}\text { Suitable for water models. Not suitable for } \\
\text { liquid } \mathrm{Al} /\end{array}$ \\
\hline $\begin{array}{l}\text { Ultrasound } \\
\text { Doppler } \\
\text { velocimetry }\end{array}$ & $\begin{array}{l}\text { Tested up to } \\
200^{\circ} \mathrm{C}\end{array}$ & $0.01-0.75$ & May be suitable for liquid Al. \\
\hline $\begin{array}{l}\text { Melting } \\
\text { probe }\end{array}$ & Up to $1200^{\circ} \mathrm{C}$ & $\begin{array}{l}0.1-0.5 \\
\text { Averaged over } \\
\text { volume and } \\
\text { time velocities }\end{array}$ & $\begin{array}{l}\text { Sensitive to temperature of the melt, } \\
\text { fluctuation is velocities. Can be used for } \\
\text { liquid Al. }\end{array}$ \\
\hline $\begin{array}{l}\text { Magnetic } \\
\text { probe }\end{array}$ & $\mathrm{Up}$ to $720^{\circ} \mathrm{C}$ & $\begin{array}{l}0.005-0.5 \\
\text { Two velocity } \\
\text { components }\end{array}$ & $\begin{array}{l}\text { Very weak output signal requires expensive } \\
\text { and laborious data acquisition and processing. } \\
\text { High-temperature applications special } \\
\text { magnets. Can be used for liquid Al. }\end{array}$ \\
\hline
\end{tabular}


Table 2.

Summary of reported observations on duplex grain structures in direct-chill cast ingots and billets

\begin{tabular}{|c|c|c|c|c|}
\hline Alloy & $\begin{array}{l}\text { Ingot size/ billet } \\
\text { diameter (mm) }\end{array}$ & $\begin{array}{l}\text { Non-grain } \\
\text { refined }\end{array}$ & Grain refined & Ref. \\
\hline $\mathrm{Al}$ & $900 \times 300$ & - & $\mathrm{D}, \mathrm{CF}$ & 64 \\
\hline $\mathrm{Al}-(1-4) \% \mathrm{Cu}$ & $\varnothing 200$ & $\mathrm{D}, \mathrm{CF}$ & - & 33,48 \\
\hline $\mathrm{Al}-3.6 \% \mathrm{Cu}$ & $\varnothing 200$ & Not observed & $\mathrm{D}, \mathrm{CF}$ & 74 \\
\hline $\mathrm{Al}-4.5 \% \mathrm{Cu}$ & $\varnothing 533.4$ & Not observed & $\begin{array}{l}\mathrm{D}, \mathrm{CF} \text { (positive } \\
\text { segregation) }\end{array}$ & 68 \\
\hline 2024 & $\varnothing 400$ & $\mathrm{D}, \mathrm{CF}$ & - & 28 \\
\hline 2024 & $\begin{array}{l}\text { Flat ingot, } \\
\text { commercial size }\end{array}$ & - & $\mathrm{D}, \mathrm{CF}$ & 8 \\
\hline 2024 & $\varnothing 200$ & $\mathrm{D}, \mathrm{CF}$ & $\mathrm{D}, \mathrm{CF}$ & 58 \\
\hline 7075 & $\varnothing 200$ & Not observed & $\mathrm{D}, \mathrm{CF}$ & 21 \\
\hline $7 \mathrm{XXX}$ & $1270 \times 406.5$ & $\mathrm{D}, \mathrm{FF}$ & - & 9 \\
\hline 5182 & $1850 \times 550$ & $\begin{array}{l}\mathrm{D}, \mathrm{FF} \text { (fine } \\
\text { grains) }\end{array}$ & $\begin{array}{l}\text { Not observed, FF } \\
\text { (fine grains) }\end{array}$ & 70 \\
\hline 5182 & $1050 \times 550$ & $\begin{array}{l}\mathrm{D}, \mathrm{FF} \text { (fine } \\
\text { grains) }\end{array}$ & FF (fine grains) & 59 \\
\hline 6061 & $\varnothing 200$ & Not observed & $\mathrm{D}, \mathrm{CF}$ & 69 \\
\hline
\end{tabular}

CF - floating grains with coarse cells; FF - floating grains with fine cells; D - duplex structure 


\section{Table 3}

Partition coefficients for various alloying elements in aluminium

\begin{tabular}{lllllllll} 
Element & $\mathrm{Fe}$ & $\mathrm{Si}$ & $\mathrm{Cu}$ & $\mathrm{Mg}$ & $\mathrm{Zn}$ & $\mathrm{Mn}$ & $\mathrm{Ti}$ & $\mathrm{Cr}$ \\
\hline $\mathrm{K}$ & 0.03 & 0.13 & 0.17 & 0.43 & 0.45 & 0.90 & 9.0 & 2.0
\end{tabular}


Table 4

Minimum concentrations (in wt\%) in dendrite cells measured during line scan

\begin{tabular}{lllll}
\multirow{2}{*}{ Element } & \multicolumn{2}{c}{ NGR } & \multicolumn{2}{c}{ GR } \\
\cline { 2 - 5 } & Coarse & Fine & Coarse & Fine \\
\hline $\mathrm{Cu}$ & 0.68 & 1.09 & 0.72 & 0.96 \\
\hline $\mathrm{Mg}$ & 0.45 & 0.74 & 0.46 & 0.63
\end{tabular}


Table 5

GRF (Q) values for common solute elements in aluminium [108]

\begin{tabular}{lllll} 
Element & $\mathrm{K}^{*}$ & $\mathrm{~m}_{\mathrm{L}}$ & $\mathrm{Q} / \mathrm{C}_{0}=(\mathrm{K}-1) \mathrm{m}_{\mathrm{L}}$ & Reaction type \\
\hline $\mathrm{Ti}$ & $\approx 9$ & 30.7 & 245.6 & Peritectic \\
\hline $\mathrm{Cr}$ & 2.0 & 3.5 & 3.5 & Peritectic \\
\hline $\mathrm{Zr}$ & 2.5 & 4.5 & 6.8 & Peritectic \\
\hline $\mathrm{Fe}$ & 0.02 & -3.0 & 2.9 & Eutectic \\
\hline $\mathrm{Si}$ & 0.11 & -6.6 & 5.9 & Eutectic \\
\hline $\mathrm{Cu}$ & 0.17 & -3.4 & 2.8 & Eutectic \\
\hline $\mathrm{Mg}$ & 0.43 & -6.2 & 3.0 & Eutectic \\
\hline $\mathrm{Zn}$ & 0.45 & -1.8 & 0.96 & Eutectic \\
\hline $\mathrm{Mn}$ & 0.94 & -1.6 & 0.1 & Eutectic
\end{tabular}

*K data is also given in Table 3 
Table 6

GRF (Q) computed for some commercial Al alloys*

\begin{tabular}{ccc} 
Alloy & Composition & $\mathrm{Q}=\sum \mathrm{m}_{\mathrm{L}}(\mathrm{K}-1) \mathrm{C}_{0}$ \\
\hline 1050 & Al-0.12Si-0.20Fe & 1.3 \\
\hline 2024 & Al-0.25Si-0.25Fe-4.35Cu-0.6Mn-1.5Mg-0.05Cr & 19.1 \\
\hline 3004 & Al-0.12Cu-0.15Si-0.35Fe-1.25Mn-1.05Mg-0.12Zn & 5.6 \\
\hline 5182 & Al-0.10Si-0.17Fe-0.07Cu-0.35Mn-4.5Mg-0.05Cr & 15.0 \\
\hline 6061 & Al-0.6Si-0.35Fe-0.27Cu-0.07Mn-0.10Mg-0.08Cr & 5.9 \\
\hline 7075 & Al-1.6Cu-2.5Mg-1.15Mn-0.20Si-0.25Fe-0.23Cr-5.6Zn & 20.2
\end{tabular}

* Elemental concentration is taken as the average of the composition limits without any residual Ti. Cr may have a poisoning effect on the grain refining. 
Table 7

Data on coherency temperatures and volume fractions for some commercial wrought $\mathrm{Al}$ alloys [16]

\begin{tabular}{llllll} 
Alloy & Ti (\%) & $\begin{array}{l}\text { Liquidus } \\
\left(\mathrm{T}_{\mathrm{L}}\right),{ }^{\circ} \mathrm{C}\end{array}$ & $\begin{array}{l}\text { Coherency } \\
\left(\mathrm{T}_{\text {coh }}\right),{ }^{\circ} \mathrm{C}\end{array}$ & $\begin{array}{l}\text { Fraction solid } \\
\text { at coherency }\end{array}$ & $\mathrm{T}_{\mathrm{L}}-\mathrm{T}_{\text {coh }}$ \\
\hline \multirow{2}{*}{1050} & 0.001 & 660.3 & 658.2 & 25 & 2.1 \\
& 0.02 & 662.1 & 656.6 & 53 & 5.5 \\
& 0.04 & 663.7 & 652.2 & 55 & 11.5 \\
\hline \multirow{2}{*}{3004} & 0.001 & 651.8 & 648.8 & 17 & 3 \\
& 0.02 & 651.2 & 645.5 & 49 & 8.7 \\
\hline \multirow{2}{*}{5182} & 0.005 & 637.0 & 631.9 & 23 & 5.1 \\
& 0.02 & 639.9 & 626.9 & 44 & 13 \\
\hline \multirow{2}{*}{6063} & 0.008 & 657.8 & 653.9 & 33 & 3.9 \\
& 0.02 & 658.8 & 652.3 & 52 & 6.5
\end{tabular}




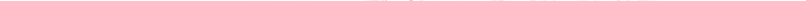




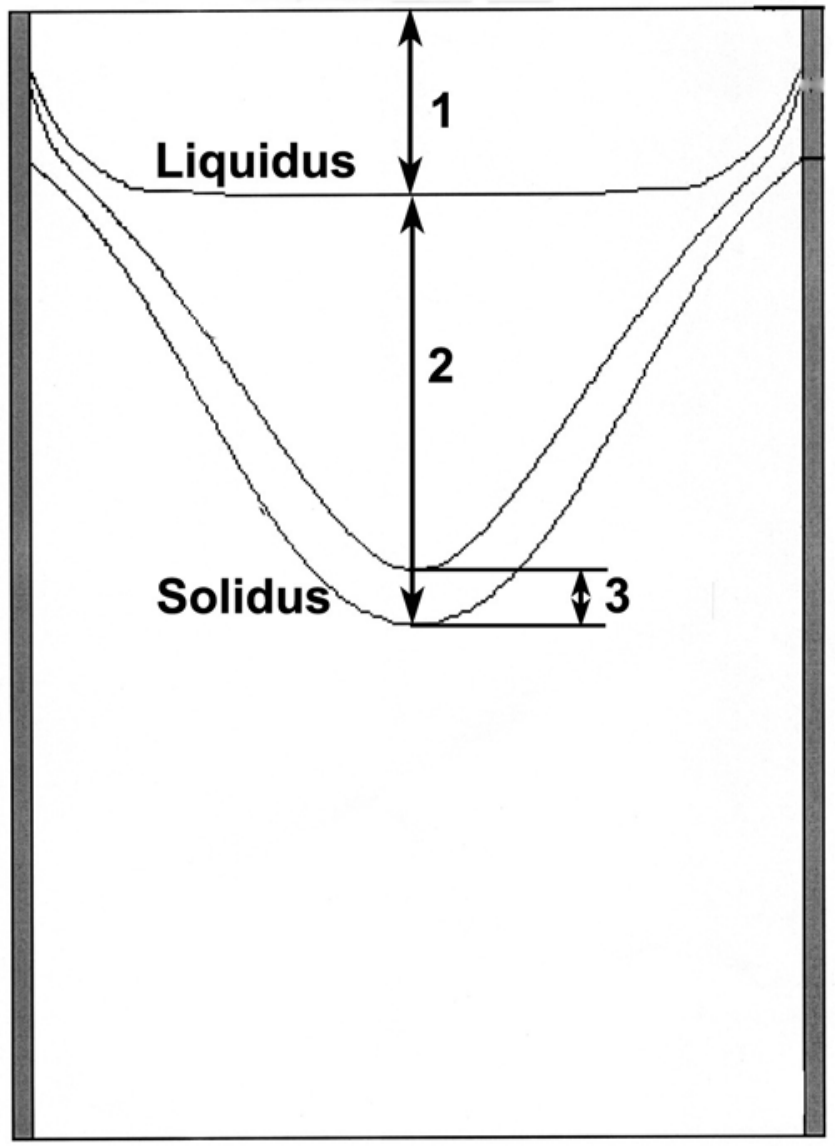



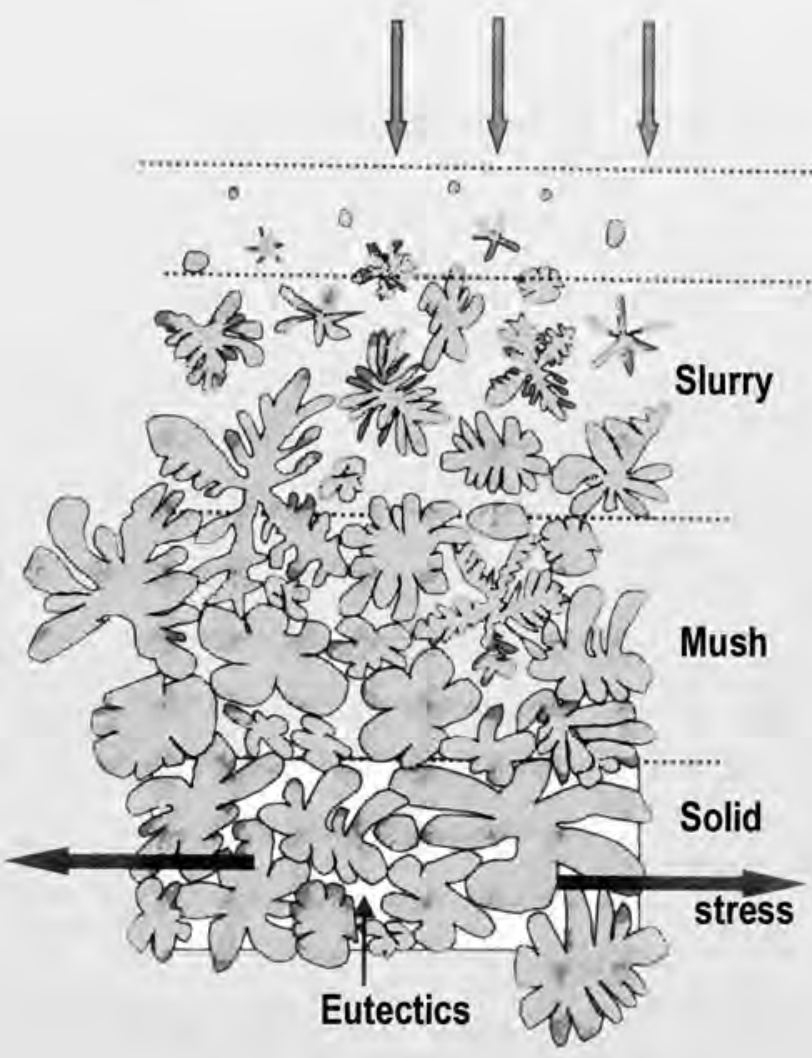

Thermo-solutal convection

Transport of solid grains

Shrinkage-driven flow

Deformation-driven flow 


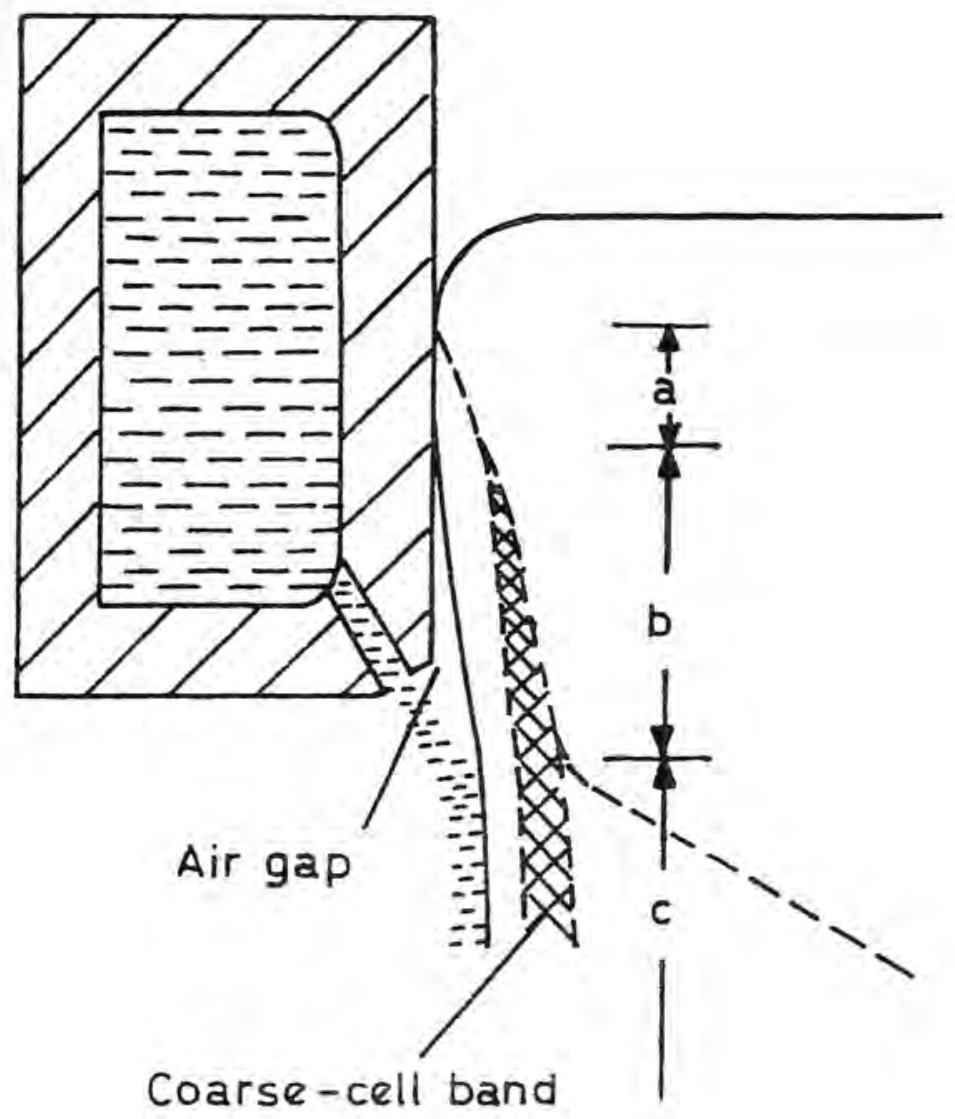




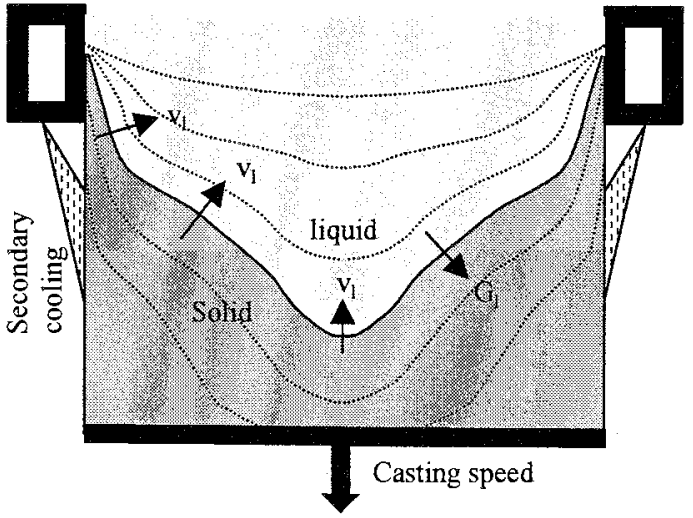




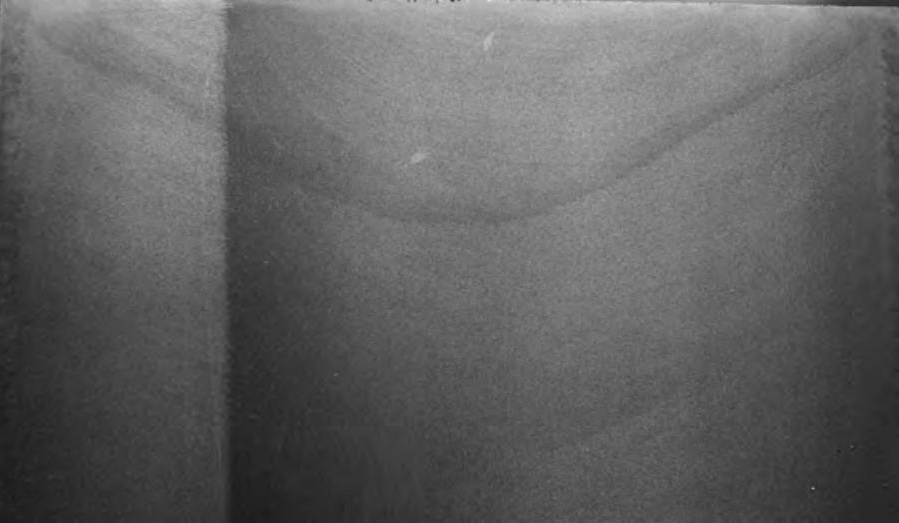




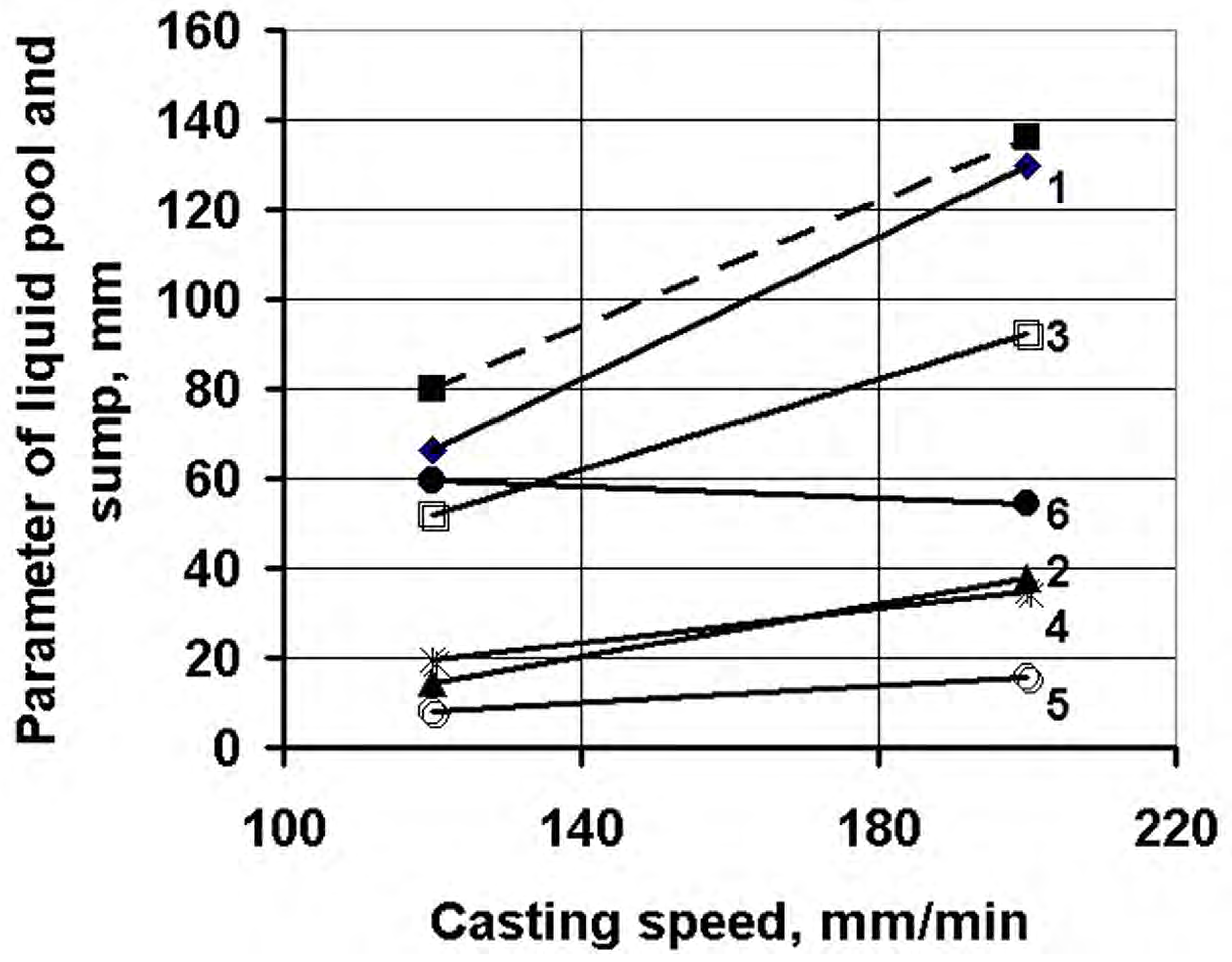




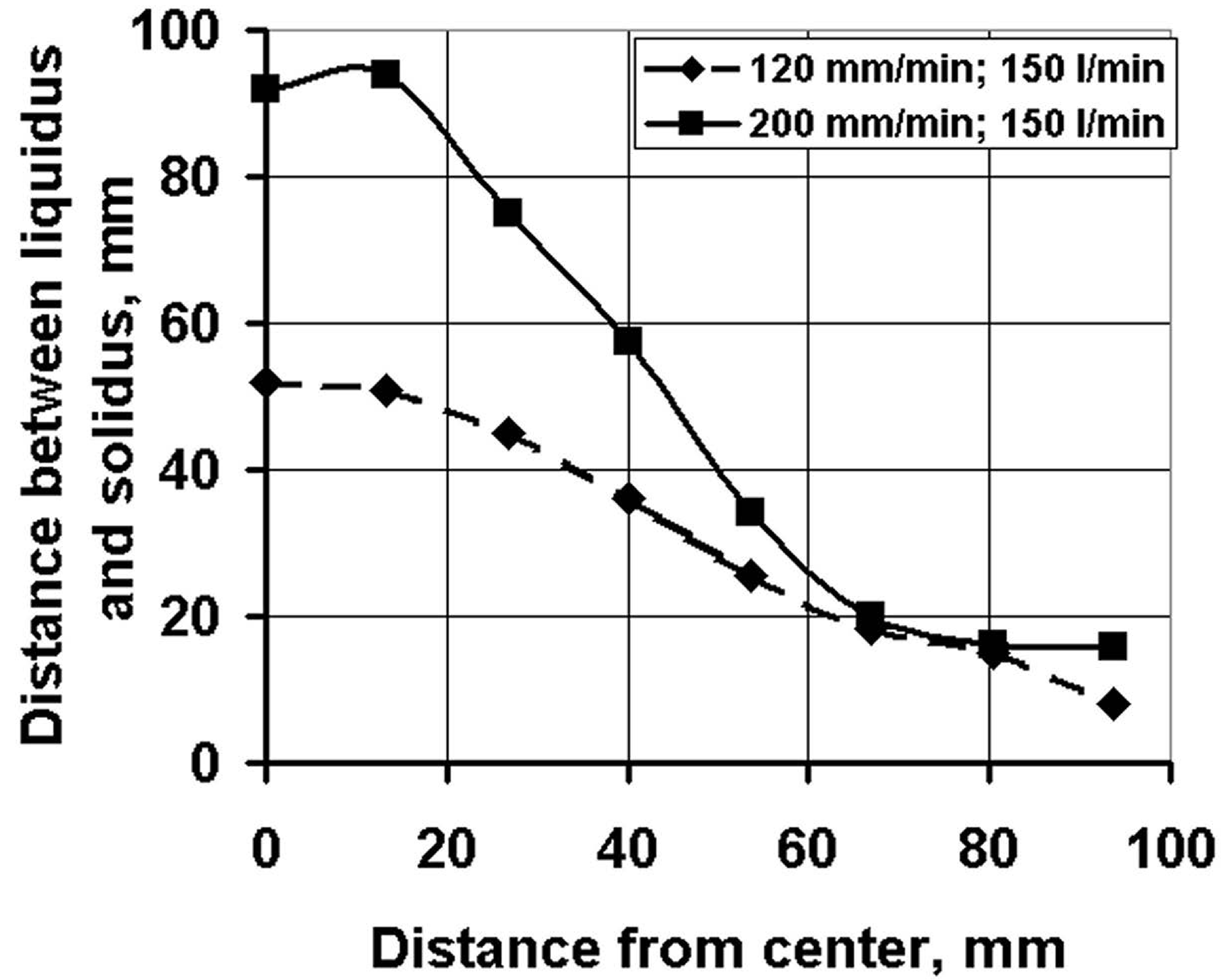




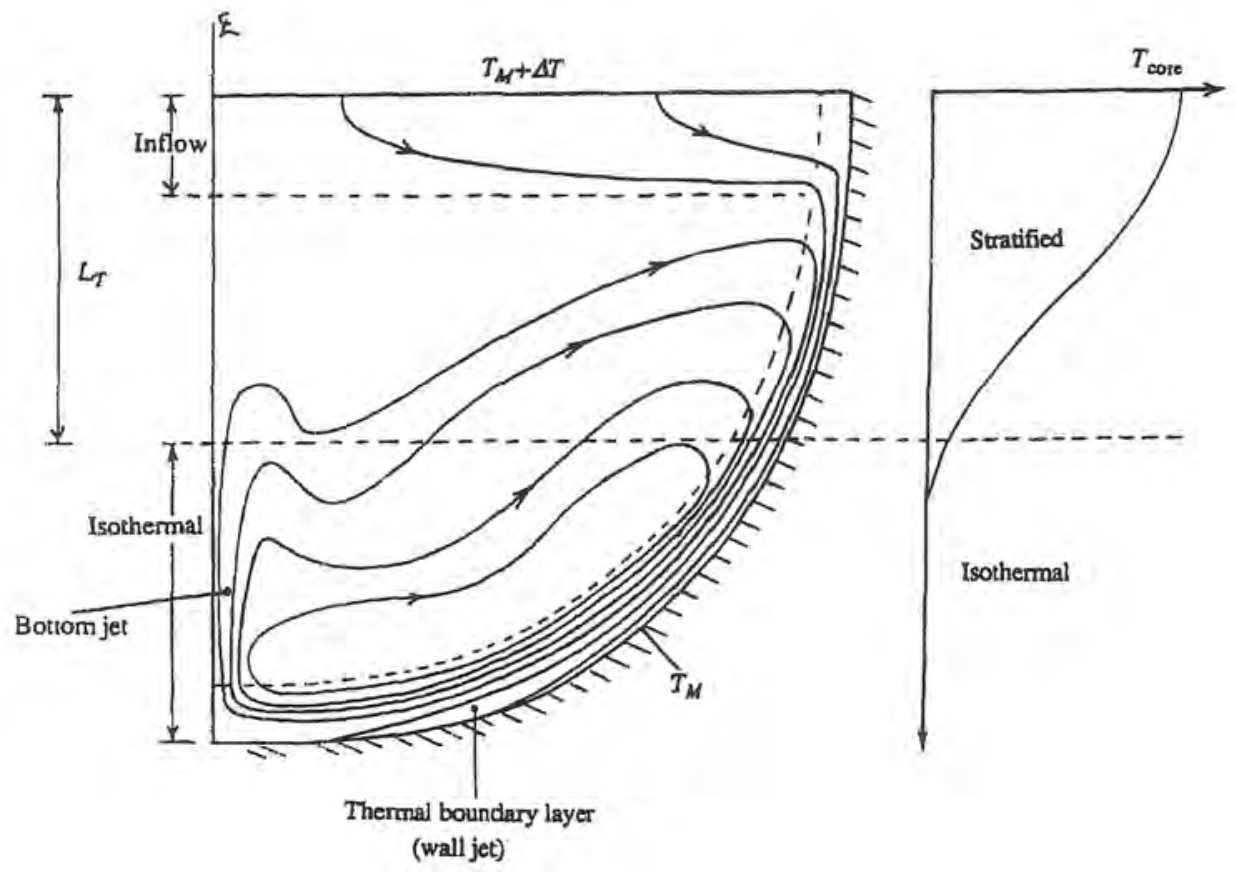




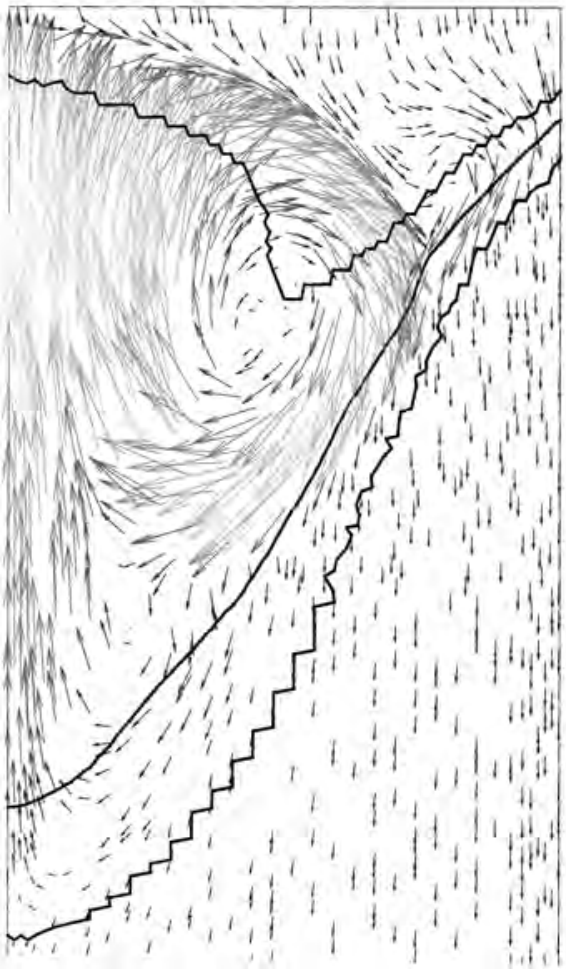




\section{Ingot size/ geometry}

\begin{tabular}{|l|}
\hline Dimensions \\
and geometry \\
of transition \\
region \\
\hline
\end{tabular}

DC casting parameters
Alloy composition/grain refinement

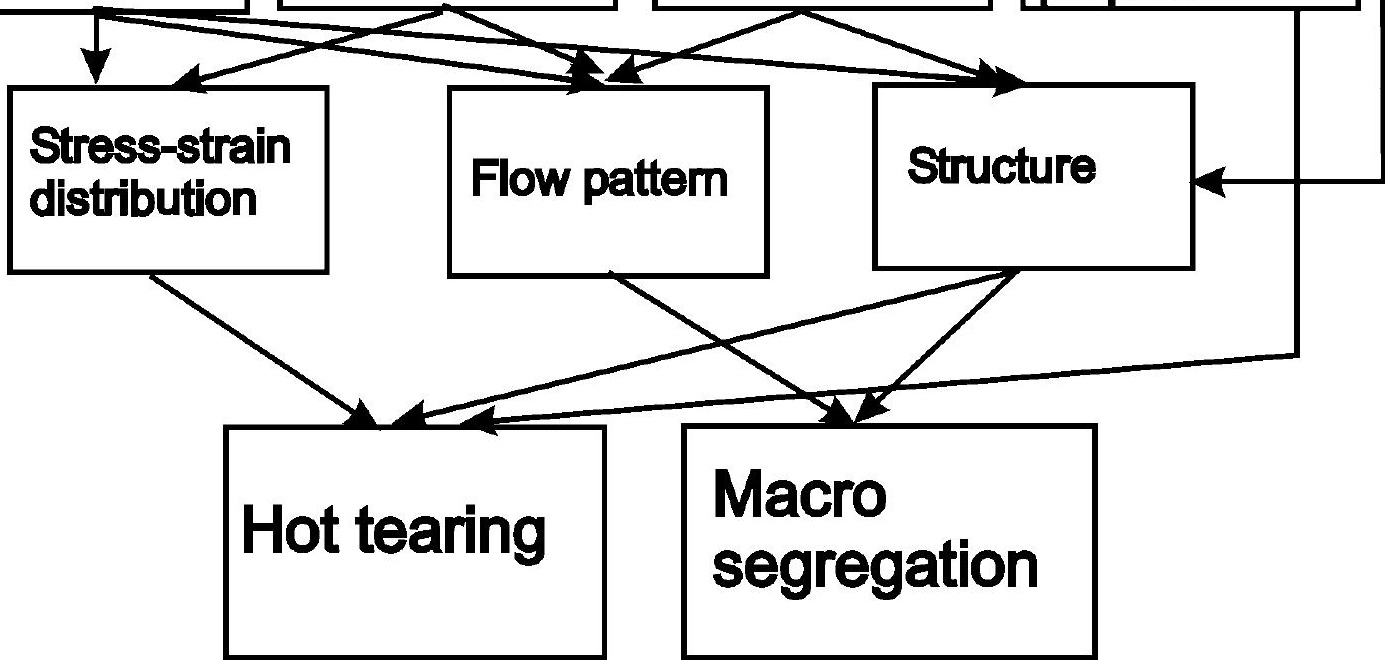




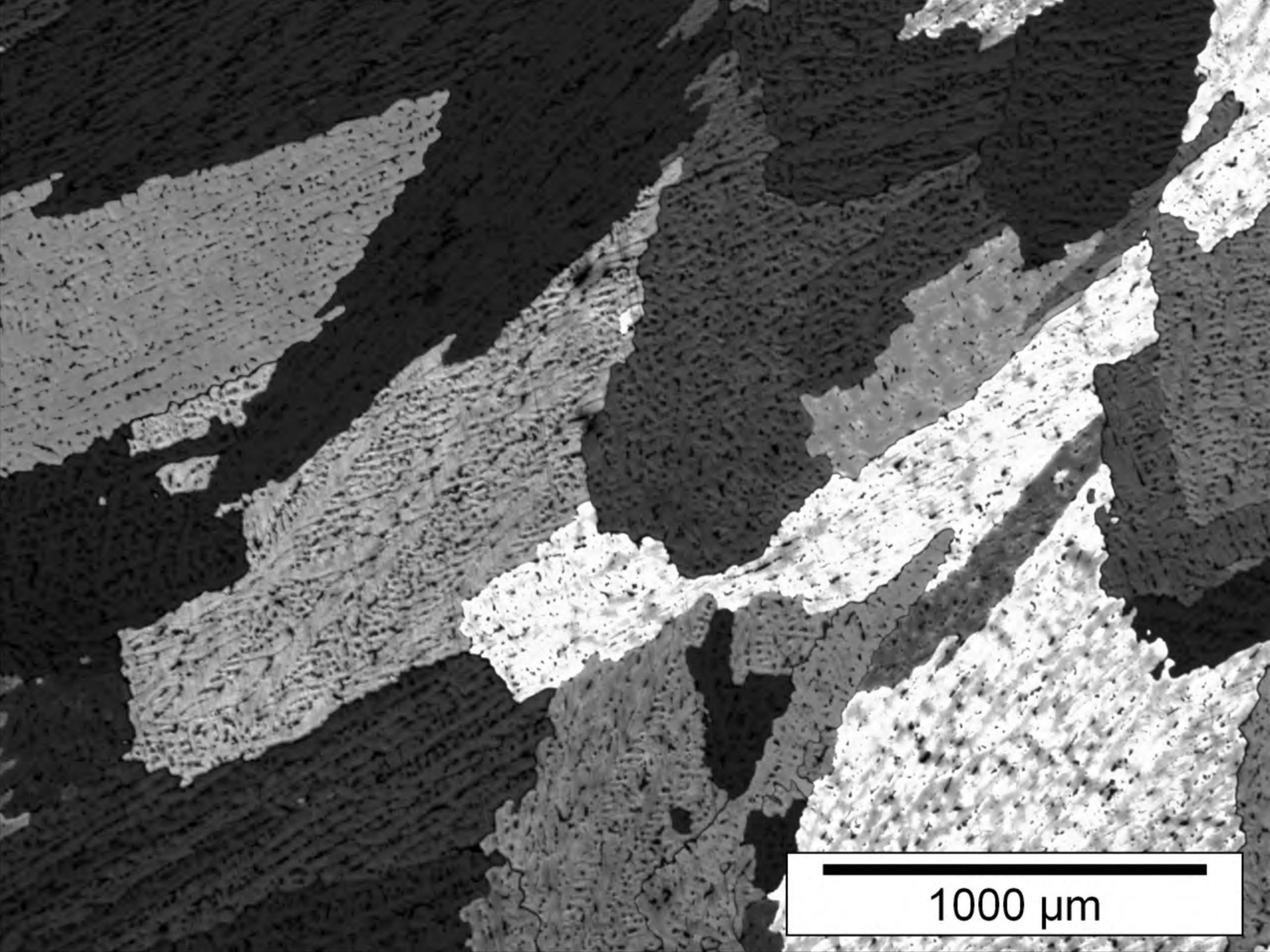




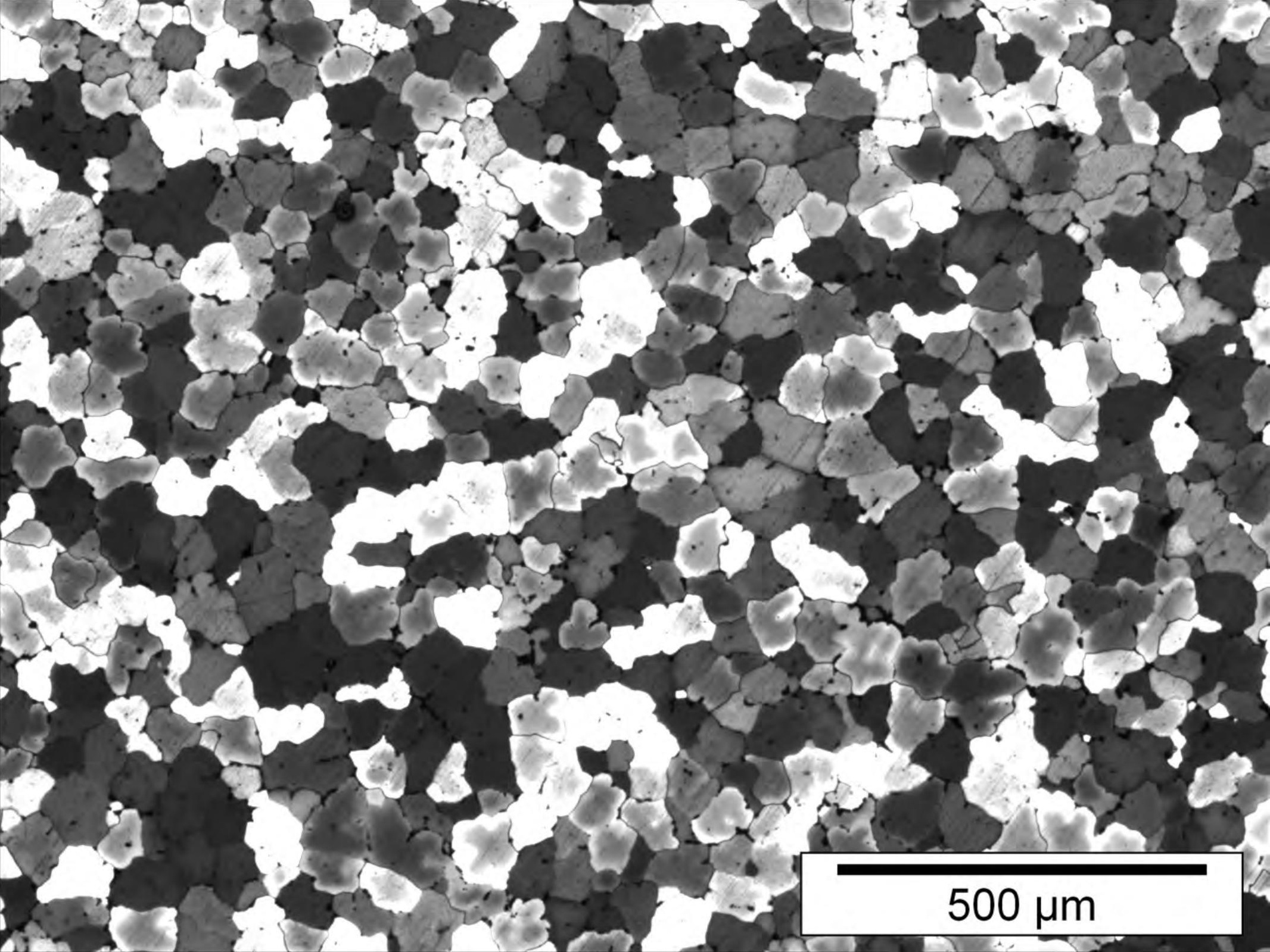




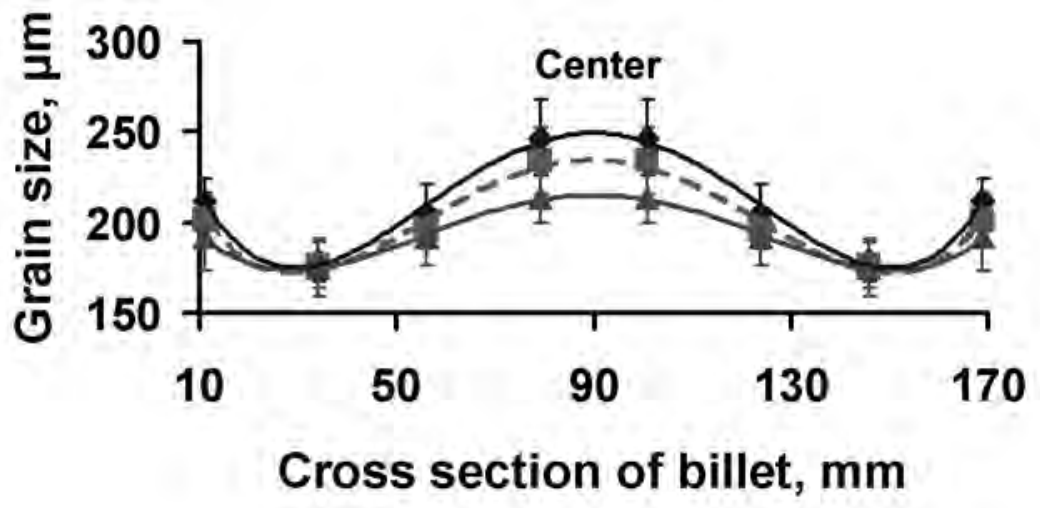




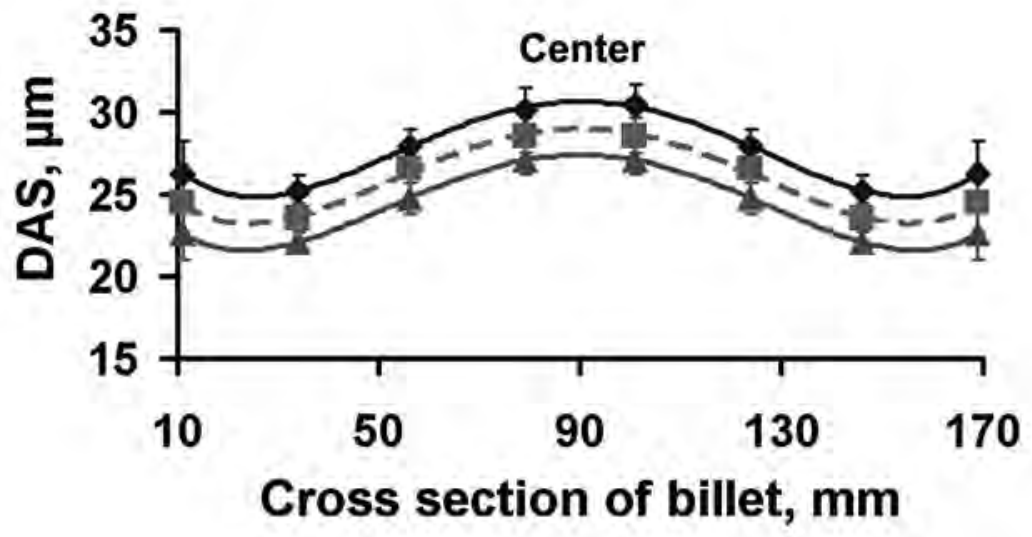




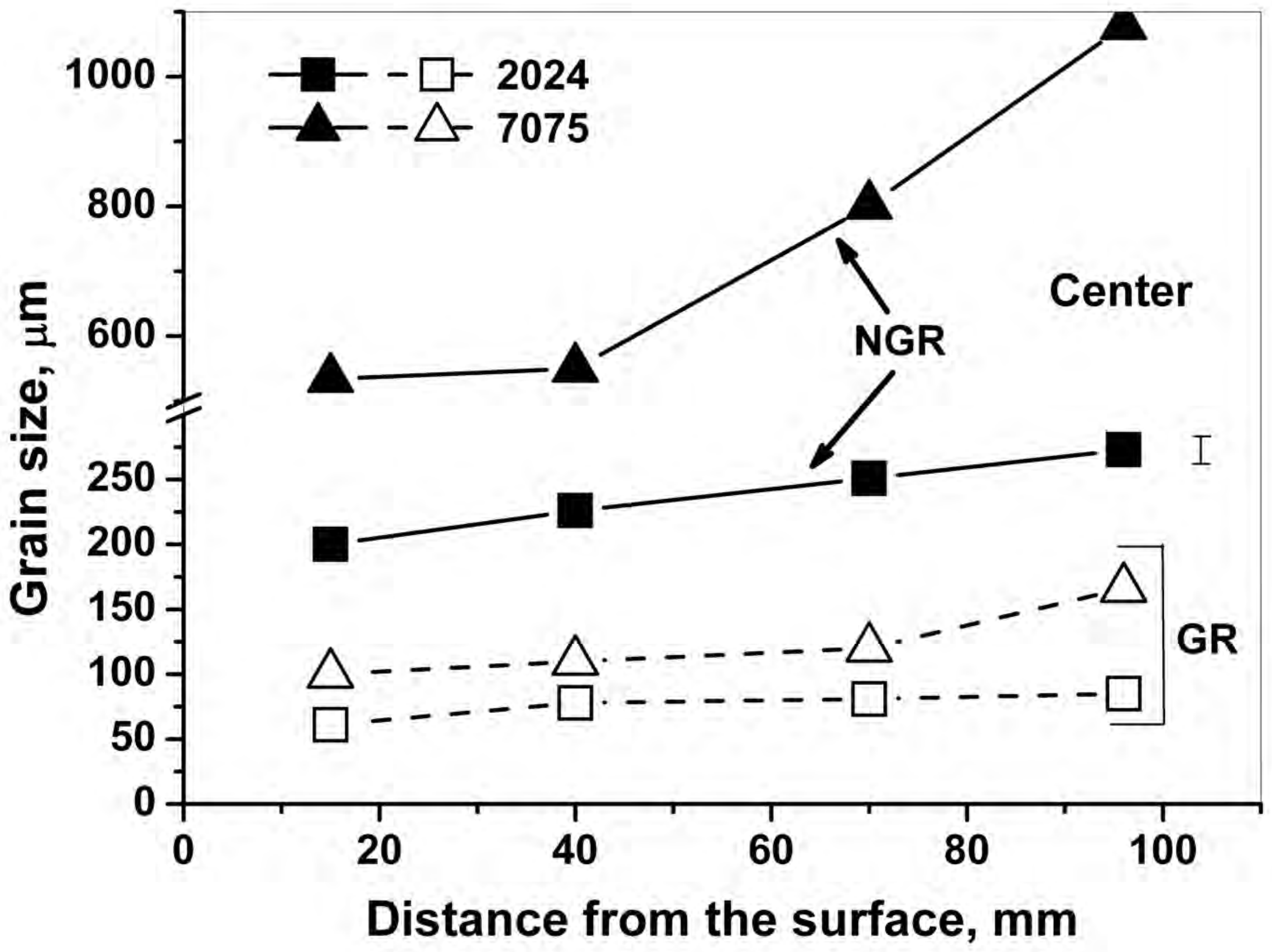




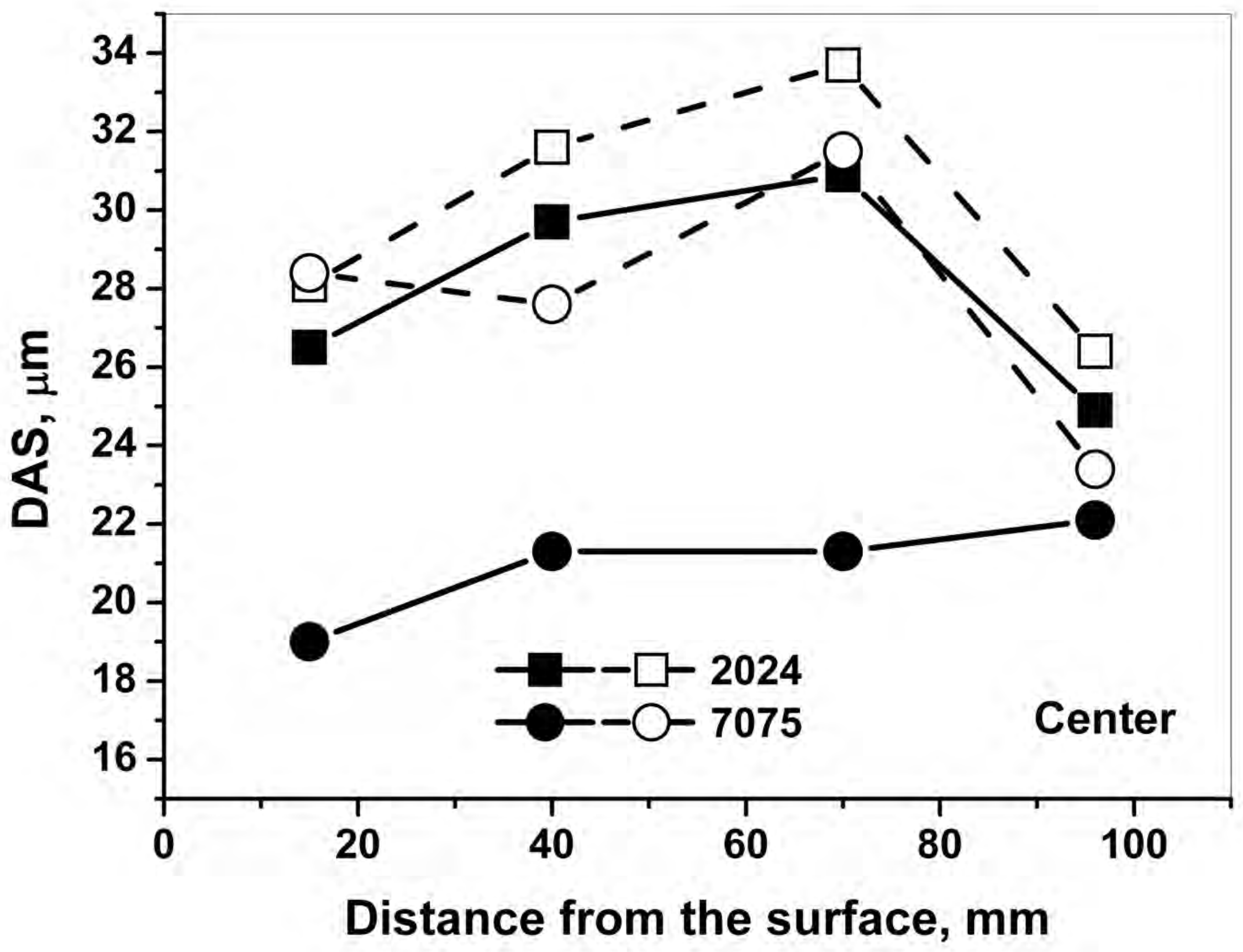


Mit 5

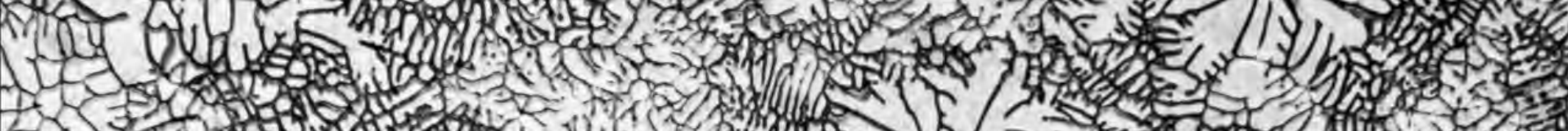

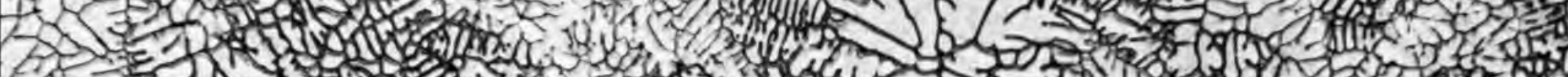
E

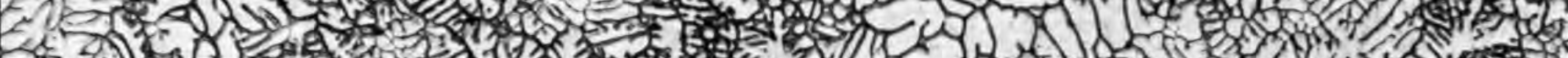

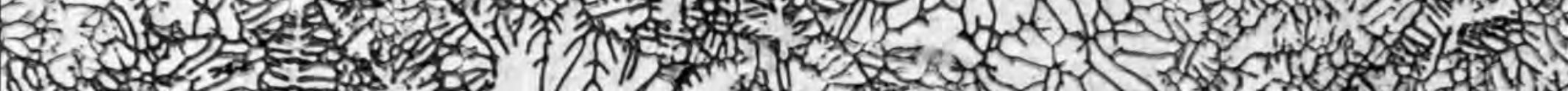

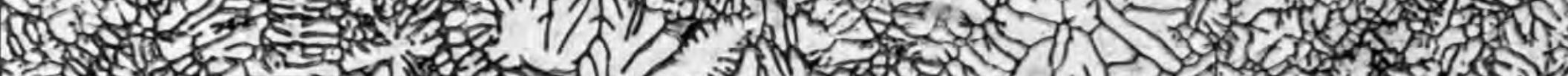

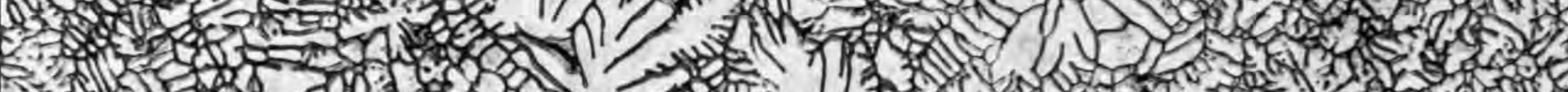

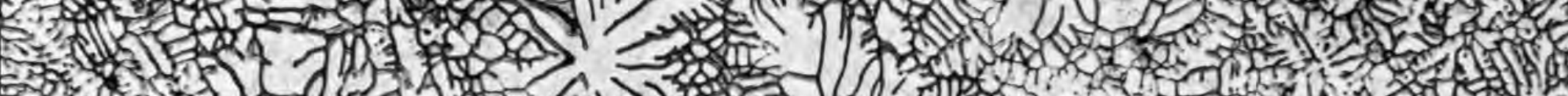

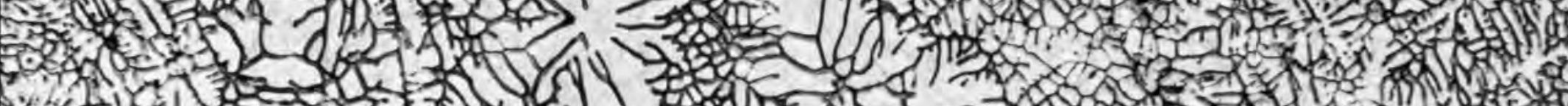

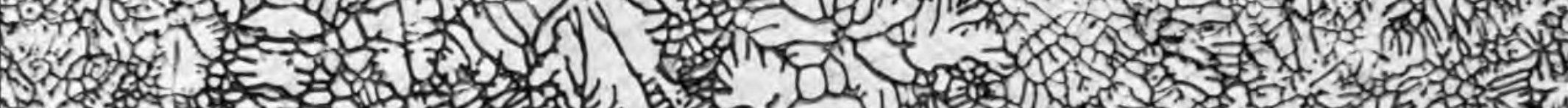

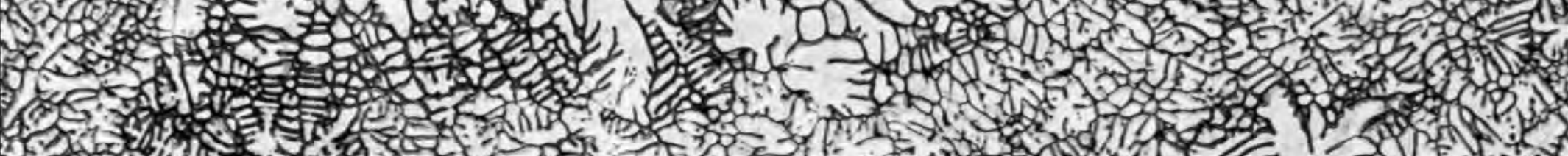

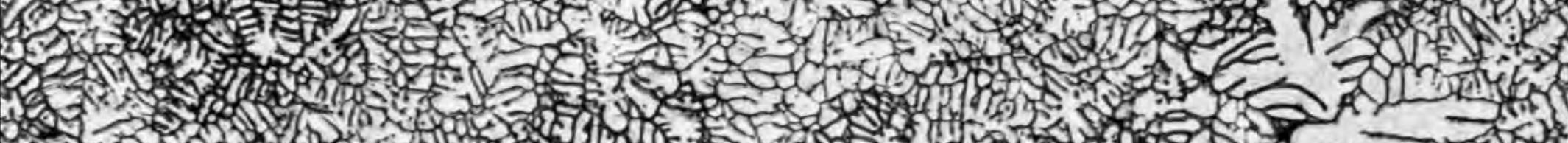

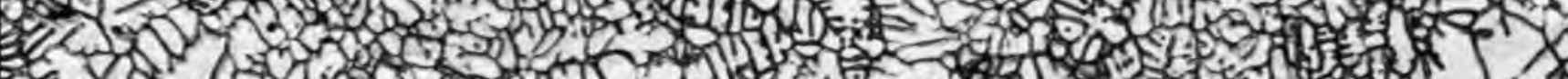

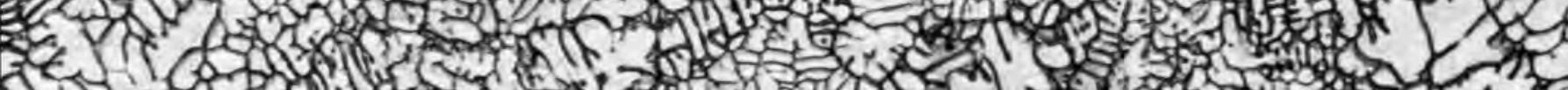

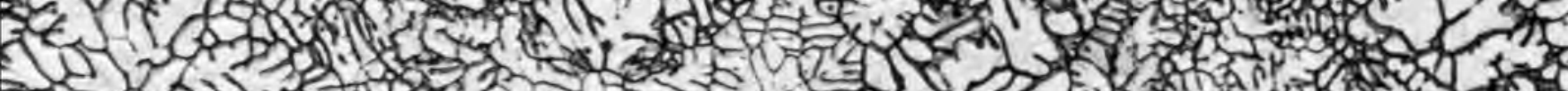
1. I

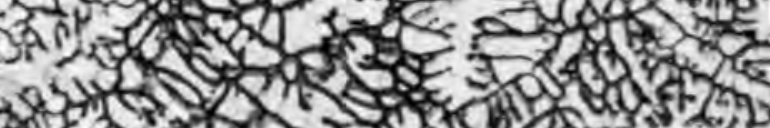
3. 25.

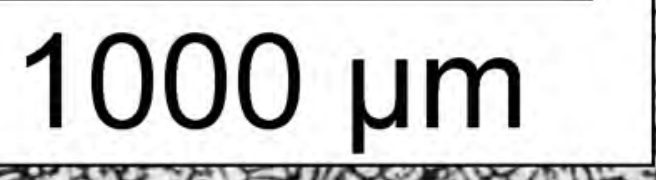


S. St

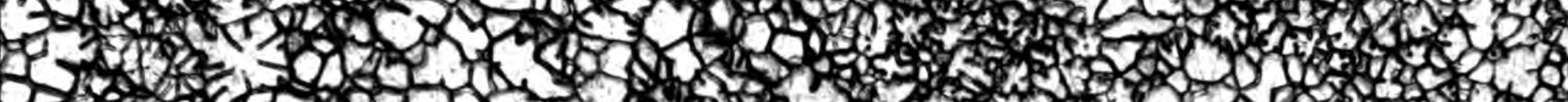

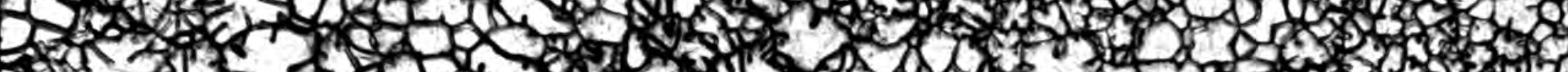

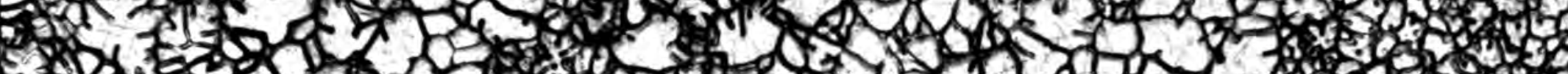

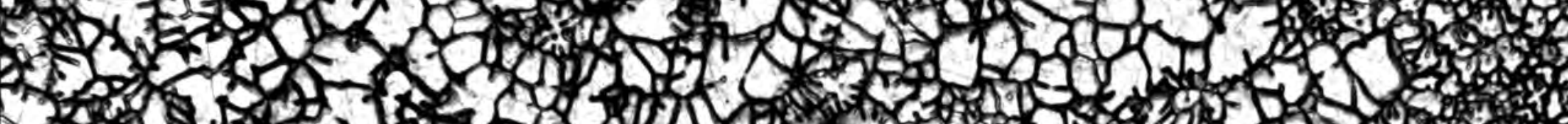

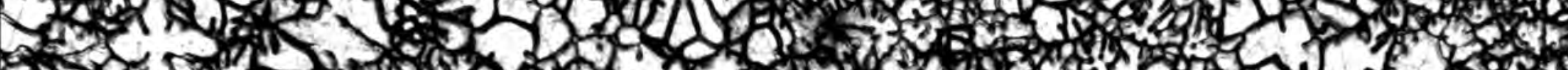

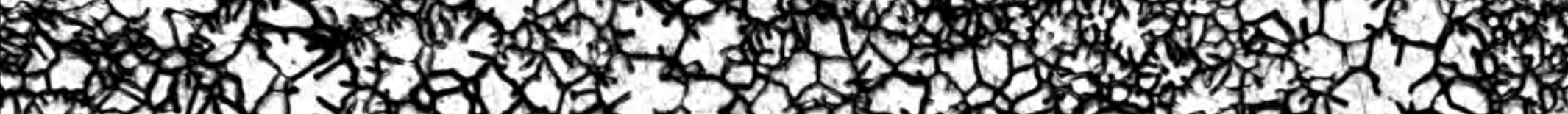

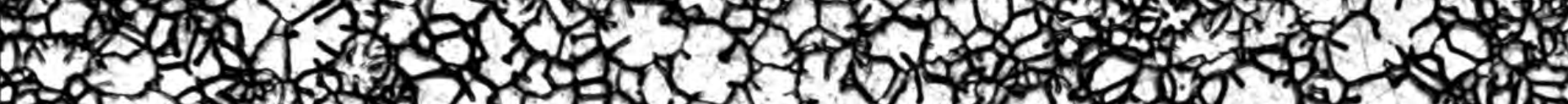

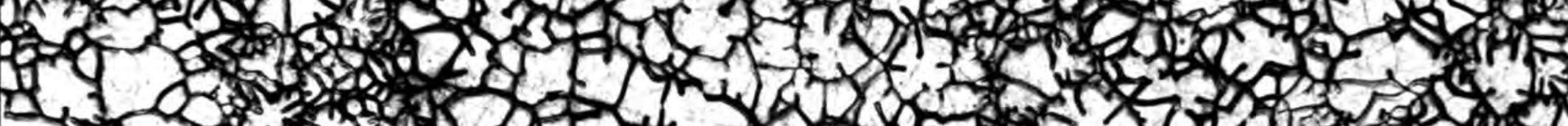
(1) 30 , 620,120

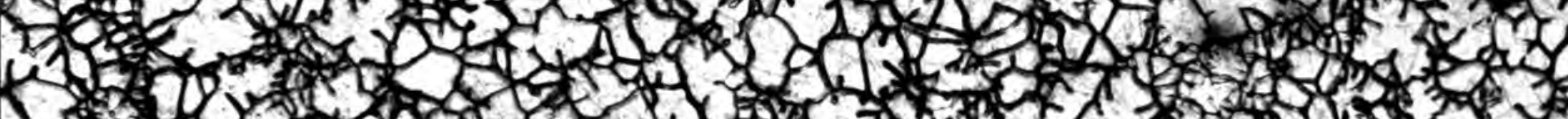

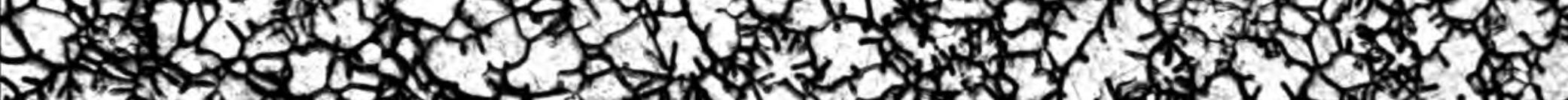
2

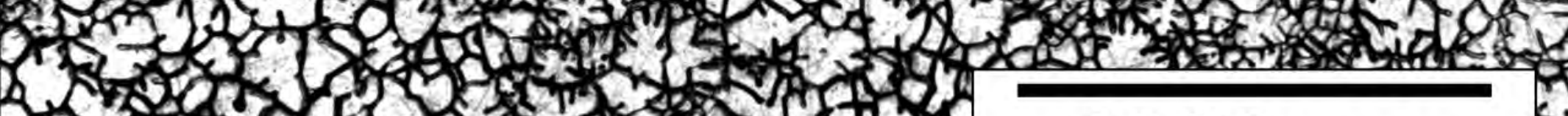

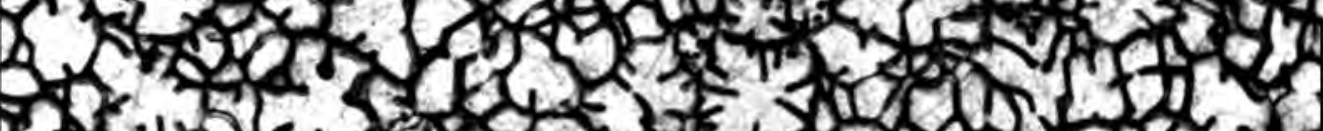

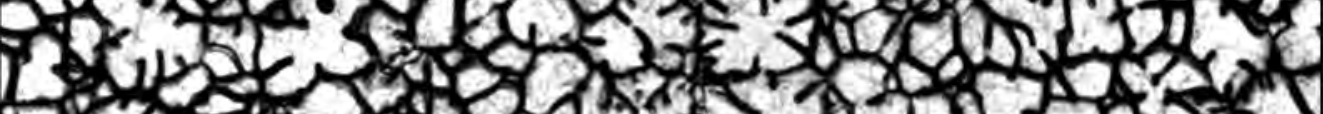
1) 


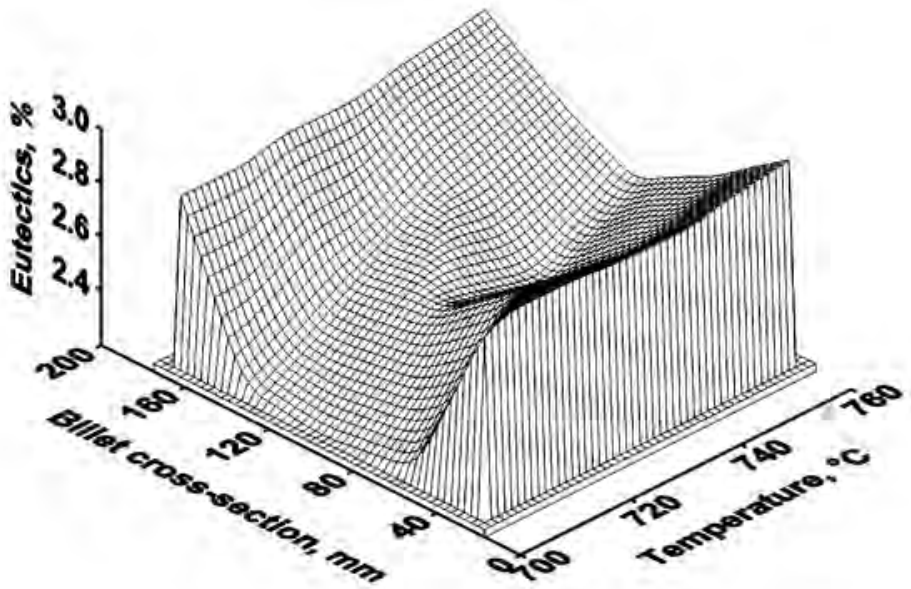




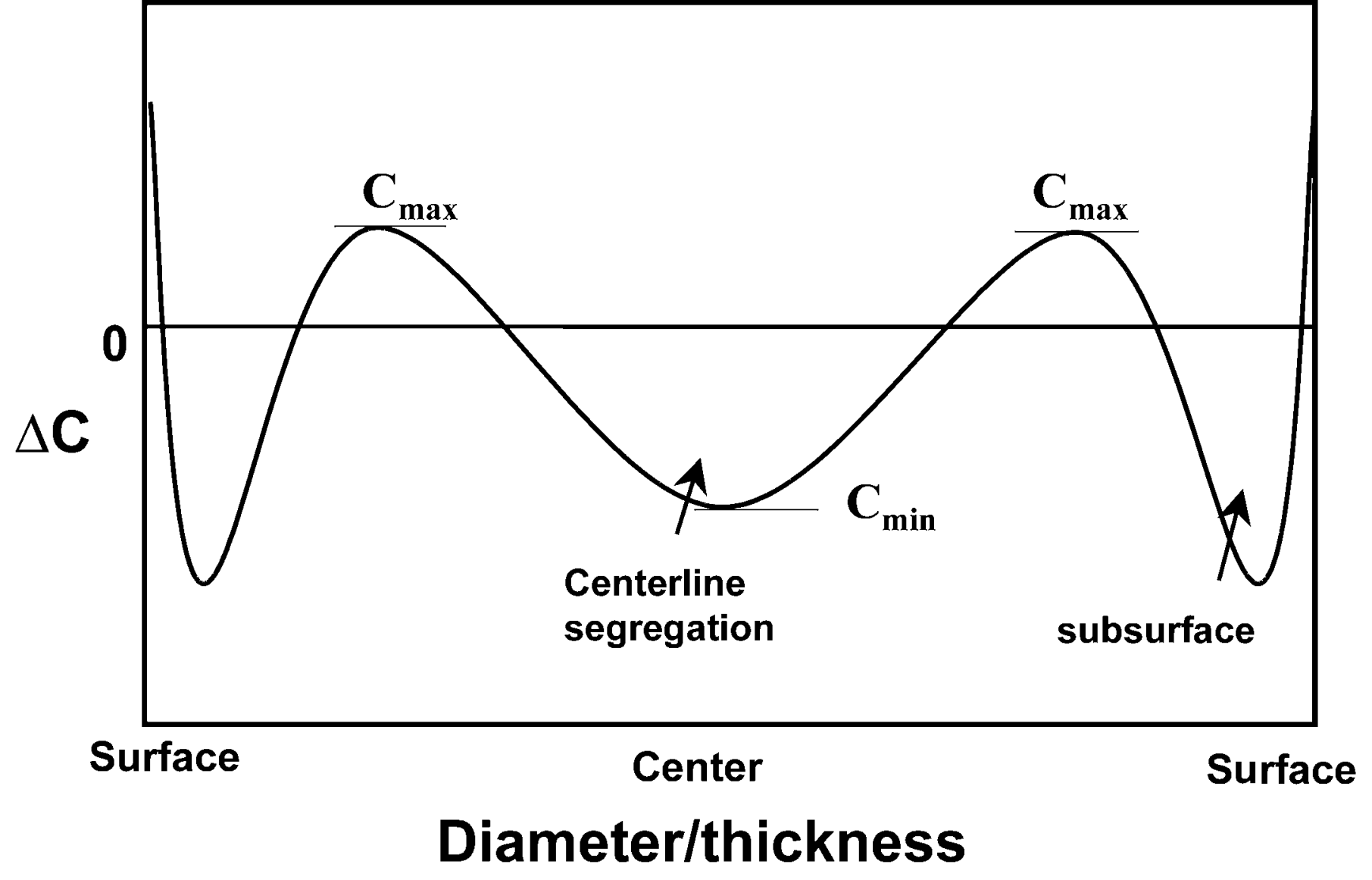




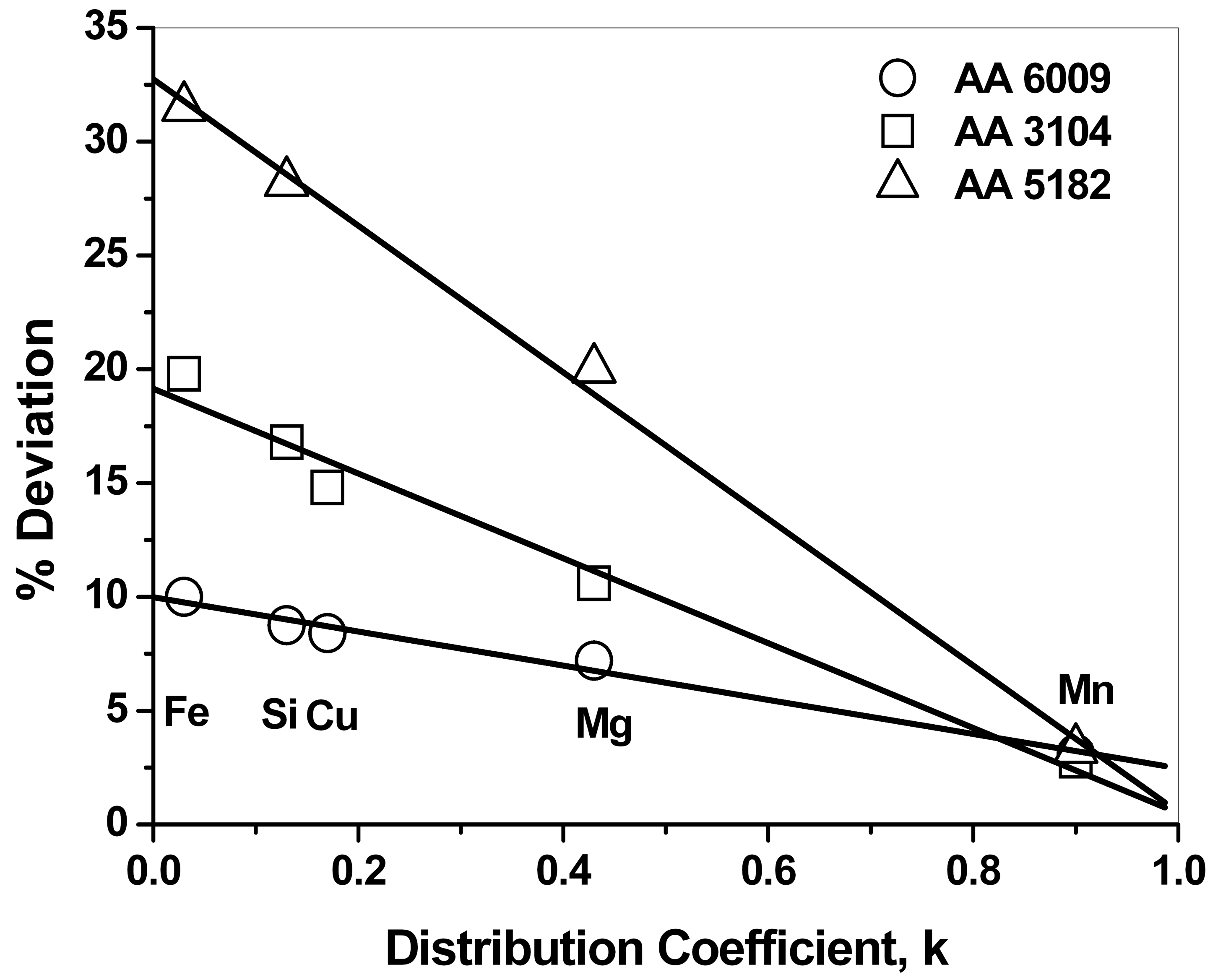




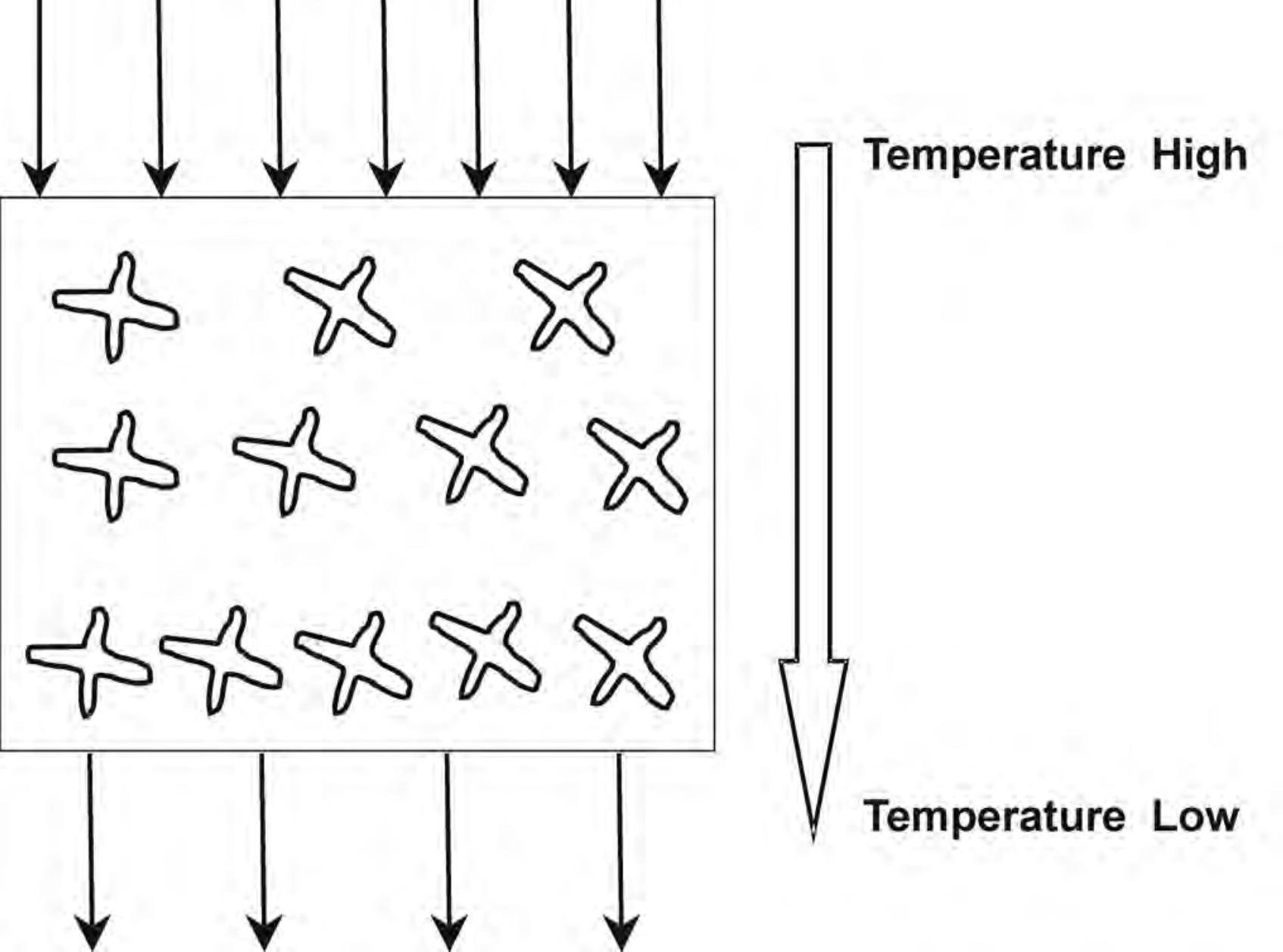



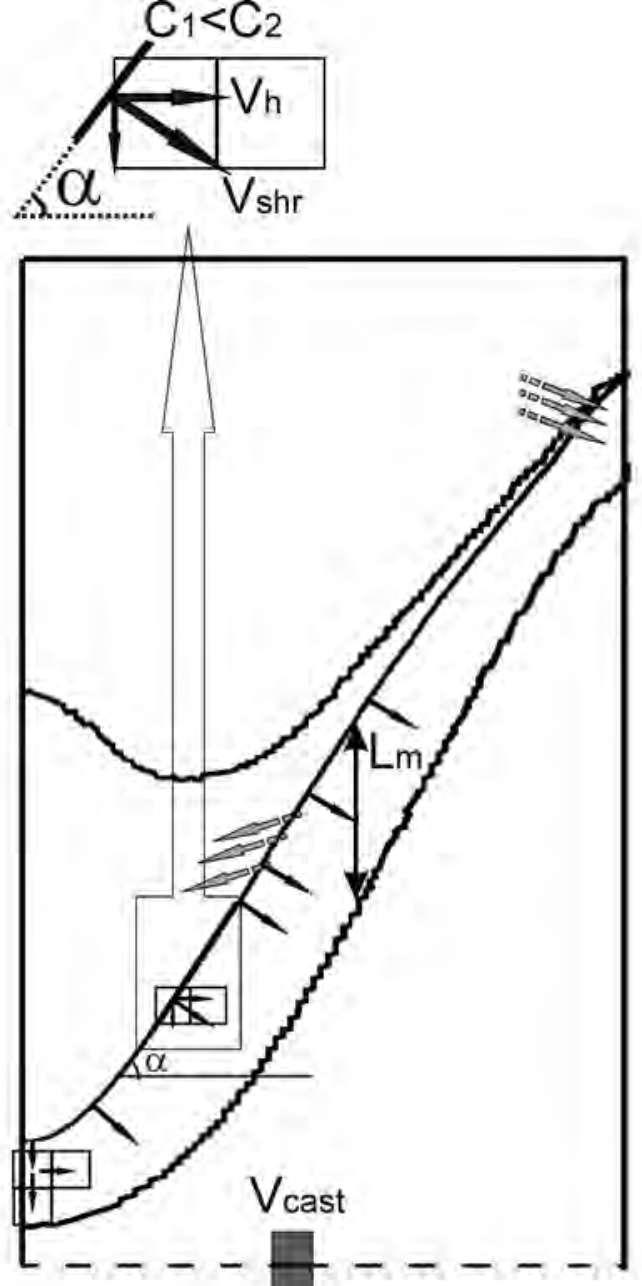


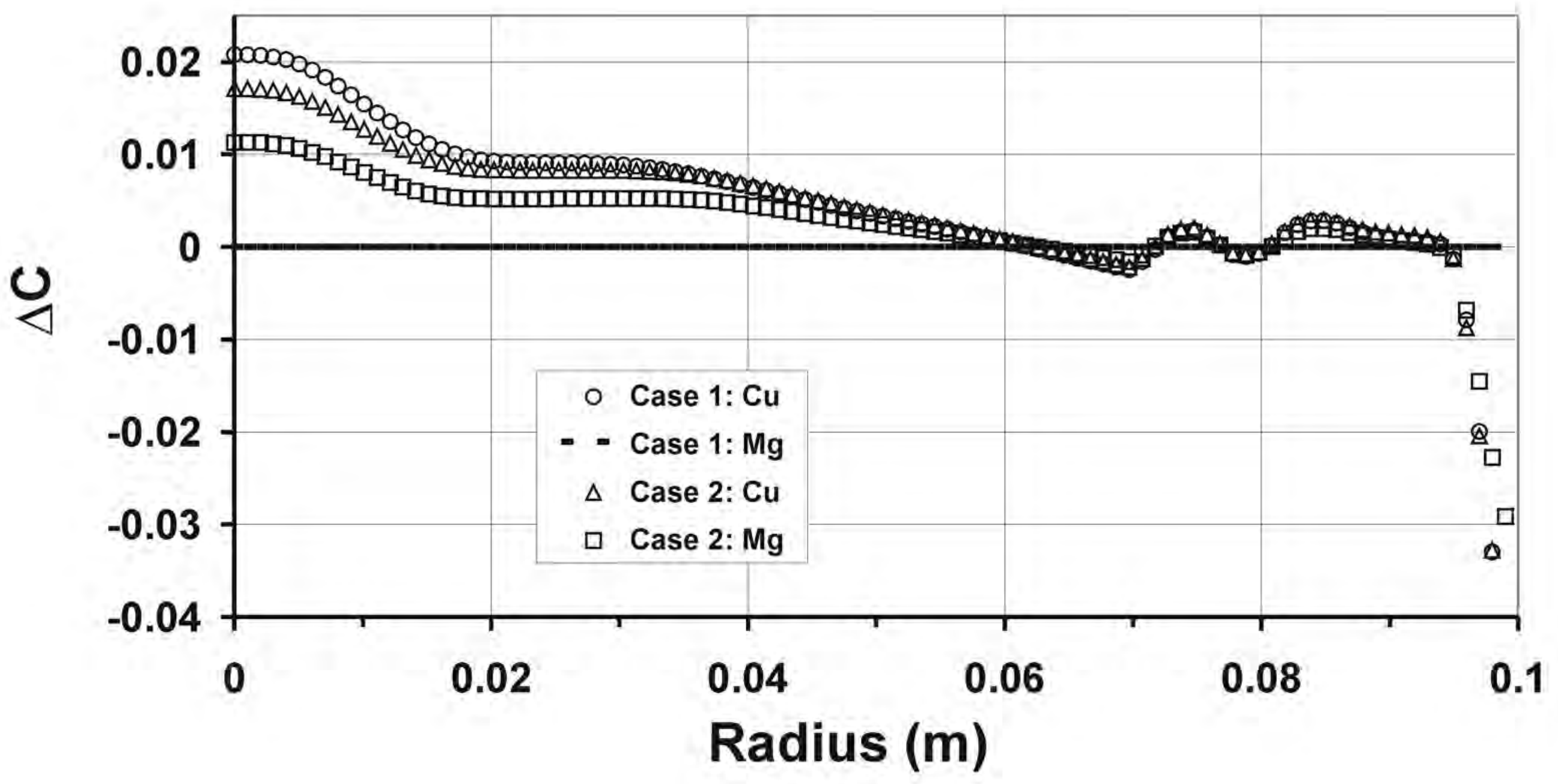




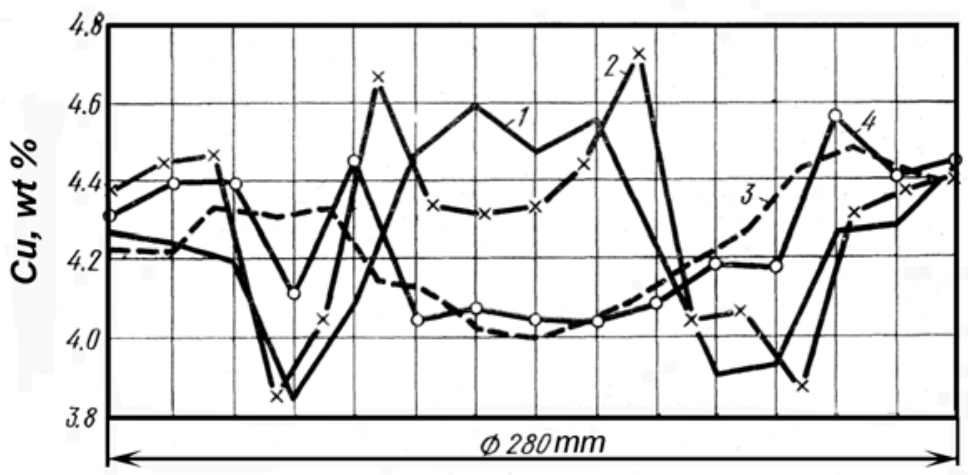




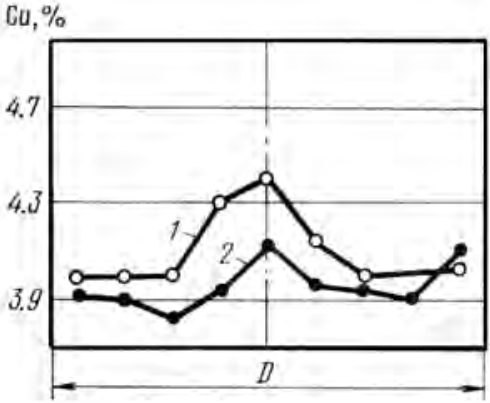




\section{Cu, $\%$}

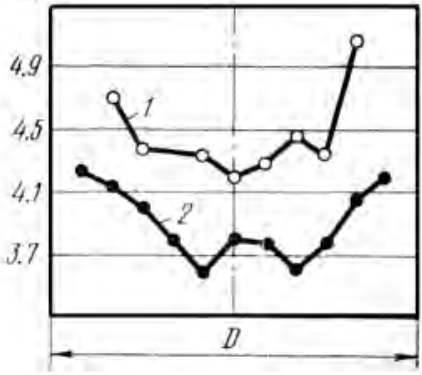




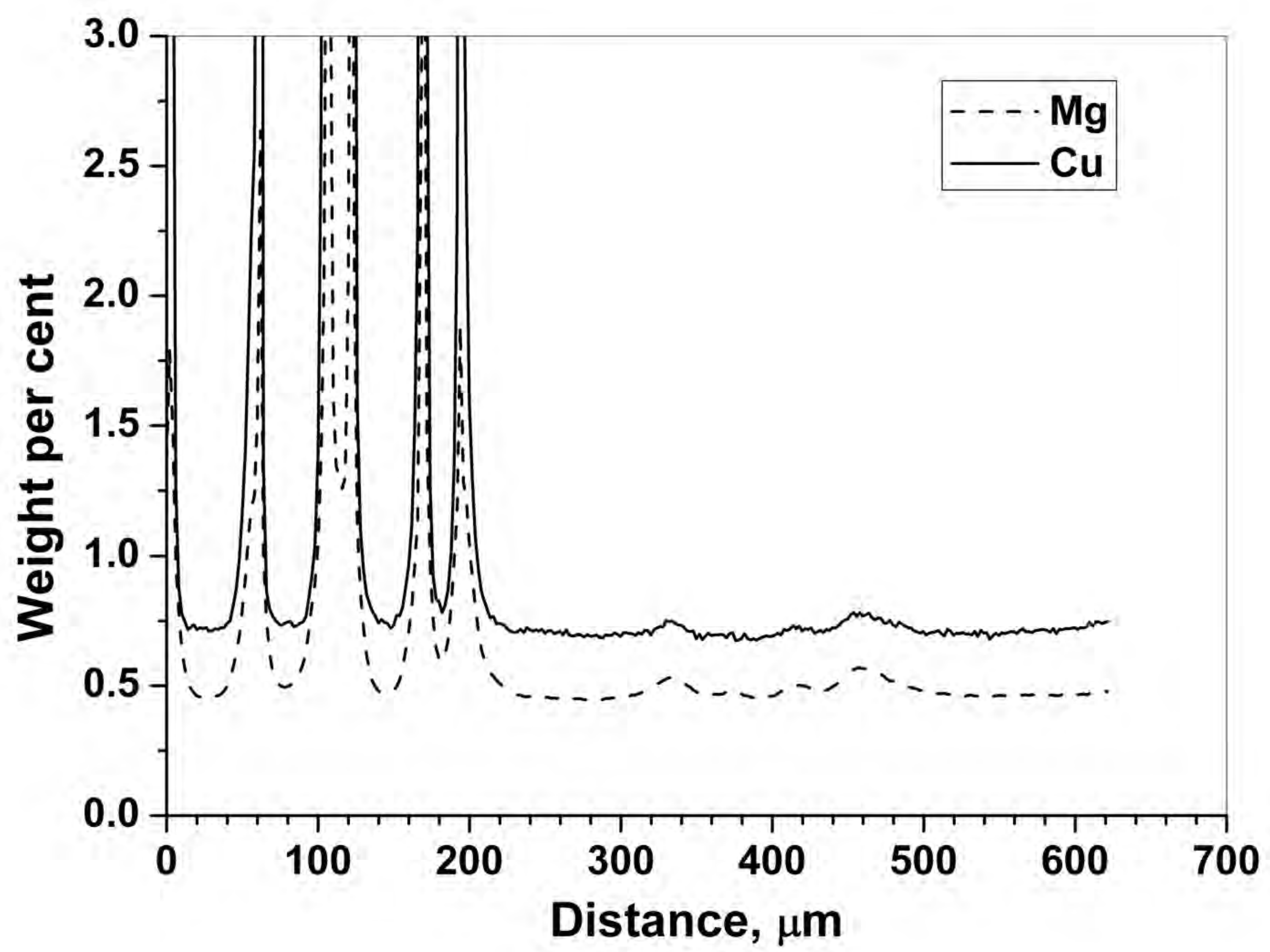




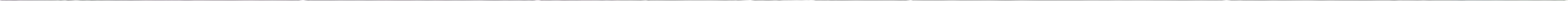




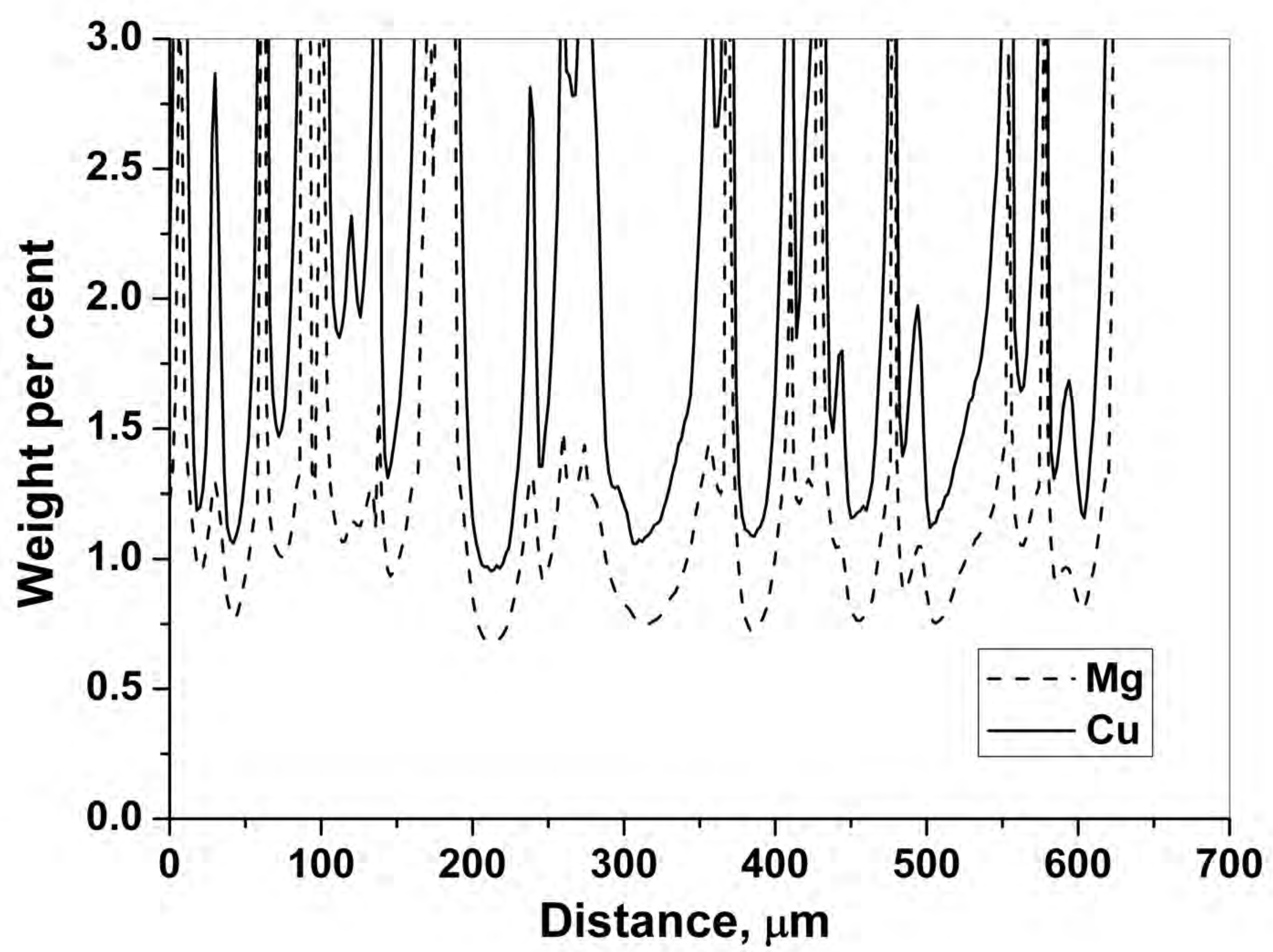




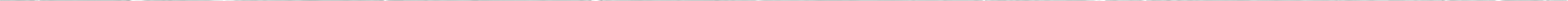



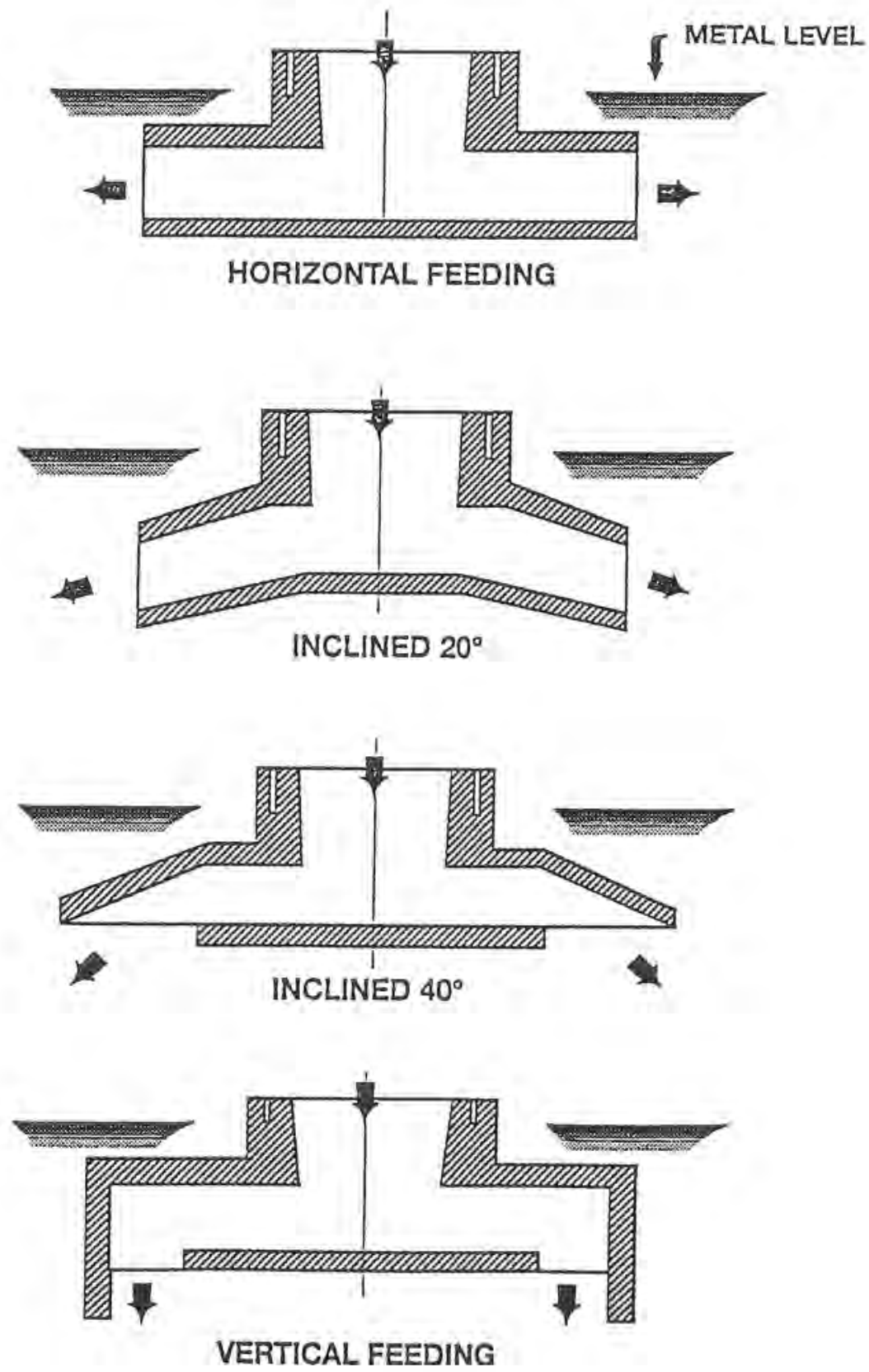


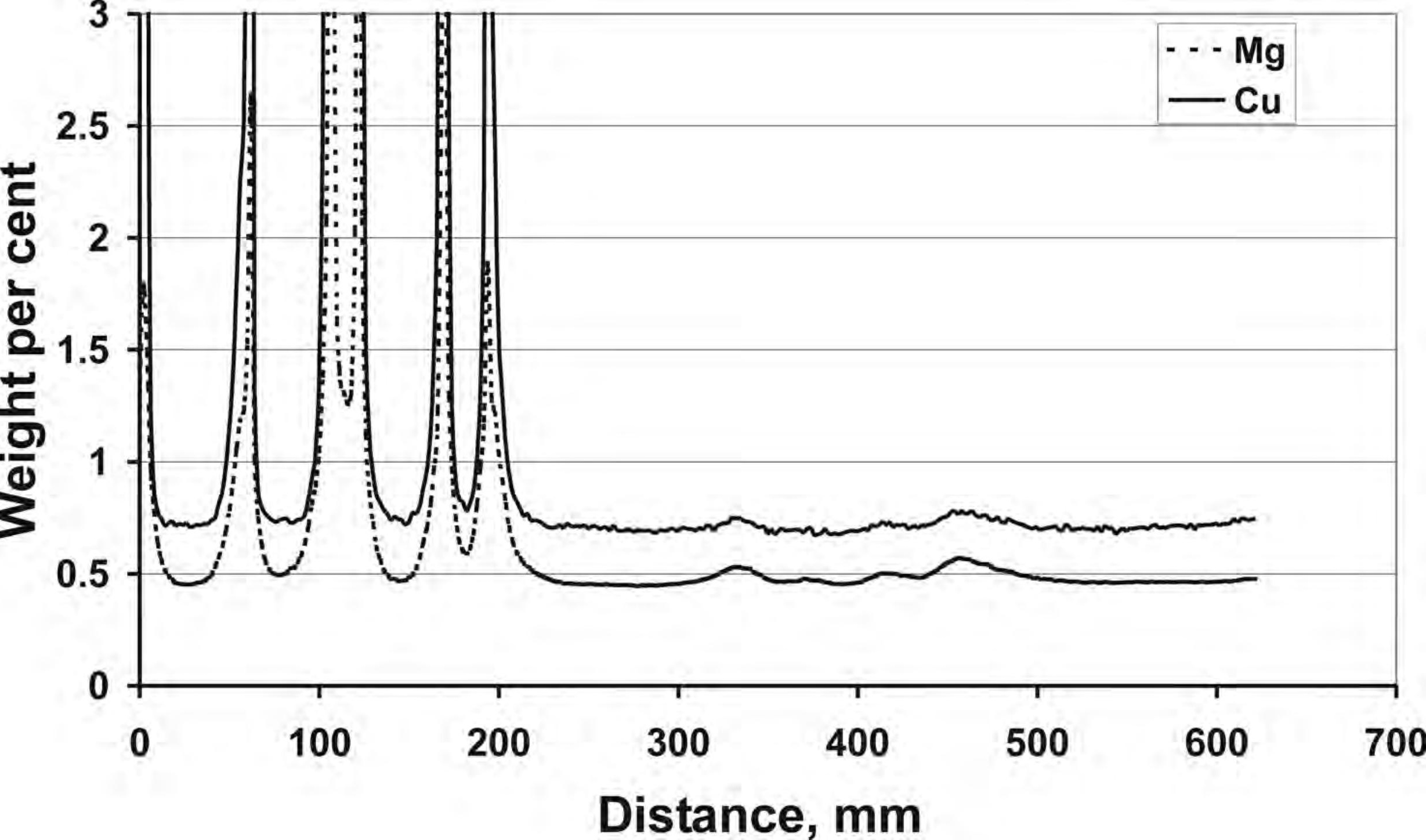



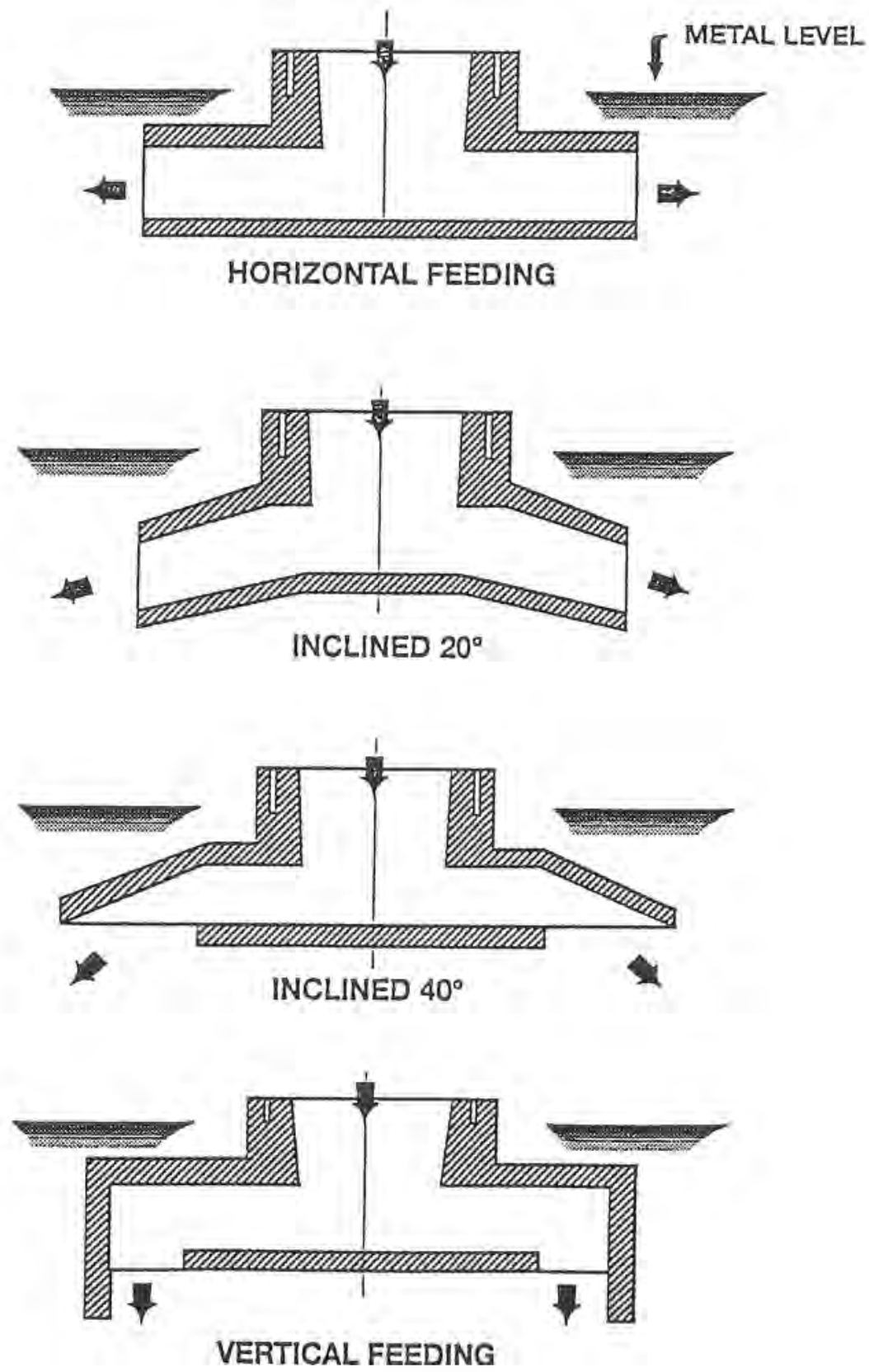


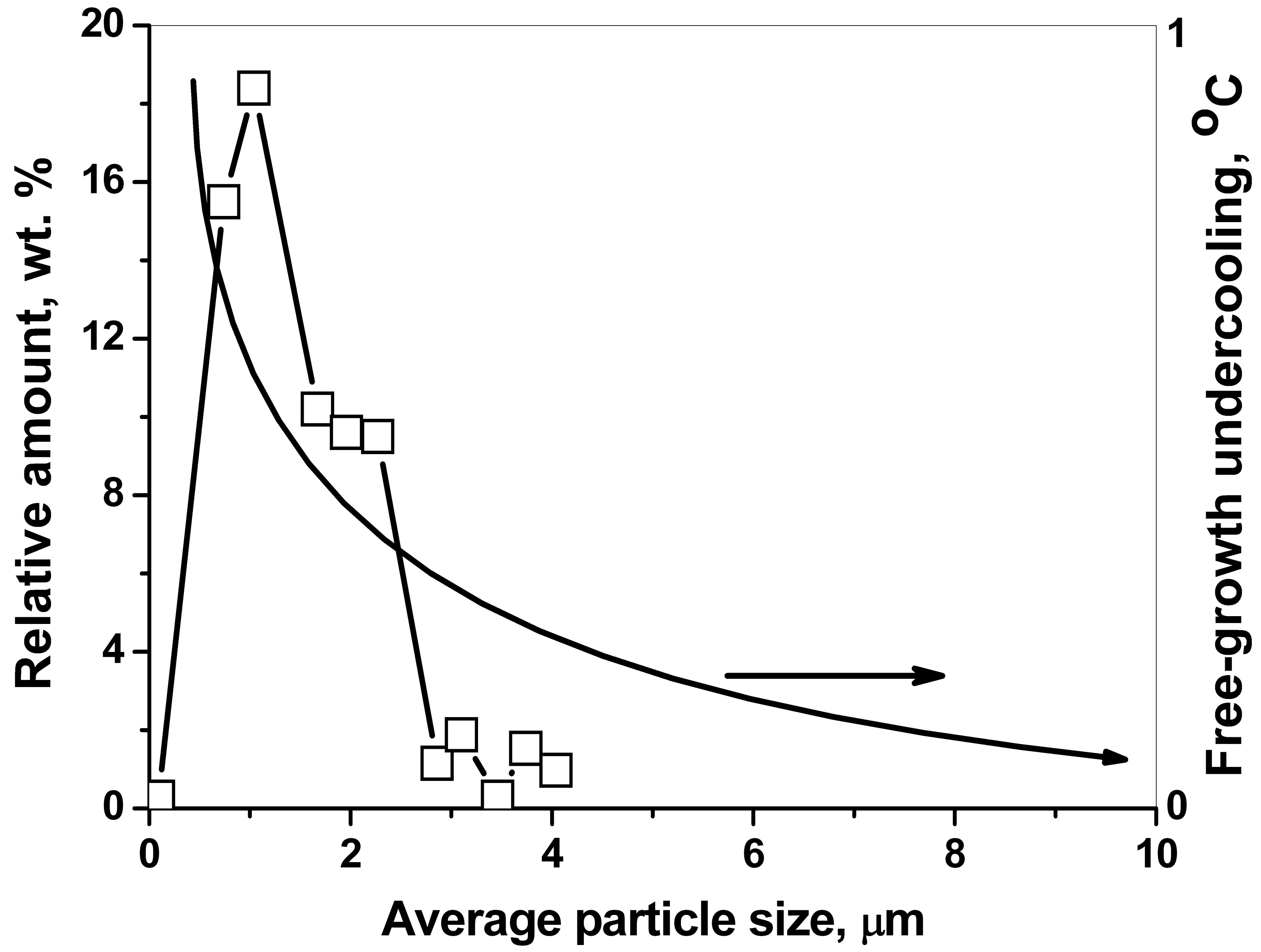




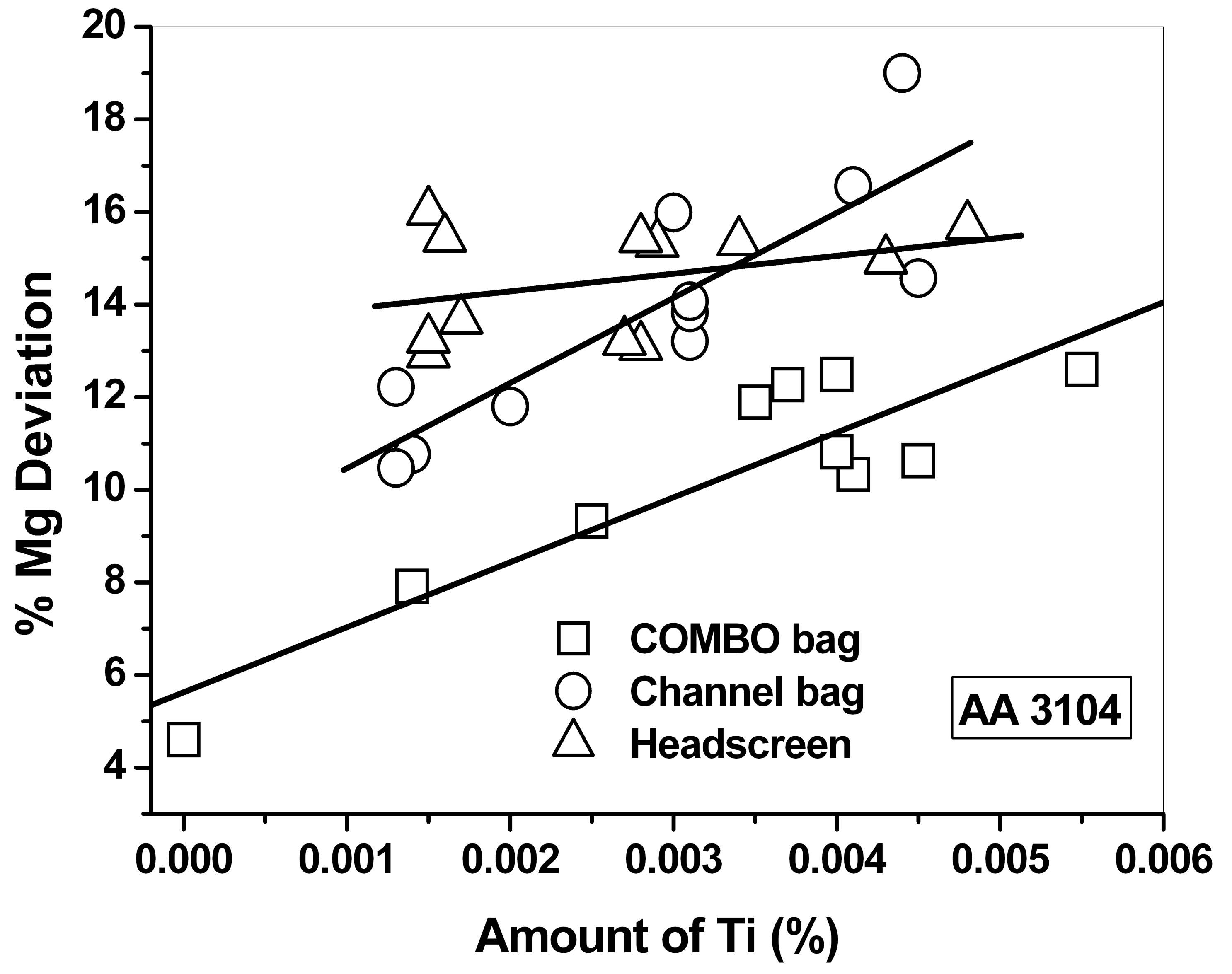




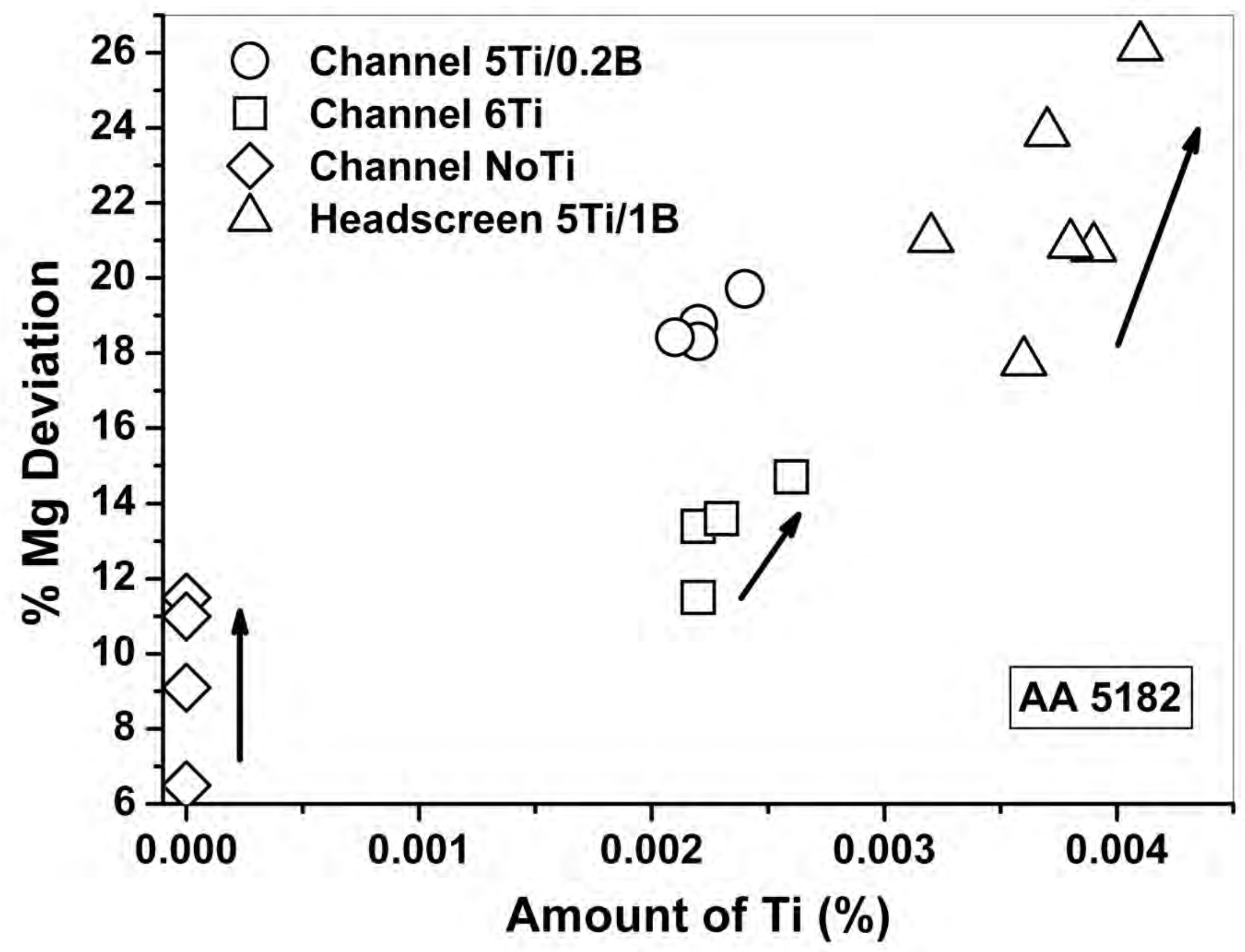




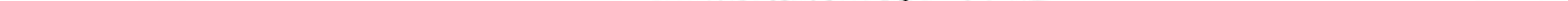

